FÚLVIA JUNG BORGES

INTEGRAÇÃO DOS PROCESSOS DE ELETRODIÁLISE E DE DEGRADAÇÃO FOTOQUÍMICA PARA O

TRATAMENTO DE EFLUENTES SALINOS CONTENDO

FENOL

São Paulo

2009 
FÚLVIA JUNG BORGES

\title{
INTEGRAÇÃO DOS PROCESSOS DE ELETRODIÁLISE E DE DEGRADAÇÃO FOTOQUÍMICA PARA O TRATAMENTO DE EFLUENTES SALINOS CONTENDO FENOL
}

\author{
Tese apresentada à Escola \\ Politécnica da Universidade de \\ São Paulo para obtenção do título \\ de Doutor em Engenharia.
}

Área de Concentração:

Engenharia Química

Orientadores:

Prof. Roberto Guardani

Prof. Hélène Roux-de Balmann

São Paulo 
Este exemplar foi revisado e alterado em relação à versão original, sob responsabilidade única do autor e com a anuência de seu orientador.

São Paulo, de setembro de 2009.

Assinatura do autor

Assinatura do orientador

FICHA CATALOGRÁFICA

\section{Borges, Fúlvia Jung}

Integração dos processos de eletrodiálise e de degradação fotoquímica para o tratamento de efluentes salinos contendo fenol / F.J. Borges. -- ed.rev. -- São Paulo, 2009. $139 \mathrm{p}$.

Tese (Doutorado) - Escola Politécnica da Universidade de São Paulo. Departamento de Engenharia Química.

1. Integração (Processos) 2. Efluentes (Tratamento) 3. Oxidação (Processos) 4. Eletrodiálise 5. Modelos matemáticos I. Universidade de São Paulo. Escola Politécnica. Departamento de Engenharia Química II. t. 


\section{AGRADECIMENTOS}

Deixo expresso, de antemão, o meu sincero reconhecimento:

Ao meu mentor Prof. Dr. Roberto Guardani pela atenção, orientação e estímulo;

À Prof. Dra. Hélène Roux-de Balmann pela gentil acolhida e orientação;

Ao Prof. Dr. Galo Antonio Carrillo Le Roux pelas sugestões e apoio;

Aos colegas do Centro de Engenharia de Sistema Químicos - Laboratório de Simulação e Controle de Processos, em especial ao amigo Fernando Sassano, pela colaboração e apoio;

Aos colegas do Laboratoire de Génie Chimique de Toulouse, em especial a Elodie Singlande pelo apoio e a Ernesto Casademont pela assistência nos experimentos de eletrodiálise;

Ao Prof. Dr. Antônio Carlos Silva Costa Teixeira pelas contribuições valiosas durante o projeto e qualificação;

Ao Prof. Dr. Cláudio Augusto Oller do Nascimento, Prof. Dr. Xavier Joulia, e ao Prof. Dr. Cristiano Piacsek Borges pelo apoio;

Às amigas Dra. Rita Maria de Brito Alves e Dra. Elen Aquino Perpetuo;

Aos meus pais e familiares pelo estímulo;

À CAPES, Coordenação de Aperfeiçoamento de Pessoal de Nível Superior, pelo suporte financeiro;

$\mathrm{E}$ a todos aqueles que me auxiliaram direta ou indiretamente. 
"Sou do tamanho do que vejo"

Fernando Pessoa 


\section{RESUMO}

Os processos oxidativos podem ser utilizados no tratamento de efluentes contendo compostos orgânicos não-biodegradáveis. No entanto, a presença de sais dissolvidos pode inibir ou retardar o processo. Neste estudo, a dessalinização de efluentes por eletrodiálise (ED) associada a um processo de oxidação avançada (foto-Fenton) foi aplicada a uma solução aquosa contendo $\mathrm{NaCl}$ e fenol.

O processo de ED foi avaliado em escala piloto. Um estudo experimental foi realizado no qual a influência das variáveis de processo na perda de fenol e remoção do cloreto de sódio foi investigada. Experimentos também foram realizados sem corrente elétrica para determinar a transferência de fenol devido à difusão. As variações de concentração de fenol e sal nos compartimentos do sistema de ED foram medidas com o tempo utilizando-se procedimentos pertinentes e um planejamento experimental para determinar os parâmetros característicos globais. Uma abordagem fenomenológica foi utilizada para relacionar os fluxos de fenol, sal e água com as forças motrizes (concentração e gradiente de potencial elétrico). Nas condições de ED estudadas duas contribuições ao transporte do fenol se destacaram: difusão e convecção, sendo a última devido ao fluxo de água relacionado com eletroosmose pela migração do sal. Os parâmetros estimados das equações de transporte possuem bom ajuste com os resultados experimentais na faixa de condições investigadas.

O processo foto-Fenton foi estudado em um reator de batelada em escala de laboratório. Os resultados confirmam o efeito negativo da concentração de sal na eficiência de remoção de fenol por oxidação. Este efeito não foi considerado linear em relação à concentração de sal e taxa de degradação. Devido à complexidade das reações do sistema, um modelo baseado em redes neurais artificiais foi desenvolvido para ajustar os dados experimentais no equacionamento da taxa de reação em função das variáveis de entrada. O modelo descreve a evolução da concentração do poluente, fenol, pela taxa de reação, durante o tempo de irradiação para diferentes condições operacionais.

O modelo matemático das etapas de ED e de foto-oxidação foi utilizado para avaliar a sensibilidade do processo em relação às variáveis consideradas. Um modelo 
dinâmico foi desenvolvido para o processo de ED e um modelo contínuo, utilizando uma aproximação de um reator "Plug Flow", para o processo oxidativo. Finalmente, simulações híbridas dos processos puderam validar diferentes cenários do sistema integrado e poderão ser utilizadas para futuros trabalhos de otimização do sistema.

Palavras-chaves: Integração (processos). Efluentes (Tratamento). Oxidação (Processo). Eletrodiálise. Modelos Matemáticos. 


\begin{abstract}
Chemical oxidation processes can be used to treat industrial wastewater containing non-biodegradable organic compounds. However, the presence of dissolved salts may inhibit or retard the treatment process. In this work, a coupled process is studied including a desalination step by electrodialysis (ED) associated with an advanced oxidation process (photo-Fenton) with a synthetic wastewater containing $\mathrm{NaCl}$ and phenol.

The experimental study concerning ED was carried out using a pilot plant. The influence of process variables, like the initial water composition and the electrical current intensity, on the demineralization factor was investigated. Experiments were also performed without electrical current application, in order to determine the unfavorable phenol transfer through the membranes due to diffusion. The phenol and salt concentration variations in the ED compartments were measured over time, using dedicated procedures and an experimental design to determine the global characteristic parameters. A phenomenological approach was used to relate the phenol, salt and water fluxes with the driving force (concentration and electric potential gradients). Under normal ED conditions, two contributions were pointed out for the phenol transport, i.e. diffusion and convection, this latter coming from the water flux due to electroosmosis related to the migration of salts. The fitting of the parameters of the transport equations resulted in good agreement with the experimental results over the range of conditions investigated.

Photo-Fenton oxidation process was studied in a laboratory batch reactor. As expected, the results confirm the negative effect of the salt concentration on the phenol removal efficiency by oxidation. This effect was not found to be linear concerning salt concentration and degradation rate. Due to the complexity of these reaction systems, a model based on artificial neural networks has been developed to fit the experimental data. This model describes the evolution of the pollutant concentration i.e. phenol, by means of a reaction rate, during irradiation time under various operating conditions.
\end{abstract}


The mathematical model comprising the ED and photo-oxidation steps were used to evaluate the process sensitivity in relation to the process variables considered. A dynamic model was developed to ED and a continuous model, using a plug flow reactor approach, to the oxidation process. Finally, the hybrid resulting simulation could validate different scenarios of the integrated system and can be used for further optimization.

Keywords: Integration (Process). Wastewater (Treatment). Oxidation (Process). Electrodialysis. Mathematical Models. 


\section{SUMÁRIO}

LISTA DE FIGURAS

LISTA DE TABELAS

LISTA DE ABREVIATURAS

LISTA DE NOTAÇÕES E SÍMBOLOS

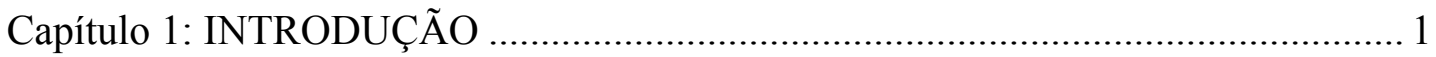

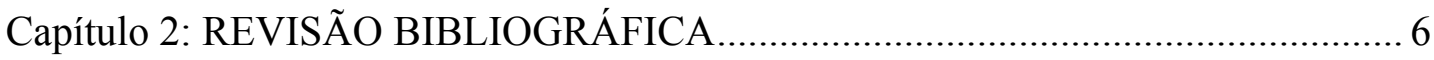

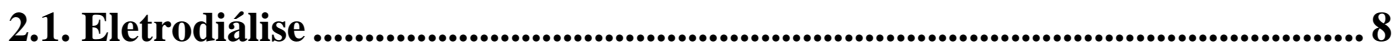

2.1.1. Membranas trocadoras de íons.......................................................................8 8

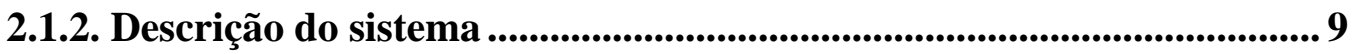

2.1.3. Mecanismos de transporte................................................................................. 11

2.1.4. Transferência de solutos e solução ..................................................... 17

2.2. Processos oxidativos avançados ......................................................................... 22

2.2.1. Fotólise de $\mathrm{H}_{2} \mathrm{O}_{2}$............................................................................ 23

2.2.2. Reações Fenton e foto-Fenton ............................................................. 24

2.2.3. Fotocatálise com $\mathrm{TiO}_{2}$............................................................................... 24

2.2.4. Processos oxidativos em meio salino................................................... 27

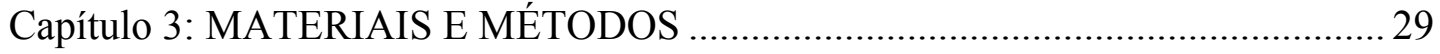

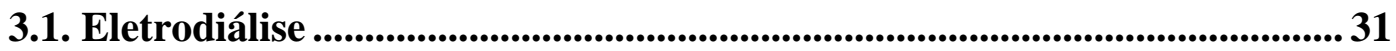

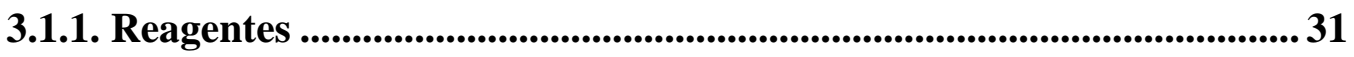

3.1.2. Célula de difusão ...................................................................................... 31

3.1.3. Piloto de eletrodiálise ........................................................................32

3.2. POA …............................................................................................................................. 38

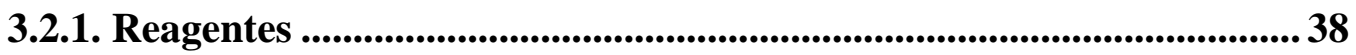

3.2.2. Equipamento............................................................................................................. 38

3.2.3. Procedimento experimental .......................................................................... 40

3.2.4. Planejamento experimental............................................................... 41

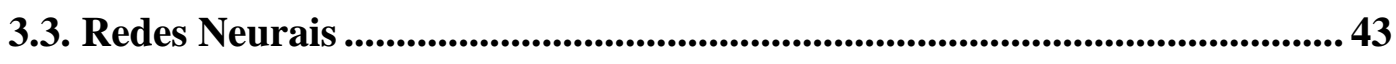

Capítulo 4: RESULTADOS EXPERIMENTAIS E DISCUSSÃO …...................... 47

4.1. Eletrodiálise ................................................................................................................ 49 
4.1.1. Determinação da Corrente Limite................................................................ 49

4.1.2. Experimentos Prévios .....................................................................50

4.1.3. Planejamento Experimental.................................................................5 53

4.1.4. Transporte de sal e água........................................................................... 55

4.1.5. Transporte de fenol .............................................................................60 60

4.1.6. Difusão de fenol através das MTCs e MTAs ..................................... 64

4.1.7. Tratamento dos resultados experimentais ........................................65

4.2. POA

4.2.1. Experimentos exploratórios ..............................................................69

4.2.2. Resultados Experimentais .................................................................. 72

4.2.3. Comparação com outros POAs........................................................... 79

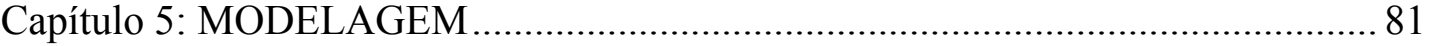

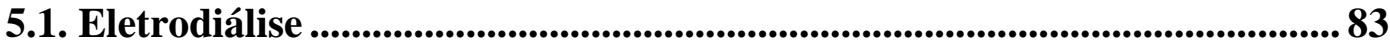

5.1.1. Modelo Piloto .......................................................................................... 87

5.1.2. Modo Contínuo - estado estacionário ........................................................ 91

5.1.3. Modelo Contínuo com Reciclo ................................................................. 93

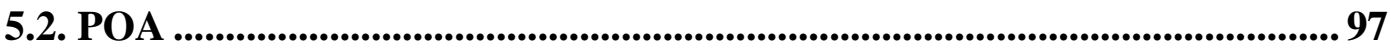

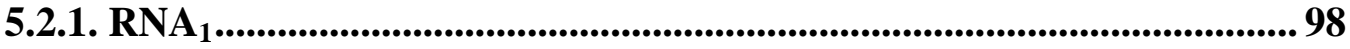

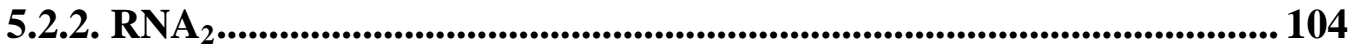

5.2.3. Modelo Contínuo........................................................................................ 107

5.3. Integração dos processos ..................................................................... 110

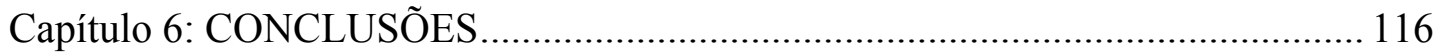

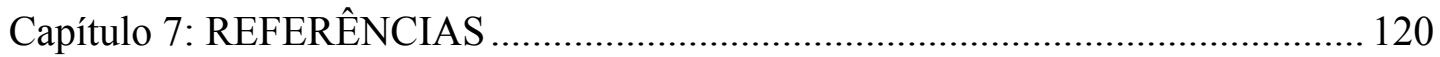

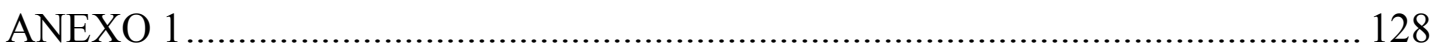

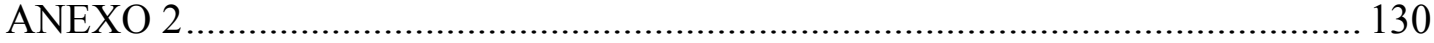




\section{LISTA DE FIGURAS}

Figura 1 - Esquema ilustrativo da estrutura de uma membrana trocadora de cátions (Strathmann, 2004).....

Figura 2 - Representação esquemática da desmineralização de uma solução salina contendo fenol por eletrodiálise, MTC: membrana trocadora de cátion, MTA: membrana trocadora de ânion.

Figura 3 - Fenômeno de polarização de concentração; membrana trocadora de cátion. 13

Figura 4 - Curva de intensidade de corrente versus potencial elétrico. 15

Figura 5 - Princípio da determinação da $I_{\text {lim }}$ pelo método de Cowan e Brown (1959).

Figura 6 - Esquema ilustrativo dos diferentes processos de transferência de massa no processo de ED, para solução de fenol e $\mathrm{NaCl}$ em água.

Figura 7 - Esquema representativo da partícula do semicondutor dióxido de titânio na geração de radicais hidroxila. .25

Figura 8 - Diagrama da célula de difusão. 1: compartimento do concentrado da MTC; 2: compartimento do diluído (alimentação); 3: compartimento do concentrado da MTA; 4: célula de difusão; 5: MTC; 6: MTA: 7a-c: bombas.

Figura 9 - Vista frontal da planta piloto de eletrodiálise utilizada; 1 - empilhamento de membranas, 2 - tanque do eletrólito; 3 - tanque do concentrado; 4 - tanque do diluído.

Figura 10 - Esquema hidráulico da piloto de eletrodiálise; ED: empilhamento de membranas; TC: tanque do concentrado; TE: tanque do eletrólito; TD: tanque do diluído; R: rotâmetro.

Figura 11 - Representação da matriz Doehlert para duas variáveis, concentração inicial de $\mathrm{NaCl}\left(\Delta C_{s}^{0}\right)$ e densidade de corrente (i) indicando os números dos experimentos adotados; VN: variável normalizada; VR: variável real. 37

Figura 12 - Esquema do reator fotoquímico de bancada utilizado.

Figura 13 - Espectro de transmitância do poço de quartzo encamisado do reator (Lira, 2006). 
Figura 14 - Representação esquemática do plano experimental - foto-Fenton; (a) 0,2 $\mathrm{mM} \mathrm{Fe}(\mathrm{II})$; (b) linha pontilhada: $0,5 \mathrm{mM}$ Fe(II), linha cheia: $0,1 \mathrm{mM} \mathrm{Fe}$ (II).

Figura 15 - Estrutura de uma rede neural artificial de tipo feedforward (Gob et al., 1999).

Figura 16 - Representação de um neurônio $j$ na camada oculta (Gob et al., 1999)... 44

Figura 17 - Gráfico da resistência do sistema em função do inverso da corrente, usado para determinação da corrente limite; $[\mathrm{NaCl}]_{\text {diluido }}^{0}=40 \mathrm{~g} / \mathrm{L}$.

Figura 18 - Variação da massa de fenol no concentrado versus tempo para diferentes concentrações iniciais de sal e densidades de corrente. 51

Figura 19 - Perda de fenol em função do tempo. 52

Figura 20 - Diagrama de Pareto normalizado para as contribuições dos fluxos. 55

Figura 21 - Volume do compartimento do concentrado em função do tempo para diferentes valores de densidade de corrente aplicadas; $\left[\Delta C_{s}^{0} \approx 55 \mathrm{~kg} . \mathrm{m}^{-3} ; \Delta C_{p}^{0}=100\right.$ ppm C]

Figura 22 - Massa de $\mathrm{NaCl}$ no compartimento do concentrado em função do tempo para diferentes densidades de corrente. 57

Figure 23 - Vazão de água (a) e de sal (b) em função da densidade de corrente....... 58 Figura 24 - Classificação de alguns íons quanto ao seu fator de hidratação (Singlande, 2006).

Figura 25 - Variação do fluxo de fenol versus diferença de concentração inicial entre os compartimentos - experimentos sem corrente elétrica......

Figura 26 - Variação de massa de fenol no concentrado pelo tempo - influência da concentração inicial de sal e fenol - experimentos sem corrente elétrica 62 Figura 27 - Variação da massa de fenol com o tempo no concentrado - influência da corrente elétrica - $\Delta C_{p}^{0} \approx 100 \mathrm{ppm} \mathrm{C}$

Figura 28 - Resultados experimentais versus calculados do fluxo de fenol. 64 Figura 29 - Massa de fenol em função do tempo através da MTC e MTA em solução aquosa com e sem a adição de $\mathrm{NaCl}\left[\Delta C_{p}^{0}=400\right.$ ppm C; $\left.I=0\right]$. 65 
Figura 30 - Concentração final de fenol no concentrado versus densidade de corrente para diferentes valores de concentração final de $\mathrm{NaCl}$ no diluído; $\left[\Delta C_{p}^{0}=100 \mathrm{ppm}\right.$ $\left.\mathrm{C} ; \Delta C_{s}^{0}=40 \mathrm{~g} / \mathrm{L}\right]$

Figura 31 - Remoção de COT em função do tempo; (a) efeito da concentração de $\mathrm{Fe}(\mathrm{II}),\left[\mathrm{H}_{2} \mathrm{O}_{2}\right]=40 \mathrm{mM}$; (b) Efeito da concentração de $\mathrm{H}_{2} \mathrm{O}_{2},[\mathrm{Fe}(\mathrm{II})]=0,5 \mathrm{mM} \ldots . .70$ Figura 32 -Remoção de COT em função do tempo; efeito do tempo de adição da solução de $\mathrm{H}_{2} \mathrm{O}_{2}$ em diferentes concentrações [0,2 mM Fe(II); (a) 20 mM $\mathrm{H}_{2} \mathrm{O}_{2}$; (b) $40 \mathrm{mM} \mathrm{H}_{2} \mathrm{O}_{2}$. 71

Figura 33 - Exemplificação do método de obtenção das respostas de decaimento de $\mathrm{COT} / \mathrm{COT}_{0}$.

Figura 34 - Remoção de COT em função do tempo para as condições experimentais no plano central; 0,2 mM Fe(II) - processo foto-Fenton; (a) $\left[\mathrm{H}_{2} \mathrm{O}_{2}\right]=10 \mathrm{mM}$; (b) $\left[\mathrm{H}_{2} \mathrm{O}_{2}\right]=20 \mathrm{mM}$; (c) $\left[\mathrm{H}_{2} \mathrm{O}_{2}\right]=40 \mathrm{mM}$; (d) $\left[\mathrm{H}_{2} \mathrm{O}_{2}\right]=80 \mathrm{mM}$ .75

Figura 35 - Remoção de COT em função do tempo para as condições do planejamento experimental; efeito $[\mathrm{Fe}(\mathrm{II})]$ - processo foto-Fenton; (a) $\left[\mathrm{H}_{2} \mathrm{O}_{2}\right]=20$ $\mathrm{mM} ;\left[\mathrm{H}_{2} \mathrm{O}_{2}\right]=40 \mathrm{mM} ;\left[\mathrm{H}_{2} \mathrm{O}_{2}\right]$ .76

Figura 36 - Respostas em função da concentração de $\mathrm{NaCl}$ para diferentes concentrações de $\mathrm{H}_{2} \mathrm{O}_{2}$ para algumas condições experimentais; (a) $k$; (b) $t_{2}$; (c) $\% R_{40}$

Figura 37 - Remoção de COT em função do tempo para algumas condições estudadas dos diferentes processos avaliados; $[\mathrm{Fe}(\mathrm{II})]=0,2 \mathrm{mM} ;\left[\mathrm{TiO}_{2}\right]=1 \mathrm{~g} / \mathrm{L} \ldots .80$ Figura 38 - Esquema do modelo desenvolvido para o processo de eletrodiálise; $F$ : fluxo molar; $X$ : fração molar; $T$ : tanque; subscrito $i$ : fenol, sal ou água. Figura 39 - Esquema da configuração do modelo piloto; $Q$ : vazão das correntes; $C$ : concentração dos componentes; subscrito $i$ : fenol e sal.

Figura 40 - Variação do volume (a), concentração de sal (b) e fenol (c) com o tempo nos tanques $T_{E}$ e $T_{W}$; predição modelo e valores experimentais; $i=275 \mathrm{~A} / \mathrm{m}^{2}$. 88 Figura 41 - Superfície de resposta para $C_{E_{S}}$ (a) e $C_{W_{P}}$ (b) em 30 minutos de operação em função da área de membrana, $A$, e da densidade de corrente, $i$.

Figura 42 - Variação de $C_{W_{P}}$ (a) e $C_{E_{S}}$ (b) em função da densidade de corrente para diferentes valores de área de membrana $\left(\mathrm{m}^{2}\right)$ em 30 minutos de operação. 90 
Figura 43 - Configuração para operação contínua em regime estacionário; $Q$ : vazão das correntes; $C$ : concentração; subscrito $i$ : fenol e sal.

Figura 44 - Variação de (a) $C_{C_{P}}$ e $A$ (b) em função da densidade de corrente para diferentes percentuais de dessalinização.

Figura 45 - Configuração do modelo contínuo com reciclo no concentrado; $Q$ : vazão das correntes; $C$ : concentração; subscrito $i$ : fenol e sal. .93

Figura 46 - Variação da concentração de sal (pontos) e fenol (linha e retângulos) em função do percentual reciclado - compartimento concentrado; $i=175 \mathrm{~A} / \mathrm{m}^{2}, A=20 \mathrm{~m}^{2}$.

Figura 47 - (a) Fluxos de fenol: total, $J_{P}$, convectivo, $J_{\text {conv }}$, e difusivo, $J_{\text {diff }}$, (b) Concentrações de fenol no diluído, $C_{D_{P}}$, concentrado, $C_{C_{P}}$, e diferença entre elas, $\left(C_{D_{P}}-C_{C_{P}}\right)$, versus percentual reciclado - compartimento concentrado; $i=175 \mathrm{~A} / \mathrm{m}^{2}$, $A=20 \mathrm{~m}^{2}$ 96

Figura 48 - Diagrama ilustrativo do modelo de redes neurais para estimativa da taxa de degradação $(-r)_{\text {sim }}$. 97

Figura 49 - RMSTT (Test set) em função do número de apresentações para a RNA para diferentes números de neurônios. 100

Figura 50 - Resultados experimentais versus calculados de COT/COT 0 para $\mathrm{RNA}_{1}$. 101

Figura 51 - Resultados experimentais (pontos) e calculados (linha cheia) para experimentos do Test set; (a) $\left[\mathrm{H}_{2} \mathrm{O}_{2}\right]=80 \mathrm{mM},[\mathrm{NaCl}]=25 \mathrm{~g} \mathrm{~L}^{-1},[\mathrm{Fe}(\mathrm{II})]=0,2 \mathrm{mM}$; (b) $\left[\mathrm{H}_{2} \mathrm{O}_{2}\right]=20 \mathrm{mM},[\mathrm{NaCl}]=5 \mathrm{~g} / \mathrm{L},[\mathrm{Fe}(\mathrm{II})]=0,2 \mathrm{mM}$; (c) $\left[\mathrm{H}_{2} \mathrm{O}_{2}\right]=40 \mathrm{mM},[\mathrm{NaCl}]=25$ $\mathrm{g} / \mathrm{L},[\mathrm{Fe}(\mathrm{II})]=0,2 \mathrm{mM}$;

Figura 52 - Remoção de COT em 30 minutos (a) e 40 minutos (b) de reação em função da concentração de $\mathrm{NaCl}$ para diferentes concentrações de $\left.\mathrm{H}_{2} \mathrm{O}_{2} ; \mathrm{Fe}(\mathrm{II})\right]=0,2$ $\mathrm{mM}$. 103

Figura 53 - RMSTT (Test set) em função do número de apresentações para a RNA2.

Figura 54 - Resultados experimentais versus calculados do módulo da taxa de reação para $\mathrm{RNA}_{2}$ 105 
Figura 55 - Volume do reator fotoquímico versus concentração de sal para diferentes concentrações de $\mathrm{H}_{2} \mathrm{O}_{2}$ para remoção de COT de $70 \%$.

Figura 56 - Volume de reator necessário em função da concentração de $\mathrm{NaCl}$ da solução para diferentes percentuais de remoção de COT; $\left[\mathrm{H}_{2} \mathrm{O}_{2}\right]=40 \mathrm{mM}$; [Fe(II)] $=0,2 \mathrm{mM}$ 108

Figura 57 - Esquema do sistema integrado. 110

Figura 58 - Potência elétrica estimada e área de membrana (linha contínua) no processo de ED para diferentes percentuais de dessalinização.

Figura A1-1. (a) superfície de resposta para o fluxo de água $\left(j_{w}\right)$; (b) resultados experimentais versus calculados para $j_{w}$.... 128

Figura A1-2. (a) superfície de resposta para o fluxo de sal $\left(j_{s}\right)$; (b) resultados experimentais versus calculados para $j_{s}$ 129

Figura A1-3. (a) superfície de resposta para o fluxo de fenol $\left(j_{p}\right)$; (b) resultados experimentais versus calculados para $j_{p}$. 129 


\section{LISTA DE TABELAS}

Tabela 1 - Propriedades das membranas trocadoras de íons utilizadas (Astom

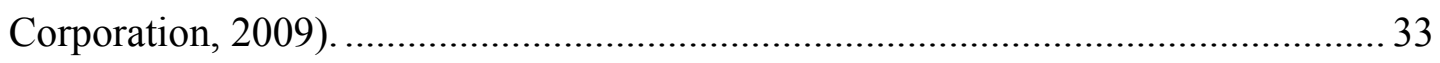

Tabela 2 - Características da planta piloto de eletrodiálise convencional................. 35

Tabela 3 - Condições de operação no início do experimento.................................... 36

Tabela 4- Propriedades típicas do $\mathrm{TiO}_{2}$ Degussa P25 (Tanaka e Saha, 1995).......... 38

Tabela 5 - Condições nos experimentos prévios de eletrodiálise baseadas na matriz Doehlert. 50

Tabela 6 - Condições experimentais de eletrodiálise baseadas na matriz Doehlert e resultados. .54

Tabela 7 - Comparação do número de transferência deste estudo com outros reportados.

Tabela 8 - Condições operacionais (densidade de corrente e concentração de fenol) e resultados (fluxo de fenol) dos experimentos realizados para avaliar as diferentes contribuições ao transporte de fenol. .60

Tabela 9 - Coeficientes de transporte obtidos nos experimentos de ED. 65

Tabela 10 - Resultados experimentais - processo foto-Fenton. .74

Tabela 11 - Resultados da análise de sensibilidade de $C_{E_{S}}$ e $C_{W_{P}}$ em relação à área de membrana e densidade de corrente. 90

Tabela 12 - Resultados da análise de sensibilidade de $C_{C_{P}}$ e $C_{D_{S}}$ em relação à área de membrana e densidade de corrente. 93

Tabela 13 - Resultados da análise de sensibilidade de $C_{C_{S}}$ e $C_{C_{P}}$ em relação ao percentual de reciclo. .96

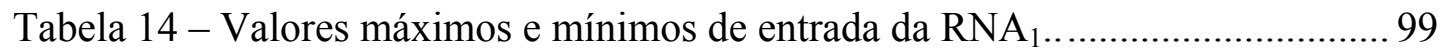

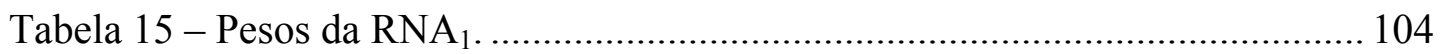

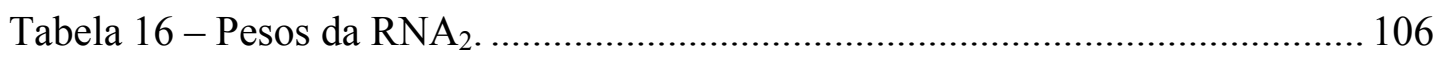

Tabela 17 - Resultados em diferentes cenários do processo integrado. .................. 112 


\section{LISTA DE ABREVIATURAS}

ED: eletrodiálise

POA: processo oxidativo avançado

MTI: membrana trocadora de íon

MTC: membrana trocadora de cátions

MTA: membrana trocadora de ânions

UV: luz ultravioleta

COT: carbono orgânico total

RNA: redes neurais artificiais

NH: número de neurônios na camada oculta

LS: conjunto de aprendizado da RNA (Learning Set)

TS: conjunto de teste da RNA (Test Set)

RMSTT: raiz quadrada do erro quadrático médio do TS 


\section{LISTA DE NOTAÇÕES E SÍMBOLOS}

$\bar{C}$ : concentração dentro da membrana

$C$ : concentração

$\Delta C_{p}^{0}$ : diferença de concentração de fenol entre os compartimentos (ppm C)

$C_{p}^{0}$ : concentração inicial de fenol (ppm C)

$\Delta C_{s}^{0}$ : diferença de concentração de sal entre os compartimentos $(\mathrm{g} / \mathrm{L})$

$t$ : tempo

$z$ : valência

$j^{+}$: fluxo de cátions $\left(\mathrm{mol} / \mathrm{m}^{2} . \mathrm{s}\right)$

$\delta$ : espessura da camada limite

$D$ : coeficiente de difusão $\left(\mathrm{m}^{2} / \mathrm{s}\right)$

$t_{i}$ : número de transporte da espécie $i$

$u$ : mobilidade eletroforética

$i_{\text {lim }}$ : corrente elétrica limite $\left(\mathrm{A} / \mathrm{m}^{2}\right)$

$F$ : constante de Faraday $(96.485 \mathrm{C} / \mathrm{mol})$

$i$ : densidade de corrente elétrica $\left(\mathrm{A} / \mathrm{m}^{2}\right)$

I: intensidade de corrente elétrica (A)

$U$ : potencial elétrico $(\mathrm{V})$

$J_{v}$ : fluxo volumétrico do solvente $\left(\mathrm{m}^{3} / \mathrm{m}^{2} . \mathrm{s}\right)$

$J_{i}$ : fluxo molar do soluto $i\left(\mathrm{~mol} / \mathrm{m}^{2} . \mathrm{s}\right)$

$L_{p}$ : permeabilidade da membrana ao solvente $\left(\mathrm{m}^{3} / \mathrm{m}^{2}\right.$.s.bar)

$\Delta \Pi_{i}$ : gradiente de pressão osmótica através da membrana (bar)

$\Delta p$ : gradiente de pressão hidrostática através da membrana (bar)

$\bar{C}_{i}$ : concentração média de soluto nos dois lados da membrana $\left(\mathrm{mol} / \mathrm{m}^{3}\right)$

$P_{i:}$ coeficiente de permeabilidade ( $\mathrm{mol} / \mathrm{m}^{2}$.s.bar)

$\sigma$ : coeficiente de reflexão

$T_{w}$ : número de transferência de solvente (moléculas de água/íons)

$\Delta C:$ diferença de concentração

$\beta$ : coeficiente de corrente elétrica $(\mathrm{kg} / \mathrm{s} . \mathrm{A})$ 


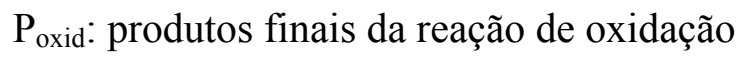

$\mathrm{e}^{-}:$pares elétron

$\mathrm{h}^{+}$: vacância

$z P c$ : ponto de carga zero

$W_{i, j}$ : peso do neurônio $i$ da camada $j$ da RNA

$x_{i}$ : variáveis de entrada da RNA

$O_{i}$ : variáveis de saída da RNA

$S_{k}$ : soma dos pesos da RNA

$E$ : desvio quadrático

$y_{k}$ : respostas experimentais

$m$ : massa $(\mathrm{kg})$

$S$ : área total de membrana ativa $\left(\mathrm{m}^{2}\right)$

$V$ : volume $\left(\mathrm{m}^{3}\right)$

$j_{w}$ : vazão volumétrica de água $(\mathrm{L} / \mathrm{h})$

$X$ : variáveis

$X^{\prime}$ : variáveis normalizadas

$U$ : variáveis reais

$Y$ : respostas

$J_{w}$ : fluxo volumétrico da água $(\mathrm{m} / \mathrm{s})$

$J_{s}$ : fluxo mássico de sal $\left(\mathrm{kg} / \mathrm{s} . \mathrm{m}^{2}\right)$

$J_{p}$ : fluxo mássico de fenol $\left(\mathrm{kg} / \mathrm{s} . \mathrm{m}^{2}\right)$

$j_{w}$ : vazão volumétrica de água $\left(\mathrm{m}^{3} / \mathrm{s}\right)$

$j_{p}$ : vazão mássica de fenol $(\mathrm{kg} / \mathrm{s})$

$j_{s}$ : vazão mássica de sal $(\mathrm{kg} / \mathrm{s})$

$M_{s}$ : peso molecular do $\mathrm{NaCl}(\mathrm{g} / \mathrm{mol})$

$T_{w}$ : número de moles de água transportados por mol de íon

$N_{w}$ : concentração molar de água $\left(\mathrm{mol} / \mathrm{m}^{3}\right)$

$k$ : velocidade de decaimento $\left(\left(\mathrm{COT} / \mathrm{COT}_{0}\right) / \mathrm{h}\right)$

$\% R$ : percentual de remoção de COT

$F$ : vazão molar

$X$ : fração molar

$N$ : número de moles 


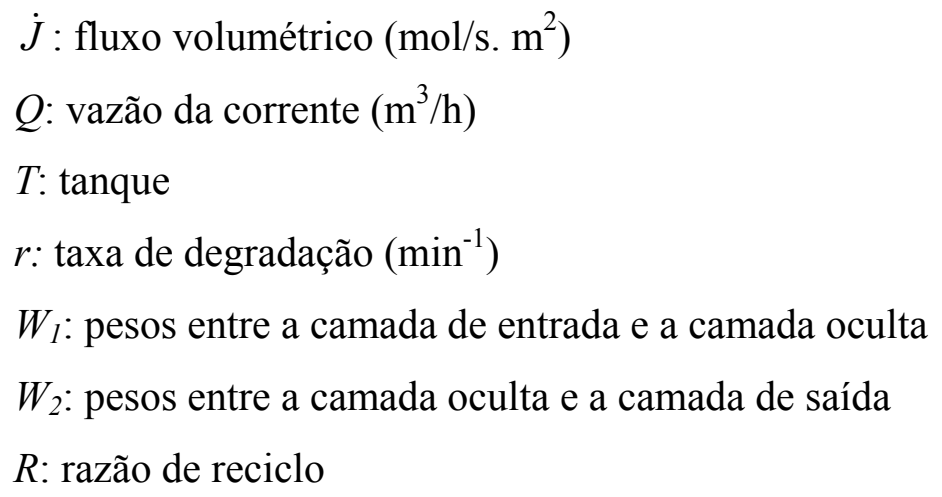

Índices

elec: eletro-osmose

os: osmose

diff: difusão

conv: convecção

$i$ : soluto $i$

$v$ : solvente

$s:$ sal

$n$ : soluto neutro

$p$ : fenol

$w$ : água

$c$ : compartimento do concentrado

$d$ : compartimento do diluído 
Capítulo 1: INTRODUÇÃO 
Muitos esforços vêm sendo desenvolvidos ultimamente nos estudos de processos que permitam a destruição de substâncias poluentes contidas em efluentes industriais. Os diferentes tipos de tratamento existentes se dividem em função de sua aplicabilidade frente à enorme gama destes. Na maior parte dos casos, as soluções são diversas e a associação entre diferentes técnicas de tratamento faz-se necessária para que se obtenha um resultado satisfatório sobressaltando-se a eficiência e a diminuição de custos necessários.

O presente trabalho consiste no estudo da associação dos processos de separação por membranas e degradação fotoquímica para tratamento de efluentes salinos contendo fenol como poluente modelo.

O fenol é um poluente abundante em efluentes industriais, freqüente em indústrias químicas e petroquímicas, destacando-se as de tintas, de tecidos, de pesticidas, de herbicidas etc. Conseqüentemente, o tratamento de águas contendo esse poluente tem gerado interesse significativo. O fenol é uma substância amplamente utilizada como poluente modelo nas avaliações de sistemas convencionais e avançados de tratamento por suas características de elevada toxicidade.

Sendo o fenol um poluente tóxico e inibidor ao tratamento biológico convencional, os Processos de Oxidação Avançada (POA) apresentam-se como alternativa atraente para o tratamento de efluentes com a presença destes contaminantes. Baseiam-se na geração de radicais hidroxila, fortemente oxidantes e pouco seletivos promovendo a degradação de uma grande variedade de poluentes orgânicos a dióxido de carbono, água e compostos inorgânicos, ou, no limite, transformando-os em produtos menos tóxicos. Portanto, esses processos são particularmente indicados para o tratamento de efluentes contendo compostos recalcitrantes e tóxicos (Legrini et al., 1993). Este trabalho pretende avaliar um dos processos que vêm se destacando neste segmento: o processo foto-Fenton.

Muitos efluentes industriais apresentam concentrações elevadas de sal, dificultando o tratamento, pois as reações fotoquímicas são inibidas por altas concentrações de determinados íons, como cloreto (Moraes et al., 2004; Pignatello et al., 1992), e normalmente as moléculas não degradadas ou seus subprodutos permanecem no 
efluente tratado, resultando assim em um processo com baixa eficiência (Oliveros et al., 1997). Neste caso, as vantagens potenciais dos POAs podem ser exploradas na integração com os processos de separação por membranas, especialmente a eletrodiálise.

Efluentes contendo altas concentrações de íon cloreto, por exemplo, são comuns em indústrias petroquímicas, de cristalização, pesticidas, entre outras indústrias químicas. Concentrações de cloreto entre 14 e $41 \mathrm{~g} / \mathrm{L}$ podem ser encontradas em efluentes petroquímicos (Middleditch, 1984), enquanto em efluentes de processos de cristalização concentrações maiores que $19 \mathrm{~g} / \mathrm{L}$ foram reportadas (Koprivanac et al., 2000).

A tecnologia de separação por membranas possibilita a concentração de contaminantes ou substâncias de interesse e se diferencia principalmente dos processos de filtração convencional por utilizar fluxo de água em paralelo, permitindo que apenas parte do efluente passe através da membrana e que partículas de pequenos tamanhos, como moléculas, e até compostos iônicos dissolvidos sejam separados (Wagner, 2001). Duas correntes são formadas neste processo, uma que é retida, denominada concentrado, e outra que atravessa a membrana, denominada permeado.

Basicamente, os processos de separação por membranas são divididos nas seguintes categorias: microfiltração, ultrafiltração, nanofiltração, osmose inversa e eletrodiálise. Particularmente, o que difere cada uma dessas categorias são os diâmetros dos poros da membrana e o tipo e intensidade da força motriz, gradiente de pressão hidráulica ou campo elétrico, utilizada para que se efetue a separação dos contaminantes. A retenção física de componentes é o principal mecanismo de rejeição em membranas de microfiltração e ultrafiltração, enquanto processos de exclusão química e/ou difusão preferencial predominam em membranas de nanofiltração, osmose inversa e eletrodiálise.

Em princípio, as técnicas de nanofiltração e eletrodiálise mostram-se promissoras para o propósito. No que se refere à remoção de poluentes em efluentes, como micropoluentes, trabalhos anteriores (Berg et al., 1997; Van der Bruggen, 1998; Boussahel et al., 2005) mostraram que a técnica de nanofiltração apresenta bom desempenho em relação aos métodos tradicionais de tratamento; enquanto a técnica de 
eletrodiálise vem sendo muito aplicada para dessalinização de efluentes, apresentando-se mais propícia para este estudo.

A eletrodiálise é uma operação baseada na migração de compostos iônicos presentes em um fluido graças à combinação de membranas seletivas de íons empilhadas (ânions e cátions) submetida à influência de um campo elétrico aplicado, permitindo a concentração de espécies iônicas e a separação dessas de substâncias não carregadas.

Assim, a eletrodiálise adequa-se como pré-tratamento do processo, para diminuir a concentração de sais de uma solução contendo fenol e assim possibilitar a degradação fotoquímica eficaz do poluente.

O estudo da integração desses processos envolve atividades experimentais e fundamentação teórica dos fenômenos envolvidos e o desenvolvimento de modelos matemáticos para os processos, possibilitando sua associação e otimização em função dos principais parâmetros e custos relacionados.

Deste modo, o objetivo principal do presente trabalho é o estudo da integração dos processos de eletrodiálise e de degradação fotoquímica para o tratamento de efluentes fenólicos salinos, utilizando o processo de eletrodiálise para a desmineralização do efluente e o processo fotoquímico foto-Fenton para a degradação do fenol, já que a presença de certos íons diminui a eficiência do mesmo. O escopo deste trabalho é contribuir para o desenvolvimento de avaliação da integração de processos para tratamento de efluentes. Trata-se de um projeto de tese em co-orientação entre o CESQ-LSCP (Centro de Engenharia de Sistema Químicos - Laboratório de Simulação e Controle de Processos) no Departamento de Engenharia Química da Escola Politécnica da Universidade de São Paulo e o Laboratoire de Génie Chimique (LGC) do Institut National Polytechnique de Toulouse da Université Paul Sabatier.A primeira etapa, referente aos estudos experimentais de eletrodiálise, foi realizada no LGC, que desenvolve pesquisas na área de tratamento de efluentes utilizando membranas, realizando experimentos em diferentes condições, assim como a modelagem matemática do processo. A etapa seguinte, que trata dos POAs, foi realizada no CESQ-LSCP. Vale ressaltar que os POAs vêm sendo alvo de muitas pesquisas realizadas no grupo. 
O trabalho ora proposto representa uma contribuição importante às pesquisas em andamento, valendo-se de resultados já obtidos e da experiência da equipe francesa na condução de experimentos e modelagem matemática em separação por membranas, além de ter contribuído para implantação do sistema no CESQ-LSCP e sua capacitação nesta área de pesquisa. Entende-se ser tal colaboração importante para o desenvolvimento de processos integrados aplicados a necessidades industriais na atualidade. 


\section{Capítulo 2: REVISÃO BIBLIOGRÁFICA}

- Eletrodiálise

o Membranas trocadoras de íons

o Descrição do sistema

o Mecanismos de transporte

o Transferência de solutos e solução

- Processos Oxidativos Avançados

0 Fotólise de $\mathrm{H}_{2} \mathrm{O}_{2}$

o Reações Fenton e foto-Fenton

o Fotocatálise com $\mathrm{TiO}_{2}$

o Processos Oxidativos em meio salino 
Como primeira etapa deste trabalho, uma pesquisa bibliográfica relacionada aos temas foi realizada. Tratando-se de um estudo de integração de processos, existem dois tópicos principais que foram abordados: o processo de separação por membranas de eletrodiálise e os processos de degradação fotoquímica. $\mathrm{O}$ estudo abordou os processos eficientes na remoção de poluentes fenólicos e, portanto, essa última vertente trata dos principais Processos Oxidativos Avançados (POAs), enfatizando o processo Foto-Fenton que foi utilizado no desenvolvimento da tese. 


\subsection{Eletrodiálise}

A eletrodiálise (ED) é um processo eletroquímico de separação no qual membranas com capacidade de troca de íons submetidas a uma diferença de potencial elétrico são utilizadas para promover a separação de espécies iônicas de uma solução aquosa e outros compostos neutros. Atualmente, os processos de ED são utilizados para dessalinização de soluções ou para a concentração de soluções salinas e para redução de teor de sal para uso industrial ou para a produção de água potável a partir de águas salobras. No entanto, a dessalinização da água não se resume à única aplicação do processo de ED. Com o estímulo ao desenvolvimento de novas membranas trocadoras de íons, com melhor seletividade, baixa resistência elétrica, e melhores propriedades térmicas, químicas e mecânicas, outros usos de ED despertaram interesse, especialmente nas indústrias farmacêutica, química e de alimentos, assim como em biotecnologia e tratamento de efluentes (Strathmann, 2004)

\subsubsection{Membranas trocadoras de íons}

O termo "eletrodiálise" designa a transferência de íons através de membranas sob o efeito de um campo elétrico. A origem do termo, que data dos anos 1930, trata da utilização de corrente elétrica para aumentar a transferência de massa de espécies carregadas, obtida por diálise. Em diálise, duas fases líquidas contendo o mesmo solvente são dispostas separadas por uma membrana na ausência de gradiente de pressão. Os fluxos de solutos neste processo são proporcionais à diferença de concentração existente entre as soluções. A separação é proporcional a diferentes coeficientes de permeabilidade dependentes do soluto; macromoléculas possuem coeficientes de difusão menores em relação a componentes de baixo peso molecular. No entanto, quando membranas carregadas ou membranas trocadoras de íons são utilizadas em vez de membranas neutras, o transporte de íons é também afetado pela presença das cargas fixas presentes na membrana (Mulder, 1996). 
As membranas trocadoras de íons (MTI) permitem a transferência de espécies carregadas segundo sua carga, positiva ou negativa, transferindo cátions no caso de membranas trocadoras de cátions (MTC) e ânions no caso de membranas trocadoras de ânions (MTA).

A transferência seletiva de espécies carregadas envolve um mecanismo de troca de íons de ponto a ponto entre os íons da solução e os contra-íons da membrana. Sendo assim, as MTC são compostas de grupos funcionais de carga negativa e o mecanismo de troca de íons depende da natureza química dos materiais que constituem as MTI.

A Figura 1 mostra, esquematicamente, a matriz de uma membrana trocadora de cátions com ânions fixos e cátions móveis chamados de contra-íons. Os ânions móveis, chamados de coíons, são, de certa maneira, excluídos da matriz polimérica por sua carga elétrica idêntica à dos ânions fixos. Devido à exclusão dos co-íons uma membrana trocadora de cátions ideal permite a passagem somente de cátions, assim como uma membrana ideal trocadora de ânions carregada de cargas positivas fixas na matriz do polímero exclui cátions e é permeável somente a ânions.

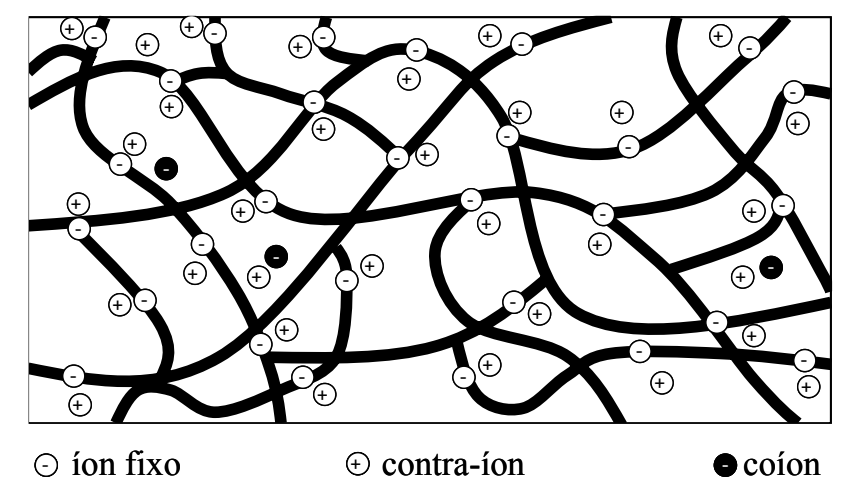

matriz do polímero

Figura 1 - Esquema ilustrativo da estrutura de uma membrana trocadora de cátions (Strathmann, 2004).

\subsubsection{Descrição do sistema}

Um esquema simplificado de uma célula típica de ED é apresentado na Figura 2 representando a dessalinização de uma solução contendo cloreto de sódio $(\mathrm{NaCl})$ e fenol. 
A célula consiste de pares de membranas dispostas em paralelo, sendo cada par composto por membranas trocadoras de cátions e ânions alternadas e separadas por um espaçador pelo qual a solução flui. Portanto, o sistema é constituído por um empilhamento de membranas, nomeado de stack, num arranjo do tipo filtro-prensa. Quando uma diferença de potencial elétrico é aplicada à célula, os cátions em solução migram em direção ao cátodo, atravessando as MTCs e confinados pelas MTAs. Da mesma maneira, os ânions migram em direção ao ânodo, atravessando as MTAs e confinados pelas MTCs. Conseqüentemente, os compartimentos alternados entre as diferentes membranas tornam-se gradativamente enriquecidos (concentrado) e empobrecidos em eletrólitos (diluído) (Mulder,1996; Strathmann, 2004).

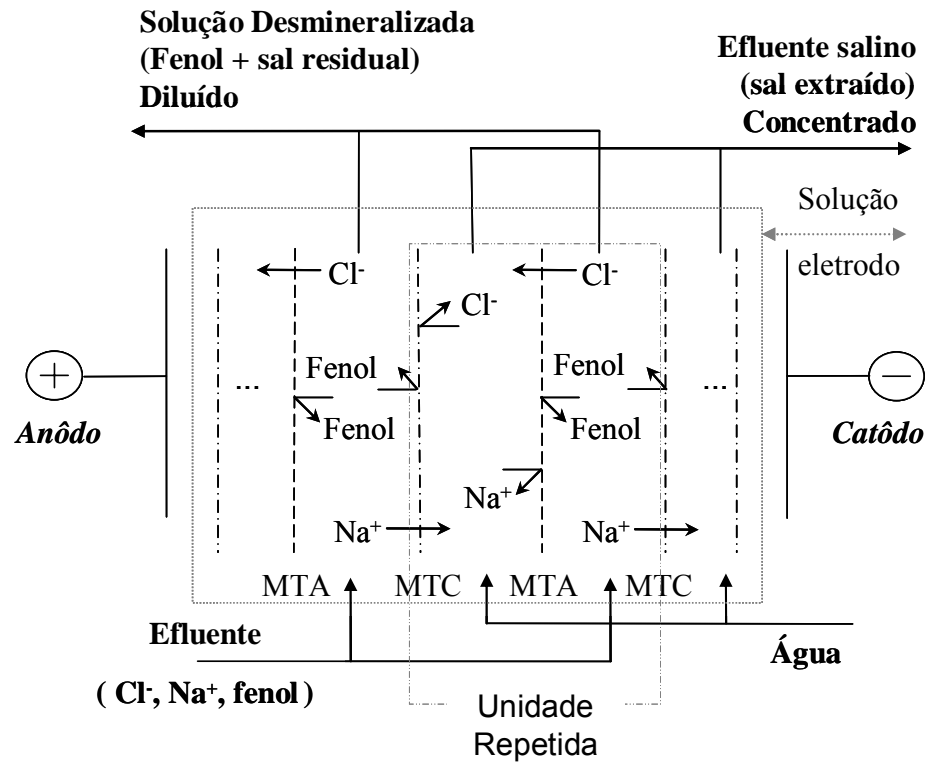

Figura 2 - Representação esquemática da desmineralização de uma solução salina contendo fenol por eletrodiálise, MTC: membrana trocadora de cátion, MTA: membrana trocadora de ânion. 


\subsubsection{Mecanismos de transporte}

\section{Exclusão de Donnan}

Diferentes abordagens podem ser utilizadas para descrever a transferência de massa em ED. Essencialmente, tratam-se de modelos termodinâmicos baseados na descrição de equilíbrio de fases (material da membrana e solução eletrolítica) e de um modelo cinético, integrando o transporte devido à aplicação de gradiente de potencial elétrico (Saracco, 1997).

Considerando uma membrana trocadora de íons, espécies carregadas com a mesma carga dos íons fixos da membrana são excluídas e não passam através da membrana. O efeito é conhecido como exclusão de Donnan e pode ser descrito pelo equilíbrio termodinâmico que permite o cálculo do potencial químico de um componente iônico nas duas fases presentes quando uma solução iônica está em equilíbrio com uma membrana iônica.

Considerando um material trocador de ânions, ou seja, portador de grupos funcionais de carga positiva, $R^{+}$, imerso em uma solução eletrolítica simples $\left(A^{+}, B^{-}\right)$, a resolução de um sistema de equações, constituído por uma descrição de igualdade de potenciais químicos e de eletroneutralidade em cada uma das fases, permite a obtenção da relação apresentada pela Equação 1, que expressa a concentração de $A$ dentro da membrana $\left(\bar{C}_{A}\right)$ em função da capacidade de troca do material, $\bar{C}_{R}$ :

$$
\bar{C}_{A}=\frac{z_{R} \bar{C}_{R}}{2}\left(\sqrt{1+\left(\frac{2 C_{A}}{z_{R} \bar{C}_{R}}\right)^{2}}-1\right)
$$

em que $z_{R}$ é a valência do íon $R$.

Esta equação permite identificar dois casos limites, segundo o valor de $\left(\frac{2 C_{A}}{z_{R} \bar{C}_{R}}\right)$ em relação a 1 . 
- $1^{\circ}$ caso em que $\left(\frac{2 C_{A}}{z_{R} \bar{C}_{R}}\right)<<1$ : a concentração da solução é baixa frente à capacidade de troca do material. A Equação 1 mostra que $\bar{C}_{A}$ tende a um valor nulo. Conseqüentemente, o íon $A$ é totalmente excluído da membrana, que tem seletividade perfeita.

- $2^{\circ}$ caso em que $\left(\frac{2 C_{A}}{z_{R} \bar{C}_{R}}\right)>>1$ : a concentração da solução é alta frente à capacidade de troca do material. A Equação 1 mostra que $\bar{C}_{A}$ tende a $C_{A}$. Conseqüentemente, a concentração em $A$ é idêntica à do material e do eletrólito, o que significa que o material não oferece nenhuma seletividade.

A mesma abordagem pode ser utilizada para explicar a seletividade de íons de mesma carga, porém com valências diferentes, ou seja, que essa seletividade se aplica somente nas condições do $1^{\circ}$ caso, ou seja, para soluções diluídas frente à capacidade de troca da membrana.

\section{Polarização de concentração e corrente limite}

O desempenho de sistemas práticos de ED é controlado pela polarização de concentração. O fenômeno, descrito pela teoria da corrente limite, é comum a todos os sistemas que operam com transferência de massa através de uma interface. No caso da ED, a polarização de concentração é originada pela diferença de mobilidade dos íons na solução eletrolítica e na MTI.

O desenvolvimento teórico que se segue, extraído das publicações de Bailly (2000) e Roux-de Balmann e Casademont (2006), considera o compartimento do diluído (subscrito $d$ ) e trata da transferência de cátions através das MTC, o qual é análogo à transferência de ânions através das MTA.

Devido à migração dos íons do compartimento do diluído para o do concentrado quando potencial elétrico é aplicado, a concentração na interface membrana - solução, concentração em ânions e em cátions para as MTA e MTC respectivamente, é mais 
diluída que a do fluido que circula pelo sistema no compartimento do diluído. Este gradiente de concentração gera um fluxo difusivo dentro da membrana contrário ao fluxo de migração.

A Figura 3 representa esquematicamente o fenômeno de polarização de concentração para o caso de uma MTC.

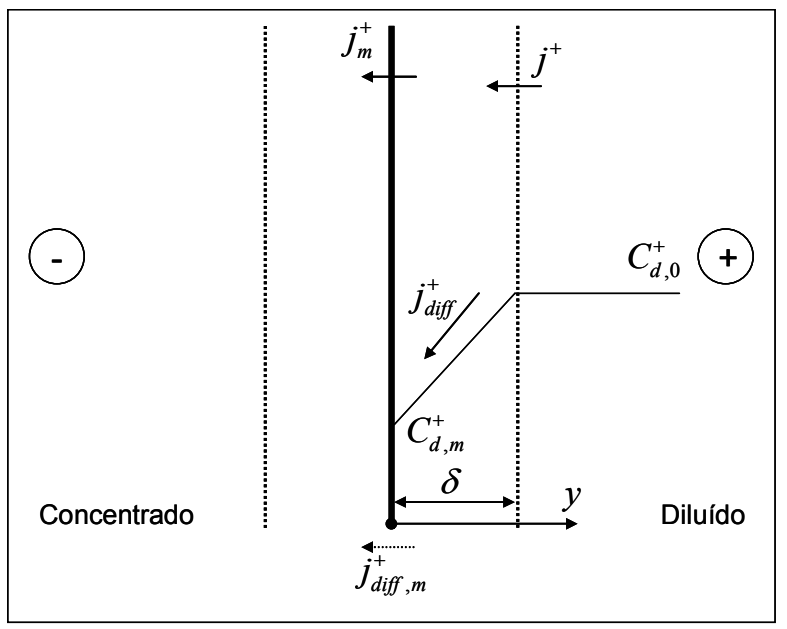

Figura 3 - Fenômeno de polarização de concentração; membrana trocadora de cátion.

em que $j^{+}$é o fluxo de cátions na solução $\left(\mathrm{mol} / \mathrm{m}^{2} . \mathrm{s}\right) ; j_{m}^{+}$a densidade de fluxo de cátions através da membrana $\left(\mathrm{mol} / \mathrm{m}^{2} . \mathrm{s}\right) ; C_{d, m}^{+}$a concentração de cátions no diluído na interface da membrana $\left(\mathrm{mol} / \mathrm{m}^{3}\right) ; C_{d, 0}^{+}$a concentração de cátions no diluído fora da camada limite $\left(\mathrm{mol} / \mathrm{m}^{3}\right) ; j_{\text {diff }}^{+}$o fluxo difusivo $\left(\mathrm{mol} / \mathrm{m}^{2} . \mathrm{s}\right) j_{\text {diff, },}^{+}$o fluxo por difusão através da membrana $\left(\mathrm{mol} / \mathrm{m}^{2} . \mathrm{s}\right)$; e, $\delta$ é a espessura da camada limite.

No estado estacionário, a equação de continuidade dos fluxos pode ser descrita pela Equação 2:

$j^{+}+D \frac{\partial C_{d}^{+}}{\partial y}=\overline{j_{m}^{+}}-\overline{j_{d i f f, m}^{+}}$

em que $C_{d}^{+}$é a concentração de cátions no diluído $\left(\mathrm{mol} / \mathrm{m}^{3}\right)$ e $D$ o coeficiente de difusão da espécie considerada $(\mathrm{m} / \mathrm{s})$. 
Na prática, o fluxo difusivo através da membrana é desprezível frente aos outros termos da Equação 2, obtendo-se a Equação 3.

$j^{+}+D \frac{\partial C_{d}^{+}}{\partial y}=j_{m}^{+}$

O número de transporte de uma espécie $i, t_{i}$, é a fração de corrente que esta transporta. Este parâmetro pode ser descrito pela Equação 4:

$t_{i}=\frac{u_{i} z_{i} C_{i}}{\sum_{i} u_{i} z_{i} C_{i}}$

em que $u_{i}, z_{i}$ e $C_{i}$ são respectivamente a mobilidade eletroforética, a valência e a concentração da espécie $i$ na solução.

Por definição a soma do número de transporte de diferentes espécies que contribuem para a condução da corrente é igual a 1 .

$\mathrm{Na}$ solução propriamente dita, todas as espécies iônicas contribuem para a condução da corrente. No entanto, através de uma membrana trocadora de íons, a corrente é transportada somente pelos íons que atravessam efetivamente a membrana, ou seja, íons de mesma carga (cátions para a MTC), supondo membranas ideais. O número de transporte de uma espécie em solução é portanto diferente e menor que o da mesma espécie dentro da membrana, $t_{m}$. Pelas relações seguintes, em que $i$ é a densidade de corrente e $F$ a constante de Faraday, $j^{+} F=i t^{+}$e $j_{m}^{+} F=i t_{m}^{+}$. A partir da Equação 3 obtem-se a Equação 5:

$\frac{i}{F}\left(t_{m}^{+}-t^{+}\right)-D \frac{\partial C_{d}^{+}}{\partial y}=0$

A integração dessa equação ao longo da espessura da camada limite, $\delta$, permite determinar o gradiente médio de concentração nesta camada, descrito por:

$$
\left(C_{d}^{+}\right)_{y=\delta}-\left(C_{d}^{+}\right)_{y=0}=\frac{i}{F}\left(t_{m}^{+}-t^{+}\right) \frac{\delta}{D}
$$

A densidade de corrente limite, $i_{\text {lim }}$, é definida pela condição particular de densidade de corrente na qual a concentração na interface membrana - solução $\left(C_{d}^{+}\right)_{y=0}$ tende a zero. A partir da Equação 6, a Equação 7 pode descrever $i_{\text {lim }}$ : 
$i_{\lim }=\frac{C_{d}^{+} D F}{\left(t_{m}^{+}-t^{+}\right) \delta}$

Pode-se constatar que a densidade de corrente limite depende de diversos parâmetros relacionados às espécies envolvidas e membrana utilizada, assim como às condições hidrodinâmicas que determinam a espessura da camada limite.

A Figura 4 apresenta uma visão geral da variação da intensidade de corrente $(I)$ que atravessa o empilhamento de membranas em função do potencial entre os eletrodos.

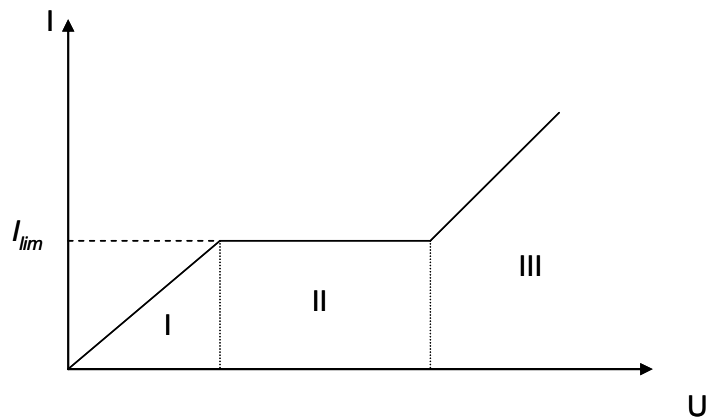

Figura 4 - Curva de intensidade de corrente versus potencial elétrico.

A curva apresentada na Figura 4 apresenta três zonas distintas. Numa primeira zona (I), a corrente varia linearmente com o potencial; o sistema segue a lei de Ohm e a inclinação da reta representa a resistência elétrica total do empilhamento (eletrólitos, membranas, camada de polarização). Numa segunda zona (II), a intensidade torna-se constante; o valor corresponde à corrente limite. Por fim, na terceira zona (III), a variação de intensidade versus potencial é uma função crescente. O fenômeno da modificação da curva após a corrente limite é comumente atribuído à concentração de íons que se torna ínfima para assegurar a condução da corrente elétrica. Nessa condição, os íons $\mathrm{H}^{+}$e $\mathrm{OH}^{-}$provenientes da dissociação das moléculas de água passam a transportar corrente no lugar dos íons do eletrólito (Roux-de Balmann e Casemond, 2006).

Para ser eficaz, a ED convencional, cujo objetivo é a migração de íons de uma solução através das membranas, deve ser operada com densidades de corrente inferiores à corrente limite. Por outro lado, as conseqüências da dissociação da água são a perda da 
utilização da corrente e drásticas mudanças de $\mathrm{pH}$ - aumento do valor de $\mathrm{pH}$ na superfície da MTA no concentrado e diminuição do valor de $\mathrm{pH}$ na superfície da MTC. $\mathrm{O}$ aumento do $\mathrm{pH}$ pode levar à precipitação de íons na superfície da membrana e sua diminuição pode danificar as membranas. Em condições industriais, a fim de evitar as perturbações provenientes da operação acima da corrente limite em qualquer ponto do empilhamento, a densidade de corrente não excede $80 \%$ da densidade de corrente limite. O valor de $i_{\text {lim }}$ condiciona portanto diretamente a capacidade de extração da operação de ED (Strathmann, 2004).

No entanto, a expressão teórica da $i_{\text {lim }}$ (Equação 7) não é utilizada na prática pois requer diversos parâmetros dificilmente acessíveis. Dadas as condições de operação (solução a ser tratada, empilhamento etc), a intensidade limite é determinada experimentalmente. Um dos métodos mais utilizados é o proposto por Cowan e Brown (1959), e se baseia na variação da resistência, U/I, em função do inverso da intensidade de corrente, 1/I. O formato particular da curva permite a determinação da $I_{\text {lim }}$ pelo ponto de inflexão da curva obtida a partir da intersecção das duas tangentes, como indicado na Figura 5.

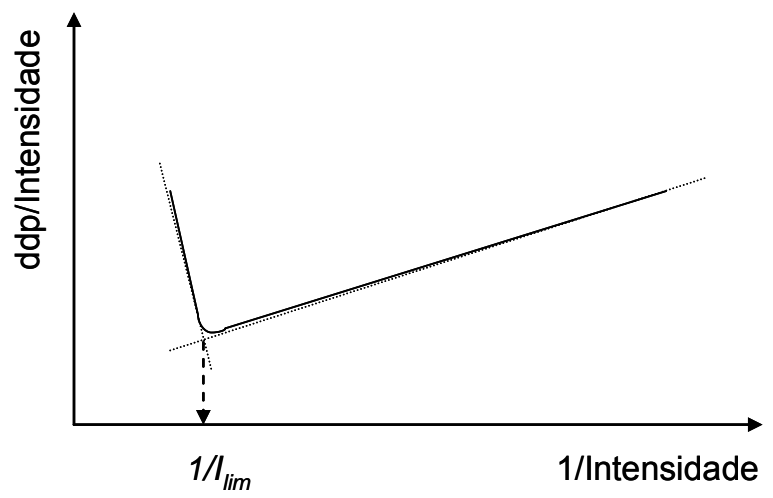

Figura 5 - Princípio da determinação da $I_{l i m}$ pelo método de Cowan e Brown (1959). 


\subsubsection{Transferência de solutos e solução}

Existem diferentes contribuições para a transferência da solução e dos solutos através das membranas na célula de eletrodiálise como é apresentado esquematicamente na Figura 6. A transferência de espécies eletricamente carregadas, que é o objetivo do processo de eletrodiálise, é acompanhada por uma série de outros fenômenos de transporte inerentes à tecnologia. Esses fenômenos descritos a seguir são a origem das limitações de desempenho do processo.

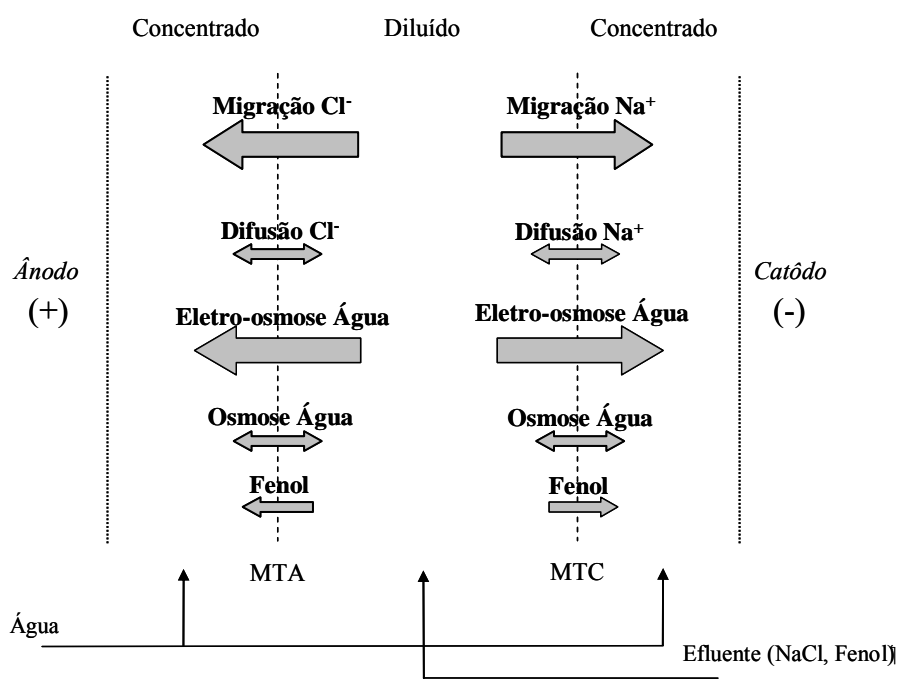

Figura 6 - Esquema ilustrativo dos diferentes processos de transferência de massa no processo de $\mathrm{ED}$, para solução de fenol e $\mathrm{NaCl}$ em água.

Sendo a concentração de soluto diferente entre as membranas, o fenômeno de difusão pode contribuir para a transferência das espécies neutras e carregadas. O fluxo se direciona no sentido decrescente de concentração, com o propósito de eliminar a diferença de potencial químico devido ao gradiente de concentração. As espécies carregadas são também transferidas por migração devido ao gradiente de potencial elétrico aplicado. Normalmente, a contribuição da difusão torna-se desprezível frente à migração para as condições de eletrodiálise (Strathmann, 2004). 
O fluxo do solvente através das membranas é o resultado da soma de dois termos. O primeiro refere-se ao fluxo eletro-osmótico, uma vez que os íons são transferidos envolvidos por uma camada de solvente, atravessando a membrana solvatados. A espessura do solvente que envolve o íon depende da carga e do tamanho do íon, assim como da natureza do solvente e do soluto, fatores cinéticos etc. As propriedades da membrana em si, particularmente o grau de reticulação, também interferem na quantidade de solvente que é transferido devido à migração dos íons. O co-transporte de solvente constitui uma limitação à concentração do fluido, a concentração máxima pretendida é fixada pelo grau de solvatação do soluto na membrana. Outra contribuição ao fluxo do solvente é devido ao gradiente de potencial químico do solvente formado através das membranas, que origina o fluxo osmótico. As transferências por osmose e eletro-osmose são orientadas na mesma direção, do diluído para o concentrado. Usualmente, sob condições de ED, ou seja, quando corrente é aplicada ao sistema, o fluxo osmótico é desprezível quando comparado ao eletro-osmótico (Bailly et al., 2001).

\section{Transporte sem migração}

Os fluxos do solvente e solutos através de uma membrana semipermeável separando dois compartimentos perfeitamente agitados podem ser descritos pelas Equações 8 e 9, como apresentado por Kedem e Katchalsky (1958). Estas equações são baseadas em termodinâmica irreversível e expressas em fluxo volumétrico do solvente, $J_{v}\left(\mathrm{~m}^{3} / \mathrm{m}^{2} . \mathrm{s}\right)$, e nos fluxos dos solutos, $J_{i}\left(\mathrm{~mol} / \mathrm{m}^{2} . \mathrm{s}\right)$, através da membrana.

$$
\begin{aligned}
& J_{v}=L_{p}\left(\Delta p-\sigma \Delta \Pi_{i}\right) \\
& J_{i}=P_{i} \Delta \Pi_{i}+\bar{C}_{i}(1-\sigma) J_{v}
\end{aligned}
$$

em que $L_{p}$ é a permeabilidade da membrana ao solvente; $\Delta \Pi_{i}$ e $\Delta p$ são respectivamente os gradientes de pressão osmótica e hidrostática através da membrana; $\bar{C}_{i}$ a concentração média de soluto nos dois lados da membrana; os subscritos $i$ e $v$ se referem respectivamente ao soluto e ao solvente. O gradiente de pressão osmótica é multiplicado pelo parâmetro $P_{i}$, coeficiente de permeabilidade, que é específico para cada 
componente $i . \sigma$ é o coeficiente de reflexão, que se refere à restrição da membrana ao fluxo do solvente ou do soluto, variando de 0 a 1 para moléculas totalmente permeáveis e impermeáveis, respectivamente. Para operações de ED, o termo de pressão hidrostática pode ser considerado desprezível em relação ao da pressão osmótica, e, portanto, no caso de soluções aquosas, o fluxo de água $\left(J_{w}\right)$ pode ser considerado resultante somente da contribuição osmótica, $J_{w}^{o s}$. Deste modo, quando corrente elétrica não é aplicada, o fluxo de água pode ser expresso pela Equação 10.

$J_{w} \cong J_{w}^{o s}=L_{p} \sigma \Delta \Pi_{i}$

Considerando soluções diluídas, a equação de Van't Hoff pode ser aplicada e o gradiente de pressão osmótica pode ser substituído pela diferença de concentração do soluto através das membranas. Portanto, neste estudo, com base na Equação 10, os fluxos de sal $\left(J_{s}\right)$ e fenol $\left(J_{p}\right)$ sem migração são expressos pelas Equações 11 e 12 , respectivamente.

$$
\begin{aligned}
& J_{s}=J_{s}^{\text {diff }}=P_{s} \Delta C_{s} \\
& J_{p}=J_{p}^{\text {diff }}=P_{p} \Delta C_{p}
\end{aligned}
$$

em que o subscrito diff se refere à contribuição difusiva.

\section{Transporte com migração}

Quando corrente elétrica é aplicada, o fluxo do solvente passa a ser o resultado de duas contribuições, osmose e eletro-osmose, $J_{w}^{e l}$. Sendo a última proporcional à corrente elétrica, $i$, multiplicada pelo número de transporte da água, $t_{w}$, que relaciona o transporte da água com a corrente, dividida pela constante de Faraday, $F$, como apresentado na Equação 13.

$J_{w}=J_{w}^{o s}+J_{w}^{e l}=L_{p} \sigma \Delta \Pi_{i}+\frac{t_{w} i}{F}$

Normalmente, a contribuição osmótica é desprezível em relação à eletro-osmose. Em aplicações práticas, a Equação 13 pode ser reescrita em um formato simplificado 
utilizando um coeficiente eletro-osmótico $\alpha$ para relacionar o fluxo eletro-osmótico com a densidade de corrente, como apresentado na Equação 14.

$$
J_{w}=J_{w}^{o s}+J_{w}^{e l}=L_{p} \sigma \Delta \Pi_{i}+\alpha i
$$

O fluxo de água devido à eletro-osmose pode também ser expresso, de forma aproximada, pelo número de transferência de solvente, $T_{w}$, que se traduz pelo número de moléculas de água transportada por um íon (Equação 15).

$$
J_{w}=T_{w} \sum_{i} J_{i}
$$

em que $J_{i}$ é o fluxo de íons através de uma dada membrana.

O número de transferência de água depende não só do tipo de membrana, mas também do eletrólito, ou seja, do tamanho dos íons, valência e concentração da solução. Segundo Strathmann (2004) para soluções aquosas e membranas comerciais trocadoras de íons, $T_{w}$ varia entre 4 e 8 . O número de moléculas de água que solvatam um único íon é também conhecido como número de hidratação.

A transferência de um sal monovalente pode ser expressa pela soma das contribuições da difusão, migração e convecção descrita na Equação 16. A contribuição da migração ao transporte do sal pode ser expressa através do número de transferência de sal, $t_{s}$, que é a fração da corrente total carregada pelos íons, nesse caso em moles de $\mathrm{NaCl}$ por moles de elétrons, expresso em Faraday (Strathmann, 2004).

$$
J_{s}=J_{s}^{d i f f}+J_{s}^{c o n v}+J_{s}^{m i g}=P_{s} \Delta C_{s}+\frac{t_{s} \cdot i}{F}+\bar{C}_{s}(1-\sigma) J_{w}
$$

Da mesma maneira, o fluxo de sal, descrito pela Equação 16, pode ser reescrito na forma da Equação 17, na qual o coeficiente $\beta$ relaciona a quantidade de sal transportado e a densidade de corrente.

$$
J_{s}=J_{s}^{d i f f}+J_{s}^{c o n v}+J_{s}^{m i g}=P_{s} \Delta C_{s}+\beta i+\bar{C}_{s}(1-\sigma) J_{w}
$$

Como citado anteriormente, normalmente a migração é preponderante à difusão e à convecção, o que torna o primeiro e o terceiro termos da Equação 17 desprezíveis em relação ao segundo.

A transferência do fenol pode ser descrita pela Equação 18 baseada na Equação 9. 
$J_{p}=J_{p}^{\text {diff }}+J_{p}^{c o n v}=P_{p} \Delta C_{p}+\bar{C}_{p}(1-\sigma) J_{w}$

As suposições adotadas nas equações apresentadas anteriormente podem ser verificadas experimentalmente, assim como a avaliação da importância dos diferentes fenômenos envolvidos no processo. Os parâmetros pertinentes são determinados pelo ajuste das equações aos dados experimentais. 


\subsection{Processos oxidativos avançados}

Muitas reações iniciadas fotoquimicamente são conhecidas para a oxidação de uma variedade de compostos orgânicos com diversidade de estruturas químicas e grupos funcionais. Essas reações, quando aplicadas à degradação de contaminantes, são usualmente agrupadas sob a denominação de Processos oxidativos avançados (POAs). Os POAs combinam a ação da luz com reagentes químicos para mineralização dos compostos orgânicos contidos em efluentes.

Os POAs representam uma alternativa importante no tratamento de efluentes contendo poluentes orgânicos tóxicos, por resultarem na transformação desses poluentes em compostos menos agressivos, podendo levar à oxidação total dos compostos. Atualmente, várias técnicas vêm sendo desenvolvidas nessa linha, permitindo a escolha mais apropriada para tratamentos específicos. A avaliação de custos desses processos indica também bons resultados frente a outras tecnologias semelhantes (Andreozzi et al., 1999).

Os principais POAs usam agentes oxidantes em presença de um catalisador apropriado e/ou luz ultravioleta (Legrini et al., 1993) como: $\mathrm{H}_{2} \mathrm{O}_{2} / \mathrm{UV} ; \mathrm{O}_{3} / \mathrm{UV} ; \mathrm{O}_{3^{-}}$ $\mathrm{H}_{2} \mathrm{O}_{2} / / \mathrm{UV}$; $\left[\mathrm{TiO}_{2}\right] / \mathrm{UV}$; Fe(III) $\left[\mathrm{TiO}_{2}\right] / \mathrm{UV}$-vísivel; UV/vácuo; reação de Fenton ou $\mathrm{H}_{2} \mathrm{O}_{2}$ - $\mathrm{Fe}$ (II); e reação de foto-Fenton ou $\mathrm{H}_{2} \mathrm{O}_{2}[\mathrm{Fe}(\mathrm{II}) / \mathrm{Fe}(\mathrm{III})] / \mathrm{UV}$.

As reações fotoquímicas mais comumente utilizadas são iniciadas pela absorção de luz sob irradiação ultravioleta, na faixa de $250-400 \mathrm{~nm}$. Sendo a irradiação ultravioleta componente natural da radiação solar, o uso de reatores fotoquímicos solares para o tratamento de efluentes é uma opção de tratamento de atrativa em muitas regiões tropicais e subtropicais. Em outras áreas com pouca intensidade de radiação solar, o uso de reatores convencionais equipados com lâmpadas ultravioletas ou associados a reatores solares pode ser adotado (Andreozzi et al., 1999).

Os processos mencionados, apesar de fazerem uso de diferentes sistemas de reação, possuem considerável similaridade devido à participação de radicais hidroxila $\left(\mathrm{HO}^{\bullet}\right)$ na maior parte dos mecanismos de reação. Esses radicais possuem elevado 
potencial de oxidação. Os principais mecanismos de reação do radical com compostos orgânicos envolvem a abstração do hidrogênio de carbonos alifáticos, adição eletrofílica a insaturações e a anéis aromáticos e transferência de elétrons (Bauer e Fallmann, 1997). Essas reações (reação 1) geram radicais orgânicos intermediários, que promovem outras reações, resultando em produtos finais $\left(\mathrm{P}_{\text {oxid }}\right)$ provenientes de uma série de reações em cadeia da molécula inicial (R).

$H O^{\bullet}+R \rightarrow P_{\text {oxid }}$

Considerando que os radicais hidroxil são muito reativos e instáveis, precisam ser gerados continuamente no reator por reações químicas e fotoquímicas. Os principais processos para a obtenção desses radicais são apresentados nos itens a seguir.

\subsubsection{Fotólise de $\mathrm{H}_{2} \mathrm{O}_{2}$}

Os processos de fotólise de $\mathrm{H}_{2} \mathrm{O}_{2}$ (peróxido de hidrogênio) são efetuados pela adição de $\mathrm{H}_{2} \mathrm{O}_{2}$ e irradiação do efluente a ser tratado com luz ultravioleta em comprimentos de ondas inferiores a $280 \mathrm{~nm}$, gerando radicais hidroxila em solução aquosa, além de radicais hidroperóxido $\left(\mathrm{OH}_{2}^{*}\right)$, como apresentado nas reações a seguir:

$$
\begin{aligned}
& \mathrm{H}_{2} \mathrm{O}_{2} \stackrel{h v}{\longrightarrow} 2 \mathrm{HO}^{\bullet} \\
& \mathrm{H}_{2} \mathrm{O}_{2}+\mathrm{HO}^{\bullet} \rightarrow \mathrm{HO}_{2}^{\bullet}+\mathrm{H}_{2} \mathrm{O} \\
& \mathrm{H}_{2} \mathrm{O}_{2}+\mathrm{HO}_{2}^{\bullet} \rightarrow \mathrm{HO}^{\bullet}+\mathrm{O}_{2}+\mathrm{H}_{2} \mathrm{O}
\end{aligned}
$$

Apesar da fotólise direta (reação 2) do $\mathrm{H}_{2} \mathrm{O}_{2}$ ser um processo muito eficiente, o $\mathrm{H}_{2} \mathrm{O}_{2}$ absorve principalmente na região $\mathrm{UV}$ em comprimentos de onda inferiores a 300 $\mathrm{nm}$, o que faz com que o processo se aplique apenas para soluções de compostos orgânicos que absorvam fortemente abaixo desse valor. Essa limitação ainda é enfatizada pelo fato do próprio $\mathrm{H}_{2} \mathrm{O}_{2}$, em concentrações elevadas, consumir radicais hidroxila, como apresentado anteriormente na reação 3 (Legrini et al., 1993). 


\subsubsection{Reações Fenton e foto-Fenton}

A reação Fenton consiste na geração de radicais hidroxila pela reação entre $\mathrm{H}_{2} \mathrm{O}_{2}$ e íons $\mathrm{Fe}^{2+}$ em meio ácido, conforme apresentado na reação 5 (Esplugas et al., 2002): $\mathrm{H}_{2} \mathrm{O}_{2}+\mathrm{Fe}^{2+} \rightarrow \mathrm{Fe}^{3+}+\mathrm{HO}^{\bullet}+\mathrm{HO}^{-}$

Este é um método simples de obtenção de radicais hidroxila, uma vez que não requer aparatos e reagentes especiais, além de ser vantajoso, pois o ferro é um elemento muito abundante e não tóxico, e o $\mathrm{H}_{2} \mathrm{O}_{2}$ possui fácil manuseio e é ambientalmente seguro (Andreozzi et al.,1999).

O processo pode ser acelerado por irradiação UV em comprimentos de onda menores que 300-410 nm. Nessas condições, a fotólise dos complexos de $\mathrm{Fe}^{3+}$ leva à regeneração do $\mathrm{Fe}^{2+}$ (reação 6) com ocorrência de reações de Fenton devido à presença de $\mathrm{H}_{2} \mathrm{O}_{2}$ (reação 5) (Andreozzi et al.,1999).

$\mathrm{Fe}(\mathrm{OH})^{2+} \stackrel{\text { hv }}{\longrightarrow} \mathrm{Fe}^{2+}+\mathrm{HO}^{\bullet}$ (reação 6)

Os processos foto-Fenton apresentam como vantagem a sensibilidade à luz em comprimentos de ondas de até $600 \mathrm{~nm}$ ( $35 \%$ da irradiação solar). O contato entre o poluente e o agente oxidante é alto, uma vez que a solução é homogênea. Entre as desvantagens do processo está a necessidade de remoção do ferro após a reação.

\subsubsection{Fotocatálise com $\mathrm{TiO}_{2}$}

A interação entre um semicondutor e radiação UV é capaz de excitar um elétron da banda de valência à banda de condução, produzindo uma vacância na banda de valência com elevado potencial de oxidação (Figura 7). Essas zonas carregadas reagem com compostos orgânicos e com água. No primeiro caso, as reações de redução são responsáveis pela destruição de compostos orgânicos, enquanto, no outro caso, radicais hidroxila são gerados e então reagem com os compostos orgânicos (Esplugas et al., 2002). O processo de fotocatálise heterogênea envolve portanto o uso de radiação ultravioleta (UV), com comprimentos de onda menores que $400 \mathrm{~nm}$, e óxidos metálicos ativados, especialmente óxido de titânio $\left(\mathrm{TiO}_{2}\right)$ ou óxido de zinco $(\mathrm{ZnO})$. Vale ressaltar 
que estes óxidos podem ainda transformar materiais poliméricos em solutos de baixo peso molecular, oxidar células microbiológicas e vírus (Ollis, 2003).

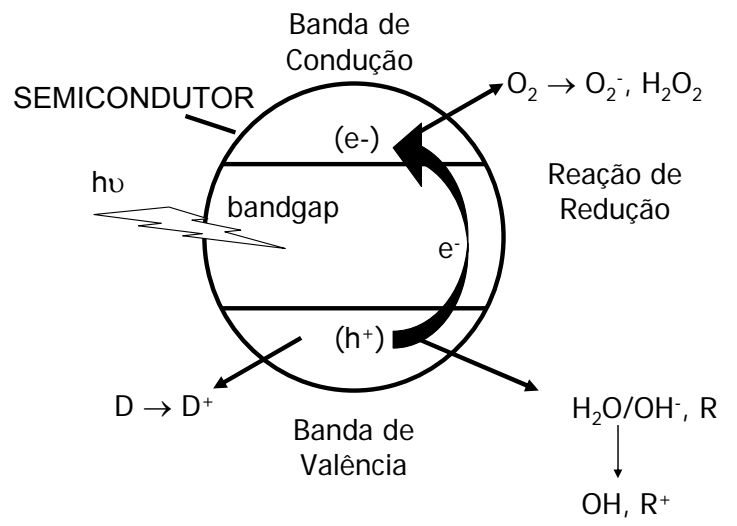

Figura 7 - Esquema representativo da partícula do semicondutor dióxido de titânio na geração de radicais hidroxila.

A fotocatálise utiliza oxigênio e um catalisador heterogêneo como ativadores de reação. A maior parte dos estudos utiliza óxidos metálicos de dimensões nanométricas, normalmente agregados formando partículas com dimensões micrométricas (Ollis, 2003).

O semicondutor mais empregado em fotocatálise é o dióxido de titânio $\left(\mathrm{TiO}_{2}\right)$. Segundo Fallmann et al. (1999) a fotogeração de radicais através desse catalisador pode ser representada pelas reações descritas a seguir.

Primeiramente, após a absorção de radiação ultravioleta (UV), ocorre a geração de pares elétron $\left(\mathrm{e}^{-}\right) /$vacância $\left(\mathrm{h}^{+}\right)$, que são separados para a banda de condução e para a banda de valência (reação 7).

$$
\mathrm{TiO}_{2} \stackrel{h v}{\longrightarrow} \mathrm{TiO}_{2}\left(e_{V B}{ }^{-}+h_{C B}{ }^{+}\right)
$$

A oxidação da água adsorvida (reação 8) ou dos íons hidroxila (reação 9) na zona carregada gera radicais hidroxila.

$$
\begin{aligned}
& \mathrm{TiO}_{2}\left(\mathrm{~h}_{\mathrm{BV}}{ }^{+}+\mathrm{H}_{2} \mathrm{O}_{\mathrm{ad}}\right) \rightarrow \mathrm{TiO}_{2}+\mathrm{OH}_{\mathrm{ad}}{ }^{\bullet}+\mathrm{H}^{+} \\
& \mathrm{TiO}_{2}\left(\mathrm{~h}_{\mathrm{BV}}{ }^{+}\right)+\mathrm{HO}_{\mathrm{ad}}{ }^{-} \rightarrow \mathrm{TiO}_{2}+\mathrm{OH}_{\mathrm{ad}} \cdot
\end{aligned}
$$


$\mathrm{O}$ oxigênio e outro receptor/aceptor de életron $\left(\mathrm{H}_{2} \mathrm{O}_{2}, \mathrm{Na}_{2} \mathrm{~S}_{2} \mathrm{O}_{8}\right)$ são reduzidos na superfície do catalisador (reação 10).

$\mathrm{TiO}_{2}\left(\mathrm{e}_{\mathrm{CB}}^{-}\right)+\mathrm{O}_{2} \rightarrow \mathrm{TiO}_{2}+\mathrm{O}_{2}^{-} \rightarrow+\mathrm{H}^{+} \rightarrow \mathrm{HO}_{2}{ }^{-}$

A degradação de compostos adsorvidos é possível por oxidação direta na superfície do catalisador (reação 11), ou por radicais hidroxila (reação 12).

$\mathrm{TiO}_{2}\left({h_{B V}}^{+}+\right.$compostos $\left._{a d}\right) \rightarrow \mathrm{TiO}_{2}+$ produtos oxidados

$\mathrm{OH}_{a d} \cdot$ compostos $_{a d} \rightarrow$ produtos oxidados

A recombinação dos pares $\mathrm{h}^{+} / \mathrm{e}^{-}$(reação 13) e a redução dos radicais hidroxila adsorvidos pelos elétrons na banda de condução (reação 14) podem ser responsáveis pela baixa eficiência do método.

$\mathrm{TiO}_{2}\left(\mathrm{~h}_{\mathrm{BV}}{ }^{+}+\mathrm{e}_{\mathrm{BC}}{ }^{-}\right) \rightarrow \mathrm{TiO}_{2}+$ calor
$\mathrm{TiO}_{2}\left(\mathrm{e}_{\mathrm{BC}}{ }^{-}\right)+\mathrm{OH}_{\mathrm{ad}}{ }^{-} \rightarrow \mathrm{TiO}_{2}+\mathrm{HO}_{\mathrm{ad}}{ }^{-}$

$\mathrm{O}$ pH exerce um efeito complexo sobre a velocidade de degradação fotocatalítica e os efeitos observados são geralmente dependentes do tipo de poluente e do ponto de carga zero $(z P c)$ do semicondutor usado no processo de oxidação, mais especificamente da interação eletrostática entre a superfície do catalisador e o poluente. Acima e abaixo do $\mathrm{pH}$ do $z P c$ as partículas ficam carregadas negativamente ou positivamente, respectivamente, como resultado da adsorção de hidrogênio e íons hidróxido (Abdulah et.al, 1990). A adsorção do poluente e o aumento das taxas de degradação são maiores perto do $z P c$ do catalisador. No entanto, uma vez que os efeitos do $\mathrm{pH}$ não podem ser generalizados, estudos em escala de laboratório são recomendados para estabelecer a condição ótima de operação. A concentração do poluente também é um parâmetro importante na fotocatálise, pois quanto mais baixa a concentração do contaminante no efluente mais rápida é sua degradação.

A concentração do catalisador influencia na taxa de reação. No entanto, seu excesso reduz a quantidade de fótons transferidos no meio devido ao espalhamento da luz causado pela turbidez. O valor ótimo depende, sobretudo, do tipo e concentração do poluente, assim como da velocidade de geração de radicais livres (governada pelas condições de operação do reator). Portanto, uma avaliação experimental normalmente 
faz-se necessária (Gogate e Pandit, 2004). Toor et al. (2006) reportou ainda que o aumento do teor de $\mathrm{TiO}_{2}$ na suspensão aumenta a agregação de suas partículas, diminuindo, assim, a área superficial de sítios ativos e ainda aumenta o espalhamento da luz, impedindo a sua passagem para o interior da suspensão.

A degradação fotoquímica de contaminantes orgânicos em água vem sendo demonstrada em pesquisas com o uso de $\mathrm{TiO}_{2}$ em suspensão e em filmes imobilizados. No entanto, devido a seu alto custo em relação a outros métodos convencionais (tratamento biológico e processos físico-químicos) a fotocatálise com $\mathrm{TiO}_{2}$ ainda está em estágio de desenvolvimento. Avanços recentes em fotocatálise têm sido focados em aumentar a atividade do catalisador e no desenvolvimento de novos tipos de reatores fotocatalíticos ou combinações com outros processos químicos ou biológicos de oxidação que tornem o processo economicamente atraente.

Segundo Ollis (2003), os estudos de fotocatálise para a destruição de poluentes em efluentes contaminados baseiam-se na utilização de partículas de $\mathrm{TiO}_{2}$, normalmente o produto Degussa P-25. Este material tem sido utilizado em reatores de batelada com recirculação, com o catalisador em suspensão e a recuperação e reciclo do catalisador, ou com as partículas do catalisador imobilizadas em suportes sólidos.

\subsubsection{Processos oxidativos em meio salino}

Os processos oxidativos de compostos orgânicos são inibidos de diversas maneiras pela presença de íons inorgânicos como cloreto, fosfato, sulfato, fluoreto, brometo, entre outros. Esses ânions são encontrados normalmente em efluentes industriais ou podem ser formados como produtos de decomposição durante o processo de oxidação.

No caso do processo foto-Fenton a inibição da oxidação pela presença de certos íons pode ser atribuída à precipitação do ferro, consumo de radicais hidroxila, ou por sua associação ao $\mathrm{Fe}(\mathrm{II})$ formando um complexo menos reativo. A inibição das reações de Fenton por $\mathrm{Cl}^{-}$se dá principalmente pelo consumo de radicais $\bullet \mathrm{OH}$, como apresentado na reação 15 , uma vez que o íon $\mathrm{Cl}^{-}$é um ligante relativamente fraco com o $\mathrm{Fe}(\mathrm{II})$ (Pignatello, 2006). 
$\mathrm{HO}^{\bullet}+\mathrm{Cl}^{-} \square \quad \mathrm{ClOH}^{\bullet-} \stackrel{\mathrm{H}^{+}\left(-\mathrm{H}_{2} \mathrm{O}\right)}{\longleftarrow} \mathrm{Cl}^{\bullet} \stackrel{\mathrm{X}^{-}}{\rightleftarrows} \mathrm{Cl}_{2}^{\bullet-}$

(reação 15)

A reação (15) é rápida, reversível e dependente da concentração de $\mathrm{Cl}^{-}$e $\mathrm{H}^{+}$. A cinética da reação de Fenton em altas concentrações de íons cloreto é alterada pela reação dos radicais cloreto com $\mathrm{H}_{2} \mathrm{O}_{2}$, espécies de ferro e com os próprios compostos orgânicos.

Da mesma maneira para o processo $\mathrm{UV} / \mathrm{H}_{2} \mathrm{O}_{2}$ pode ser considerado o efeito deletério da presença de íons como cloreto devido ao consumo de radicais hidroxila apresentado anteriormente (reação 15).

Alguns íons inorgânicos também vêm sendo reportados como inibidores nos processos de fotocatálise heterogênea. De uma maneira geral a presença de íons pode afetar o processo de degradação por adsorção de contaminantes, reações com os radicais hidroxila e/ou absorção da luz UV. Normalmente os íons $\mathrm{CO}_{3}{ }^{-}, \mathrm{HCO}_{3}{ }^{-}$(que consomem radicais e também afetam o processo de adsorção) e $\mathrm{Cl}^{-}$(que afeta fortemente o processo de adsorção e também absorve parcialmente luz UV) possuem forte efeito prejudicial aos processos oxidativos enquanto outros ânions como o fosfato e o nitrato afetam pouco a eficiência da degradação (Gogate e Pandit, 2004).

Os íons cloreto vêm sendo reportados como inibidores do processo de fotocatálise através do consumo de radicais hidroxila pelo seguinte mecanismo (reação 16) (Matthews, 1992):

$$
\mathrm{Cl}^{-}+\mathrm{HO}^{\bullet} \rightarrow \mathrm{Cl}^{\bullet}+\mathrm{OH}^{-}
$$

Outro mecanismo reportado é o consumo das vacâncias na banda de valência (Lindner et al., 1995) (reação 17):

$$
\mathrm{Cl}^{-}+h^{+} \rightarrow C l^{\bullet}
$$

Além disso, quando o $\mathrm{pH}$ médio da reação está abaixo do $\mathrm{pH}_{\mathrm{zcp}}$ do $\mathrm{TiO}_{2}$ as áreas protonadas da superfície do catalisador atraem preferivelmente o íon cloreto, repelindo espécies neutras e carregadas negativamente (Tanaka e Saha, 1995). 


\section{Capítulo 3: MATERIAIS E MÉTODOS}

- Eletrodiálise

0 Reagentes

o Célula de Difusão

o Piloto de Eletrodiálise

- POA

o Reagentes

o Equipamento

o Procedimento Experimental

o Planejamento Experimental 
O objetivo deste capítulo é apresentar os materiais e métodos utilizados durante este estudo.

As atividades experimentais de eletrodiálise foram realizadas em dois equipamentos diferentes. Com o intuito de estudar o transporte de fenol devido à difusão através dos diferentes tipos de membranas (MTC e MTA), utilizou-se uma célula de difusão sem aplicação de corrente elétrica. A maior parte dos experimentos foi realizada em uma planta piloto para o estudo da difusão do fenol e osmose da solução em experimentos sem corrente elétrica e na transferência de solutos e solução quando corrente elétrica é aplicada. Portanto, o capítulo de eletrodiálise foi divido em reagentes utilizados e descrição dos equipamentos e respectivos procedimentos e planejamento experimental.

Já o capítulo de POA descreve os reagentes, o reator utilizado, o procedimento e planejamento experimental do processo foto-Fenton e os procedimentos dos processos $\mathrm{UV} / \mathrm{TiO}_{2}$ e UV/ $\mathrm{H}_{2} \mathrm{O}_{2}$.

O método de Redes Neurais Artificiais utilizado para modelar o processo fotoFenton é apresentado ao final deste capítulo. 


\subsection{Eletrodiálise}

\subsubsection{Reagentes}

As soluções foram preparadas por diluição de fenol e/ou cloreto de sódio (Acros Organics) em água ultra pura.

\subsubsection{Célula de difusão}

Um esquema simplificado da célula de difusão utilizada é apresentado na Figura 8.

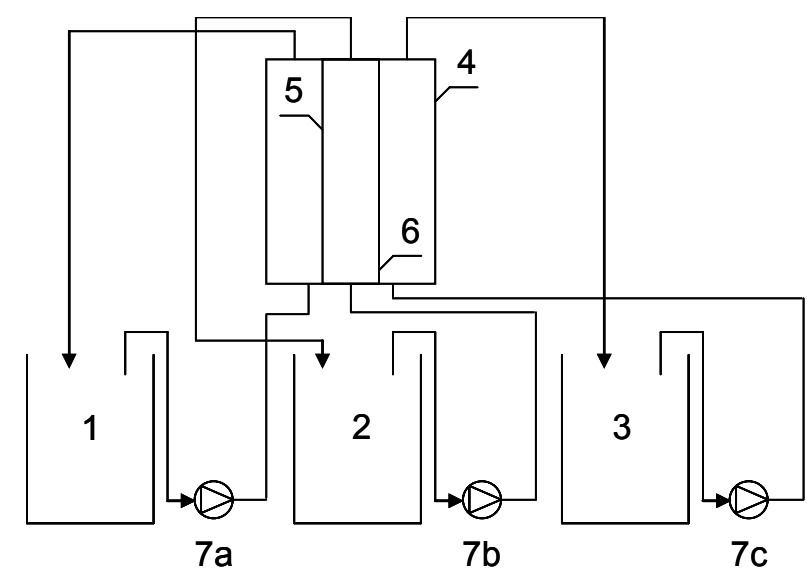

Figura 8 - Diagrama da célula de difusão. 1: compartimento do concentrado da MTC; 2: compartimento do diluído (alimentação); 3: compartimento do concentrado da MTA; 4: célula de difusão; 5: MTC; 6: MTA: 7a-c: bombas.

O sistema é composto por três circuitos de fluidos $(0,5 \mathrm{~L}$ cada): o diluído, inicialmente alimentado com solução contendo fenol e sal; e dois outros, chamados de concentrado, alimentados com água deionizada. O fenol e o sal são transportados através das diferentes membranas pela diferença de concentração do diluído para o concentrado. Conseqüentemente, as massas dos dois compostos decrescem no diluído 
enquanto aumentam no circuito do concentrado. Uma vez que os circuitos são separados, o transporte através das diferentes membranas, MTC e MTA, pode ser quantificado separadamente. Cada membrana possui área efetiva de $0,004 \mathrm{~m}^{2}$. Três bombas centrífugas foram utilizadas para as diferentes soluções.

A vazão foi fixada em $4 \mathrm{~L} / \mathrm{h}$ para todas as correntes. Um trocador de calor foi utilizado para manter a temperatura a $25 \pm 0,5^{\circ} \mathrm{C}$. Os experimentos foram realizados em 6 horas; amostras foram retiradas em intervalos de tempo apropriado e analisadas para o monitoramento da concentração de sal e fenol em função do tempo.

\subsubsection{Piloto de eletrodiálise}

\section{Equipamento}

Os experimentos de ED foram realizados em uma planta piloto 2B-10 (Figura 9), Eurodia Industrie, com 10 pares de membranas (MTC/MTA) (área ativa total de 0,2 $\mathrm{m}^{2}$, $0,02 \mathrm{~m}^{2}$ por célula, do tipo AMX e CMX Neosepta, Tokuyama Corp.). Estas membranas são tidas como membranas padrões para propósitos gerais, possuem base de poliestireno, alta seletividade iônica, alta resistência mecânica e química e baixa resistência elétrica. Membranas do mesmo tipo da célula de difusão foram utilizadas. A Tabela 1 apresenta as principais características das membranas utilizadas. 
Tabela 1 - Propriedades das membranas trocadoras de íons utilizadas (Astom Corporation, 2009).

\begin{tabular}{|l|l|l|}
\hline \multirow{2}{*}{ Propriedades } & Membranas & CMX \\
\cline { 2 - 3 } & AMX a permeável a & $\begin{array}{l}\text { Fortemente permeável a } \\
\text { cátions ácidos }\end{array}$ \\
\hline Tipo & $\begin{array}{l}\text { Fortemente } \\
\text { ânions básicos }\end{array}$ & Alta resistência mecânica \\
\hline Características & $\begin{array}{l}\text { Copolímero estireno- } \\
\text { divinil-benzeno }\end{array}$ & $\begin{array}{l}\text { Copolímero } \\
\text { divinil-benzeno }\end{array}$ \\
\hline Material & $2,0-3,5$ & $2,0-3,5$ \\
\hline $\begin{array}{l}\text { Resistência Elétrica }(0,5 \mathrm{~N} \\
\mathrm{NaCl})\left(\Omega / \mathrm{cm}^{2}\right)\end{array}$ & $0,14-0,18$ & $0,16-0,20$ \\
\hline Espessura $(\mathrm{mm})$ & $0-12$ & $0-12$ \\
\hline Intervalo de pH & $0-40$ & $0-40$ \\
\hline $\begin{array}{l}\text { Intervalo de Temperatura } \\
\left({ }^{\circ} \mathrm{C}\right)\end{array}$ & & \\
\hline
\end{tabular}

A planta piloto é composta por um sistema hidráulico e elétrico de alimentação, regulagem térmica e do sistema de eletrodiálise em si, que se difere segundo a operação desejada, eletrodiálise convencional ou bipolar. A planta é ainda equipada com um sistema de aquisição de dados que permite a obtenção em tempo real dos seguintes parâmetros: condutividade, intensidade de corrente elétrica, voltagem e $\mathrm{pH}$.

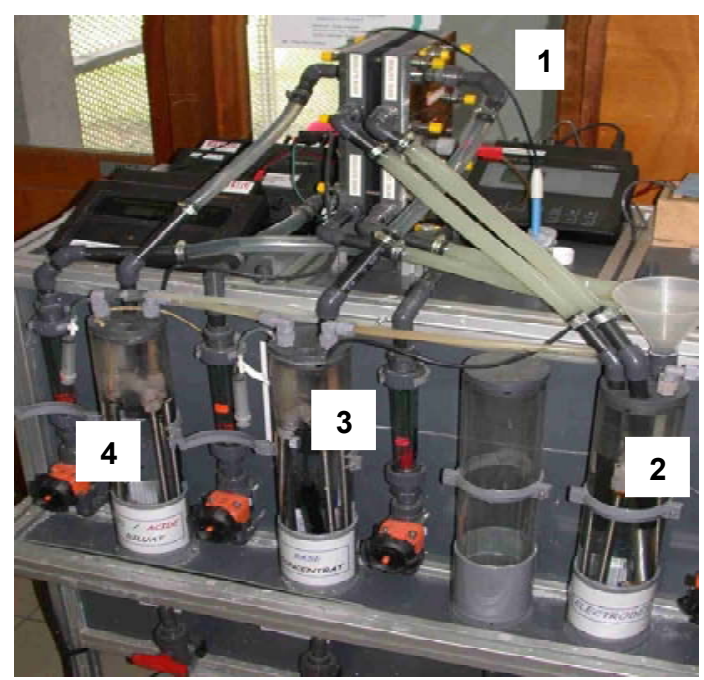

Figura 9 - Vista frontal da planta piloto de eletrodiálise utilizada; 1 empilhamento de membranas, 2 - tanque do eletrólito; 3 - tanque do concentrado; 4 tanque do diluído. 
Três bombas asseguram a alimentação independente dos diferentes fluidos, desde o reservatório até os compartimentos de células como apresentado na Figura 10. A circulação dos fluidos é realizada por três circuitos independentes correspondentes aos três tipos de compartimentos do empilhamento: diluído, concentrado e eletrólito. Este último circuito permite a circulação da solução eletrolítica para o compartimento anódico e catódico ao mesmo tempo. As vazões nos diferentes compartimentos são ajustadas por válvulas manuais.

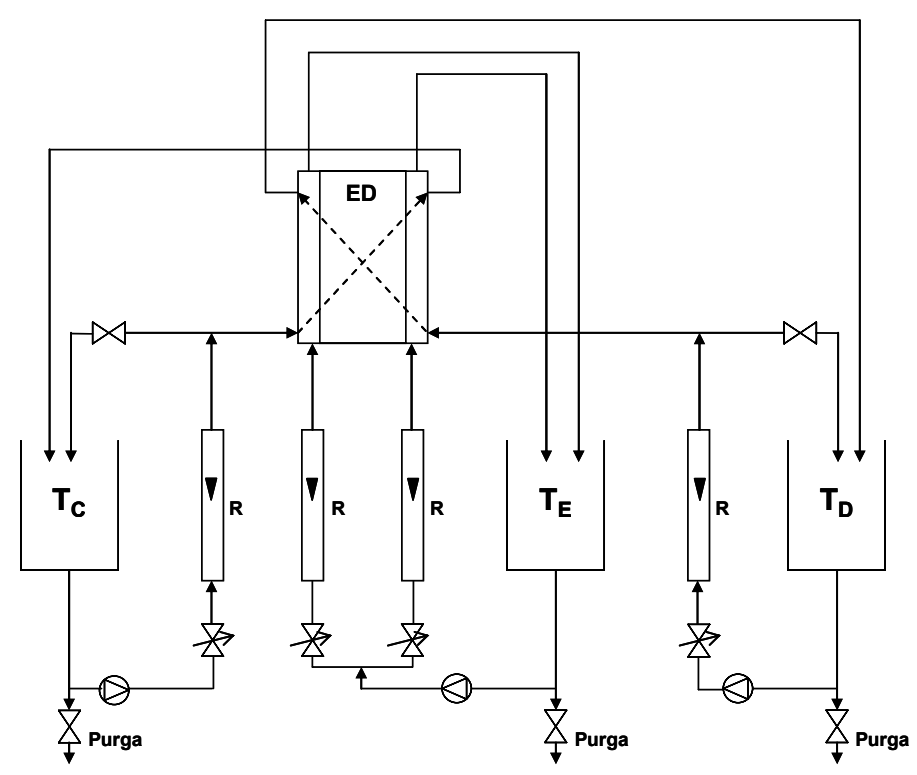

Figura 10 - Esquema hidráulico da piloto de eletrodiálise; ED: empilhamento de membranas; TC: tanque do concentrado; TE: tanque do eletrólito; TD: tanque do diluído; R: rotâmetro.

A fim de assegurar as condições constantes e reprodutivas ao longo dos experimentos de eletrodiálise, a temperatura foi mantida em torno de um valor nominal $\left(25^{\circ} \mathrm{C}\right)$ em todas as correntes. $\mathrm{O}$ controle de temperatura dos fluidos é realizado por uma serpentina imersa em um reservatório no interior do qual circula o fluido refrigerante. A aplicação de diferença de potencial elétrico nas extremidades do empilhamento das membranas é promovida por uma alimentação elétrica. A configuração utilizada para esse tipo de eletrodiálise é de dois compartimentos com membranas trocadoras de 
cátions e ânions alternadas. As características do equipamento são apresentadas na Tabela 2.

Tabela 2 - Características da planta piloto de eletrodiálise convencional.

\begin{tabular}{|c|c|}
\hline \multicolumn{2}{|c|}{$\begin{array}{c}\text { Piloto EUR 2B-10 } \\
\end{array}$} \\
\hline \multicolumn{2}{|c|}{ Membranas Neosepta - Tokuyama Corp. } \\
\hline Catiônica & MTC \\
\hline Aniônica & MTA \\
\hline Superfície ativa / membrana & $2 \mathrm{dm}^{2}$ \\
\hline Número de células & 10 \\
\hline \multicolumn{2}{|c|}{ Quadro separador } \\
\hline Junção & $\begin{array}{c}\text { EPDM } \\
\text { etileno-propileno-dieno }\end{array}$ \\
\hline Separador e distribuidor & $\begin{array}{c}\mathrm{PE}+\mathrm{PP} \\
\text { polietileno + polopropileno }\end{array}$ \\
\hline \multicolumn{2}{|c|}{ Eletrodos } \\
\hline Anodo & Titânio platinado \\
\hline Catodo & Inox 316 \\
\hline Bloco do eletrodo e tela & $\begin{array}{c}\text { PVC } \\
\text { cloreto de polivinila }\end{array}$ \\
\hline Placa de estreitamento & Inox \\
\hline
\end{tabular}

\section{Procedimento operacional e experimental}

Todos os experimentos de eletrodiálise foram operados em batelada, sendo o compartimento do diluído alimentado inicialmente com $2 \mathrm{~L}$ de solução com diferentes concentrações de cloreto de sódio, $\mathrm{NaCl}$, e fenol, e o concentrado com $2 \mathrm{~L}$ de água desmineralizada. O compartimento dos eletrodos foi alimentado com $3 \mathrm{~L}$ de uma solução de $9 \mathrm{~kg} / \mathrm{m}^{3}$ de cloreto de sódio. As vazões e composição inicial dos fluidos são apresentadas na Tabela 3 . 
Tabela 3 - Condições de operação no início do experimento

\begin{tabular}{|c|c|c|}
\hline Compartimento & Alimentação & Vazão (L/h) \\
\hline Concentrado & Água deionizada & 180 \\
\hline Dilú́do & Efluente & 180 \\
\hline Eletrólito & $\begin{array}{c}\text { Solução de } \mathrm{NaCl} \\
(9 \mathrm{~g} / \mathrm{L})\end{array}$ & 360 \\
\hline
\end{tabular}

A temperatura das soluções foi mantida a $25 \pm 2^{\circ} \mathrm{C}$ por um banho termostático. As soluções circularam uma hora antes do acionamento da corrente elétrica para minimizar os distúrbios na transferência do fenol através das membranas.

\section{Planejamento experimental}

Os primeiros experimentos de ED foram realizados sem corrente elétrica $(\mathrm{i}=0)$ com concentrações de sal e fenol no diluído entre 0 e $55 \mathrm{~g} / \mathrm{L}$ e 100 e 400 ppmC, respectivamente, para avaliar a contribuição da difusão no transporte do sal e fenol, e da osmose no transporte da solução.

A segunda série de experimentos foi focada na quantificação dos parâmetros dos modelos apresentados anteriormente na seção 2.1.4 em função das condições de operação quando corrente elétrica é aplicada.

Inicialmente, um planejamento experimental baseado no modelo de Doehlert com duas variáveis (De Aguiar e Massart, 1998) foi utilizado para avaliar o efeito da densidade de corrente e da diferença de concentração inicial de sal nos diferentes compartimentos. A Figura 11 apresenta o espaço experimental explorado. Corrente contínua foi utilizada entre 1,5 e 5,5 A $\left(75\right.$ e $\left.275 \mathrm{~A} / \mathrm{m}^{2}\right)$. A corrente limite do sistema determinou a máxima intensidade de corrente aplicada. Concentrações de sal entre $25 \mathrm{e}$ $55 \mathrm{~g} / \mathrm{L}$ foram utilizadas, valores estes representativos de efluentes salinos reais. A concentração de fenol foi fixada em 100 ppm C, concentração média normalmente utilizada em estudos de degradação do poluente modelo. Adicionalmente, experimentos com uma concentração mais elevada de fenol, $400 \mathrm{ppm} \mathrm{C}$, foram realizados. As respostas observadas foram os fluxos de fenol, sal e água através das membranas. 


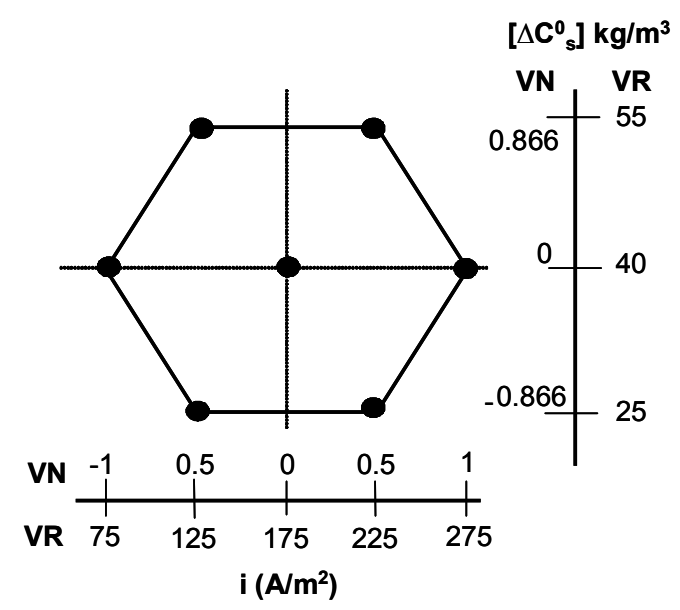

Figura 11 - Representação da matriz Doehlert para duas variáveis, concentração inicial de $\mathrm{NaCl}\left(\Delta C_{s}^{0}\right)$ e densidade de corrente (i) indicando os números dos experimentos adotados; VN: variável normalizada; VR: variável real.

Durante os experimentos a condutividade das soluções, temperatura, corrente elétrica e voltagem foram medidas em tempo real. Um condutivímetro HI933100, Hanna Instruments, foi utilizado. A variação do volume foi medida nos dois compartimentos a partir da medição da altura do nível nos compartimentos. A duração do experimento foi limitada pela condutividade no diluído. O experimento era finalizado assim que a condutividade atingia $5 \mathrm{mS} / \mathrm{cm}$, valor limite do equipamento utilizado. Conseqüentemente, diferentes durações dos experimentos foram obtidas segundo as condições de operação.

A concentração de fenol foi determinada pelo teor de carbono orgânico total (COT) (Shimadzu TOC-Analyzer 5050A) e análise de cromatografia líquida de alto desempenho (HPLC) (coluna Hypersil Hypercarb $7 \mu \mathrm{m}, 100$ x 4,6 mm, eluente águametanol 80:20, v/v, vazão de 0,5 mL/min; detector UV Water 2487 a $270 \mathrm{~nm}$; bomba P600 Waters). A concentração de sal foi avaliada por condutividade e cromatografia iônica. Utilizou-se um cromatógrafo iônico Dionex (IEC) (bomba GP40; condutivímetro $\mathrm{CD} 20 ; 30^{\circ} \mathrm{C}$; analisador de ânions: coluna Ionpac $\mathrm{AS} 11$, coluna de guarda $\mathrm{AG} 11$; supressor ASRS-ultra a 300mA; eluente $\mathrm{NaOH} 5 \mathrm{mM}$ a $1 \mathrm{~mL} / \mathrm{min}$; análise de cátions: 
coluna Ionpac CS12A, coluna de guarda CG12A, supressor CSRS-ultra a $100 \mathrm{~mA}$, eluente 200mM ácido metanosulfônico (MAS) a $1 \mathrm{~mL} \cdot \mathrm{min}^{-1}$ ).

\subsection{POA}

\subsubsection{Reagentes}

Para a realização dos experimentos fotoquímicos foram utilizados: fenol $\left(\mathrm{C}_{6} \mathrm{H}_{5} \mathrm{OH}, 99 \%\right.$ Nuclear); peróxido de hidrogênio $\left(\mathrm{H}_{2} \mathrm{O}_{2}, 30 \% \mathrm{~m} / \mathrm{m}\right)$; sulfato ferroso heptahidratado $\left(\mathrm{FeSO}_{4} \cdot 7 \mathrm{H}_{2} \mathrm{O}, 99 \%\right.$ Synth); iodeto de potássio (KI), sulfito de sódio $\left(\mathrm{Na}_{2} \mathrm{SO}_{3}\right)$, e hidróxido de sódio $(\mathrm{NaOH})$ (F.Maia). Ácido sulfúrico $\left(\mathrm{H}_{2} \mathrm{SO}_{4}\right)$ e hidróxido de sódio $(\mathrm{NaOH})$ (F.Maia) foram utilizados para o controle de $\mathrm{pH}$. Todos os reagentes utilizados eram de grau analítico.

No caso das reações $\mathrm{UV} / \mathrm{TiO}_{2}$ foi utilizado o catalisador $\mathrm{TiO}_{2}$ Degussa P25, cujas propriedades são apresentadas na Tabela 4.

Tabela 4- Propriedades típicas do $\mathrm{TiO}_{2}$ Degussa P25 (Tanaka e Saha, 1995).

\begin{tabular}{|c|c|}
\hline Estrutura do cristal & $\sim 70 \%$ anatásio e $30 \%$ rutilo \\
\hline Área superficial & $50 \pm 15 \mathrm{~m}^{2} / \mathrm{g}$ \\
\hline Tamanho médio de partícula & $30 \mathrm{~nm}$ \\
\hline Ponto isoelétrico & 6,9 \\
\hline
\end{tabular}

\subsubsection{Equipamento}

Os experimentos fotoquímicos foram realizados em batelada em um reator anular (volume interno de 1,0 L) conectado a um tanque de recirculação de vidro borossilicato (volume de 1,0 L) equipado com um agitador mecânico (Figura 12). A temperatura da solução é controlada por meio de um banho termostático a $25 \pm 2{ }^{\circ} \mathrm{C}$. A solução circula através do reator numa vazão de aproximadamente $1,5 \mathrm{~L} / \mathrm{min}$ utilizando uma bomba centrífuga. 


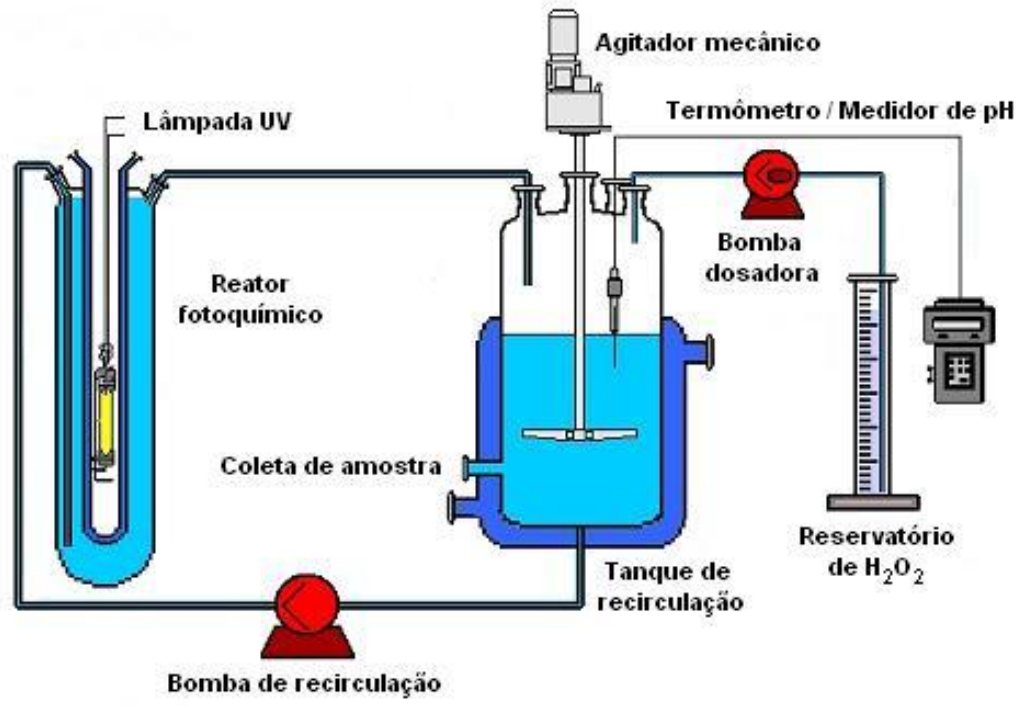

Figura 12 - Esquema do reator fotoquímico de bancada utilizado

Como fonte de luz, utilizou-se lâmpada de vapor de mercúrio de média pressão Philips de 250 W HPLN, sem o invólucro, imersa em um poço de quartzo resfriado com água. O fluxo de fótons total para esse sistema de $1,42.10^{-4}$ einstein/s (mol de fótons/s) foi determinado anteriormente no CESQ/EPUSP por actinometria com ferrioxalato de potássio 0,15 M. A Figura 13 apresenta o espectro de transmitância do poço de quartzo utilizado nos ensaios. 


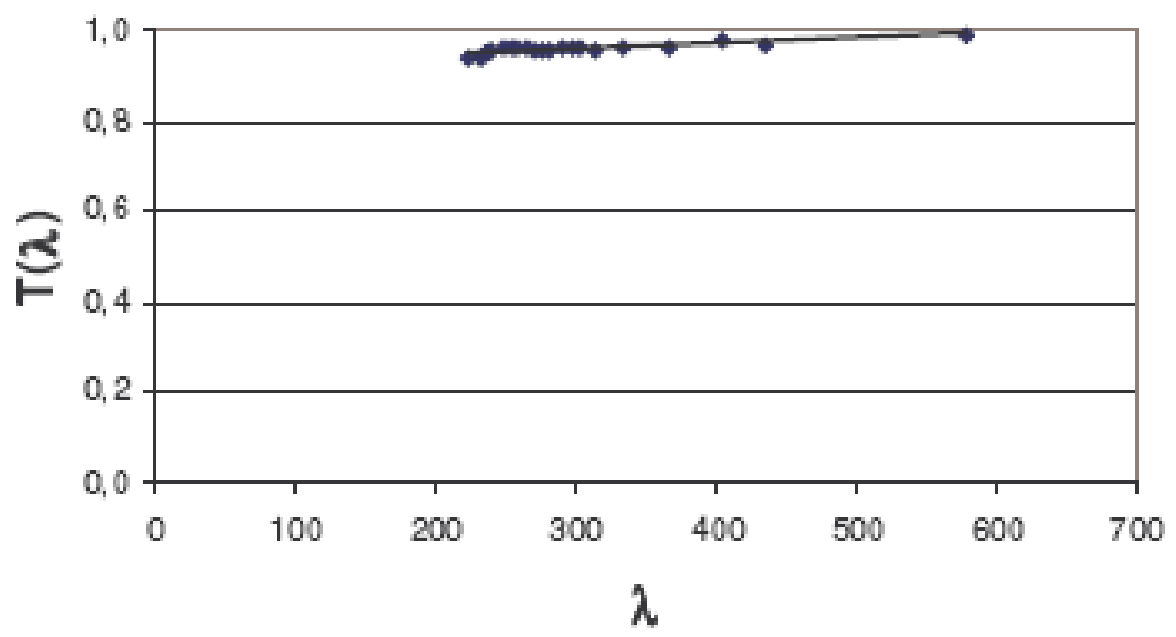

Figura 13 - Espectro de transmitância do poço de quartzo encamisado do reator (Lira, 2006).

Foi considerado neste trabalho que as reações de oxidação ocorrem apenas no volume do reator e não no tanque de recirculação.

\subsubsection{Procedimento experimental}

Nos experimentos com os processos foto-Fenton e $\mathrm{UV} / \mathrm{H}_{2} \mathrm{O}_{2}$ as reações foram iniciadas pela adição de uma solução aquosa de $\mathrm{H}_{2} \mathrm{O}_{2}$ a uma taxa de $0,83 \mathrm{~mL} / \mathrm{min}$ e o acionamento da lâmpada. As concentrações de $\mathrm{H}_{2} \mathrm{O}_{2}$ citadas neste trabalho se referem à quantidade total adicionada dividida pelo volume do sistema. No entanto, essa quantidade é adicionada a uma vazão constante durante os 90 minutos iniciais do experimento. Para as reações foto-Fenton, $\mathrm{FeSO}_{4} \cdot 7 \mathrm{H}_{2} \mathrm{O}$ foi adicionado ao sistema.

Amostras (10 mL cada) foram retiradas para análise em intervalos de tempo apropriado durante o tempo de irradiação (em média $2 \mathrm{~h}$ ). Solução inibidora $(10 \mathrm{~mL}$; contendo uma mistura de 0,05 $\mathrm{M} \mathrm{KI}, 0,05 \mathrm{M} \mathrm{Na}_{2} \mathrm{SO}_{3}$ e 0,05 M NaOH) é adicionada nas amostras provenientes dos processos foto-Fenton e $\mathrm{UV} / \mathrm{H}_{2} \mathrm{O}_{2}$ para interromper a reação; posteriormente as amostras são filtradas (membrana 0,45 $\mu \mathrm{m}$ Millipore Durapore) para remover as espécies de ferro precipitadas e analisadas para determinar o teor de carbono 
orgânico total dissolvido (COT) (Thermo Hipertoc) (verificou-se que a filtração não interfere significativamente na concentração de COT observada). Em cada experimento utilizaram-se 2,0 L de solução aquosa de 100 ppm C de fenol e concentrações diferentes de $\mathrm{NaCl}(0$ a $50 \mathrm{~g} / \mathrm{L})$. No caso do processo $\mathrm{UV} / \mathrm{TiO}_{2}$ foram utilizadas soluções com concentrações diferentes do catalisador, fenol e sal e as amostras retiradas foram filtradas. $\mathrm{O} \mathrm{pH}$ é ajustado para ao valor desejado e mantido constante durante o experimento usando-se soluções aquosas de $\mathrm{H}_{2} \mathrm{SO}_{4}$ ou $\mathrm{NaOH}$. $\mathrm{O}$ pH foi mantido em 3 para minimizar o efeito da concentração de $\mathrm{NaCl}$ no processo de oxidação (Machulek et al., 2007).

\subsubsection{Planejamento experimental}

Para avaliar o efeito da concentração de $\mathrm{H}_{2} \mathrm{O}_{2}$ e de $\mathrm{NaCl}$ na remoção de COT pelo processo foto-Fenton experimentos foram realizados baseados em um projeto Doehlert (De Aguiar e Massart, 1998). Experimentos exploratórios foram realizados para definir os valores limites no plano experimental. Trata-se de um planejamento de três fatores representado pela Figura 14, em que os níveis das variáveis estudadas variaram entre 50 e $80 \mathrm{mM}$ para a $\left[\mathrm{H}_{2} \mathrm{O}_{2}\right]$, entre 0 e $50 \mathrm{~g} / \mathrm{L}$ para a $[\mathrm{NaCl}]$ e 0,1 e 0,4 $\mathrm{mM}$ para a $[\mathrm{Fe}(\mathrm{II})]$.

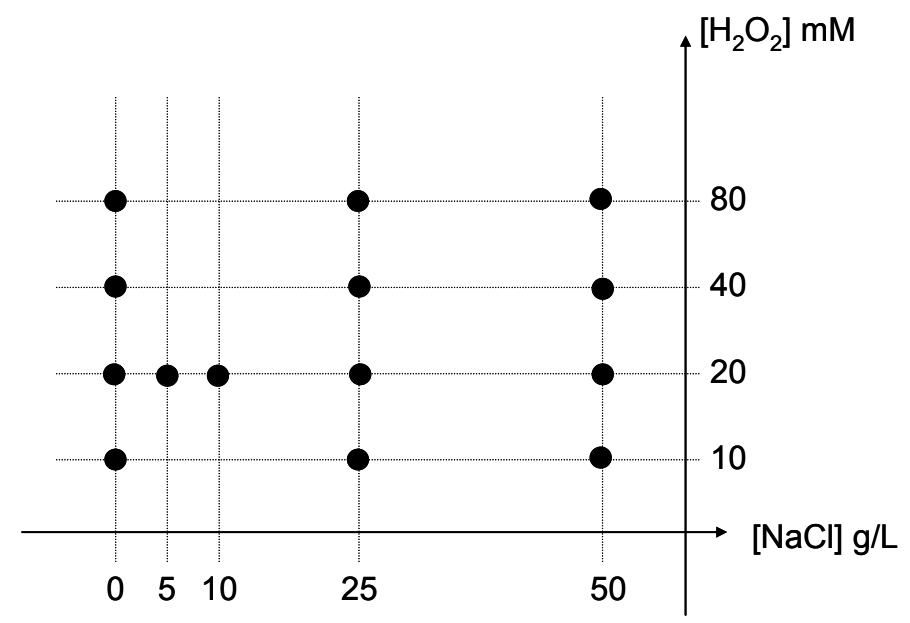

(a) 


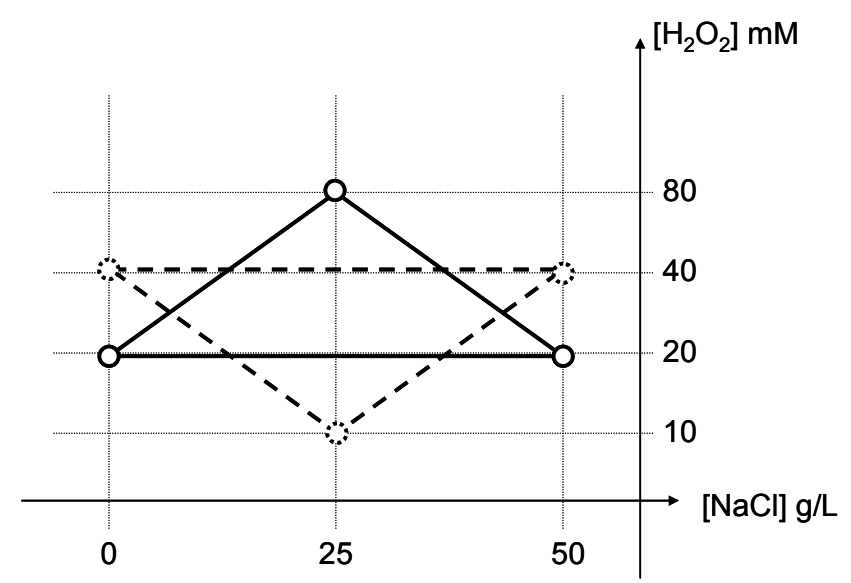

(b)

Figura 14 - Representação esquemática do plano experimental - foto-Fenton; (a) 0,2 mM Fe(II); (b) linha pontilhada: 0,5 mM Fe(II), linha cheia: 0,1 mM Fe (II). 


\subsection{Redes Neurais}

A maior parte dos Processos Oxidativos Avançados envolve reações complexas que leva a incertezas de modelos baseados em mecanismos de reação, particularmente o mecanismo de oxidação do processo foto-Fenton que ainda possui diversas controvérsias. Devido à complexidade das reações a obtenção de parâmetros cinéticos das diferentes etapas envolvidas é difícil.

Nesse contexto, as redes neurais artificiais (RNA) vêm sendo utilizadas como modelos preditivos e seu potencial explorado principalmente no tratamento de dados experimentais de processos complexos e, sobretudo de comportamento não-linear como os processos fotoquímicos (Nascimento, Oliveros e Braun, 1994; Göb et al., 1999; Teixeira, Guardani, Nascimento, 2004). As RNA não necessitam de descrição matemática dos fenômenos que ocorrem nos processos.

A RNA pode "aprender" a partir de dados experimentais, como condições de processo e respectivas respostas, sem o conhecimento de leis físicas e químicas que regem o sistema, detectando relações não-lineares entre as variáveis dependentes e independentes.

A RNA consiste em um modelo composto por diversas unidades de processamento, chamadas de neurônios, conectadas entre si, sendo composta portanto por um arranjo de neurônios artificiais inspirada no sistema neural.

Existem diferentes topologias de RNA e as mais comumente aplicadas para sistemas em estado estacionário são redes do tipo feedforward, que foram utilizadas neste trabalho, tipicamente composta de camadas alinhadas de neurônios em que a informação flui em sentido único, desde as variáveis de entrada até as saídas.

A Figura 15 apresenta a estrutura de uma rede neural artificial de tipo feedforward, em que $x_{n}$ e $O_{p}$ representam, respectivamente, as variáveis normalizadas de entrada e de saída, sendo $p$ o número de variáveis de saída do modelo da RNA. As entradas da rede são apresentadas na primeira camada, camada de entrada, que distribui as informações para a(s) camada(s) oculta(s) da rede. Na última camada, camada de saída, a resposta é obtida. 


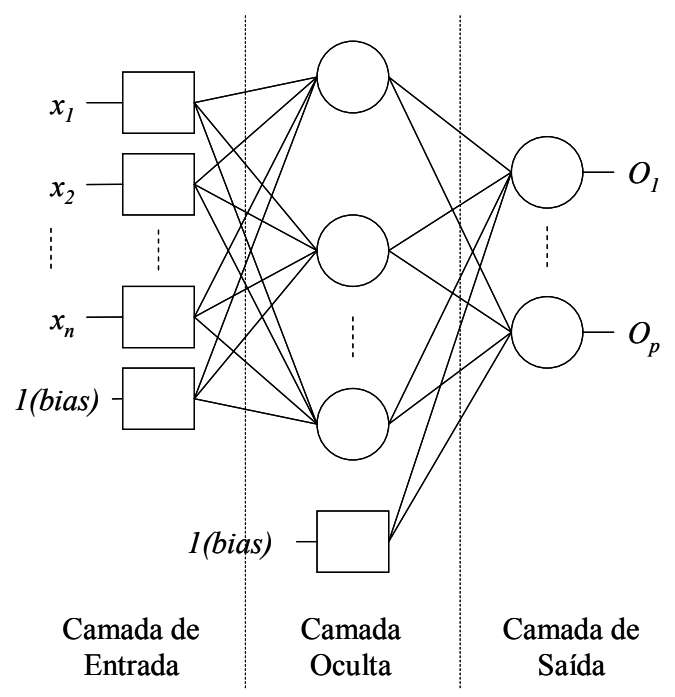

Figura 15 - Estrutura de uma rede neural artificial de tipo feedforward (Gob et al., 1999).

Um neurônio pode ser visto como um dispositivo capaz de receber estímulos (de entrada) de diversos outros neurônios e propagar sua única saída, em função dos estímulos recebidos e do estado interno, a outros neurônios. O neurônio artificial denota um simples dispositivo capaz de calcular o somatório de $N$ entradas ponderadas, cujo resultado passa através de uma função resposta. Basicamente, o dispositivo é caracterizado por um limiar interno e por algum tipo de função não-linear. A saída $O_{j}$ do neurônio $j$ é função do somatório das entradas $x_{1} \ldots x_{n}$, ponderadas pelos respectivos pesos $W_{l j} \ldots W_{i j}$, como representado na Figura 16.

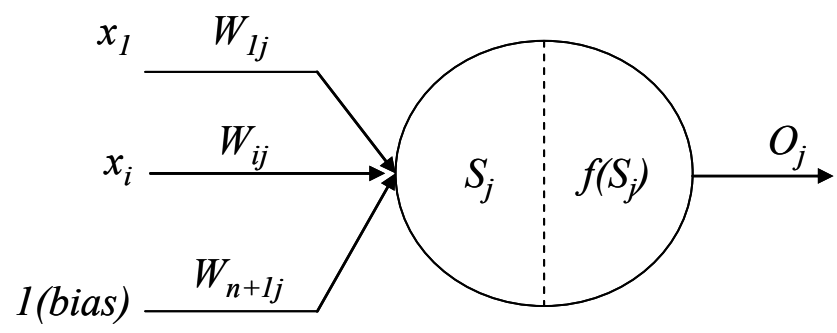

Figura 16 - Representação de um neurônio $j$ na camada oculta (Gob et al., 1999). 
Cada neurônio nas camadas ocultas e na camada de saída calcula primeiramente a soma de pesos de todos os sinais interconectados da camada anterior, somado ao termo de compensação (bias) segundo a Equação 19.

$$
S_{j}=\sum_{i=1}^{n} W_{i, j} x_{i}+W_{n+1, j}
$$

em que $S$ se refere à soma dos pesos, $j$ e $i$ aos neurônios da camada oculta e camada de entrada respectivamente, $W_{i, j}$ o peso entre esses neurônios e $x$ a variável de entrada normalizada.

O neurônio gera a saída através de uma função de ativação, $O_{j}$. A função pode ser de diversos tipos, sendo que a função sigmoidal é a mais comum (Equação 20).

$$
O_{j}=f\left(S_{j}\right)=\frac{1}{\left(1+e^{-S_{j}}\right)}
$$

A soma dos pesos calculada por um neurônio na camada de saída pode ser descrita pela Equação 21:

$$
S_{k}=\sum_{j=1}^{N H} W_{j, k} O_{j}+W_{N H+1, k}
$$

em que NH representa o número de neurônios na camada oculta.

A saída da rede consiste de um ou mais valores, $O_{k}$, obtidos por uma relação similar à Equação $20(\operatorname{com} j=k)$ aplicada a um ou mais neurônios da camada de saída. $O_{k}$ representa a variável de resposta calculada pela rede. A rede "aprende" fazendo modificações sucessivas nos pesos para aproximar as respostas do modelo, $O_{k}$, e os valores de entrada, as respostas experimentais, $y_{k}$.

O critério de ajuste utilizado é o valor mínimo do desvio quadrático:

$$
E=\sum_{m=1}^{r} \sum_{k=1}^{p}\left(y_{k}^{(m)}-O_{k}^{(m)}\right)^{2}
$$

em que $p$ é o número de variáveis de saída e $r$ o número dos pares entrada-saída dos dados experimentais.

O método geralmente utilizado para minimização do erro é o algoritmo de retroprogação, baseado no método do gradiente descendente (Nascimento; Oliveros; Braun, 1994). Os programas de preparação de dados, treinamento da RNA e simulação 
utilizados neste trabalho foram desenvolvidos pelo Laboratório de Simulação e Controle de Processos, LSCP.

O número de camadas ocultas é escolhido através de critérios de ajuste, a partir da análise de capacidade preditiva da rede. Normalmente, redes neurais com poucos neurônios na camada oculta tendem a reduzir problemas de sobreajuste (overfitting).

A precisão de um modelo de RNA depende, no entanto da escolha das variáveis de processo, qualidade de dados e sua distribuição na região experimental. Nesse caso a utilização de metodologias de planejamento experimental é vantajosa para o ajuste do modelo (Göb et al., 1999). 


\section{Capítulo 4: RESULTADOS EXPERIMENTAIS E DISCUSSÃO}

- Eletrodiálise

o Determinação da corrente limite

o Experimentos prévios

o Planejamento Experimental

o Transporte de sal e água

o Transporte de fenol

o Difusão do fenol através das MTCs e MTAs

o Desempenho do processo

- POA

o Experimentos Prévios

o Planejamento Experimental 
Os resultados experimentais e discussões referentes ao estudo da dessalinização por eletrodiálise e degradação fotoquímica são apresentados neste capítulo.

A dessalinização por eletrodiálise (ED) de uma solução salina fenólica, contendo $\mathrm{NaCl}$, foi investigada e os resultados experimentais são apresentados segundo o transporte dos íons, água e fenol no processo de eletrodiálise. Os experimentos foram realizados na unidade piloto. O primeiro item descreve a obtenção da corrente limite para operação do equipamento. Em seguida, são descritos os experimentos prévios utilizados no planejamento dos experimentos. Os efeitos dos fatores apresentados nos resultados do planejamento experimental possibilitaram o equacionamento do transporte do sal, da água e do fenol nas condições estudadas.

Nesse mesmo capítulo os resultados obtidos nos experimentos realizados na célula de difusão são apresentados: difusão do fenol através das diferentes membranas.

Os experimentos de degradação fotoquímica do fenol em solução salina foram desenvolvidos utilizando o processo foto-Fenton. Alguns experimentos comparativos foram realizados com os processos $\mathrm{UV} / \mathrm{TiO}_{2}$ e $\mathrm{UV} / \mathrm{H}_{2} \mathrm{O}_{2}$. O objetivo desta etapa do trabalho foi obter resultados de remoção de $\mathrm{COT}$ em função da concentração de $\mathrm{NaCl}$ e demais variáveis de processo. Estes fatores são estudados em faixas limitadas pelos níveis de excesso e falta dos mesmos, determinando assim um domínio adequado para modelagem do processo. 


\subsection{Eletrodiálise}

Os experimentos foram realizados em uma célula de difusão e em escala piloto para avaliar o fluxo de solvente e dos solutos através de membranas trocadoras de íon em diferentes condições do processo. A partir dos resultados do planejamento experimental foi possível estudar as diferentes contribuições para o transporte. Parte dos resultados apresentados neste capítulo foram também reportados em Borges et al., 2008.

\subsubsection{Determinação da Corrente Limite}

A corrente limite foi determinada pelo método de Cowan e Brown (1959) descrito na seção 2.1.3, baseado na curva resistência, ddp/I, versus 1/I. Utilizou-se no diluído uma solução com $40 \mathrm{~g} / \mathrm{L}$ de $\mathrm{NaCl}$. Como apresentado na Figura 17, a corrente limite foi estimada em aproximadamente 5,9 A $\left(295 \mathrm{~A} / \mathrm{m}^{2}\right)$. Para as condições do planejamento experimental a máxima corrente utilizada foi de 5,5 A $\left(275 \mathrm{~A} / \mathrm{m}^{2}\right)$.

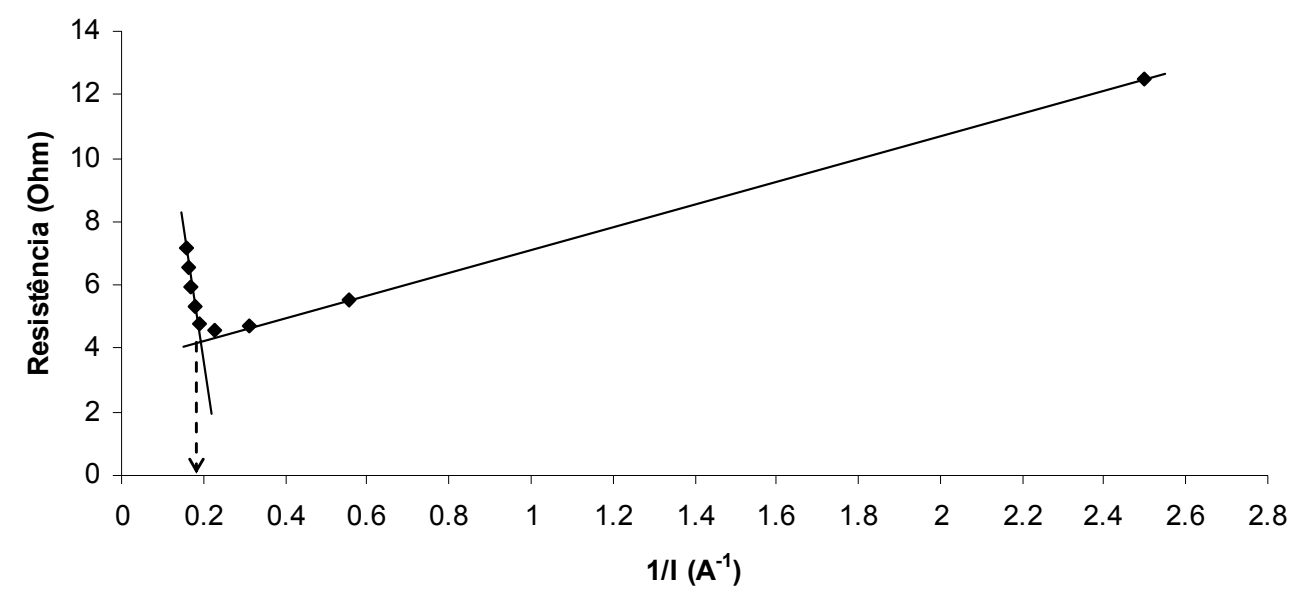

Figura 17 - Gráfico da resistência do sistema em função do inverso da corrente, usado para determinação da corrente limite; $[\mathrm{NaCl}]_{\text {diluido }}^{0}=40 \mathrm{~g} / \mathrm{L}$. 


\subsubsection{Experimentos Prévios}

A partir dos experimentos prévios realizados, o procedimento experimental foi modificado em função do comportamento da variação de massa de fenol nos compartimentos com o tempo aplicando-se potencial elétrico.

Os experimentos foram realizados mediante planejamento experimental baseado na matriz Doehlert (Tabela 5). A variação de massa de fenol no concentrado em função do tempo para as condições experimentais é apresentada na Figura 18. A concentração inicial de sal $\left(\Delta C_{s}^{0}\right)$ varia desde a alimentação do sistema até o início do experimento, uma vez que partes do sal e da água são transferidas enquanto a corrente é ajustada. Portanto, os valores reais de $\Delta C_{s}^{0}$ quando corrente elétrica é aplicada ( $\left.\mathrm{t}=0\right)$ foram utilizados para todas as condições e o planejamento experimental substituído por uma pseudo-matriz Doehlert. A Tabela 5 apresenta as condições experimentais e os fatores normalizados $\left(\mathrm{X}^{\prime}\right)$, associados aos valores reais (U), baseados na matriz Doehlert (X). Como mencionado anteriormente, a duração dos experimentos depende da condutividade do diluído, ou seja, da condição de operação.

Tabela 5 - Condições nos experimentos prévios de eletrodiálise baseadas na matriz Doehlert.

\begin{tabular}{|c|c|c|c|c|c|c|}
\hline \multirow{3}{*}{ Experimento } & \multicolumn{2}{|c|}{$\begin{array}{l}\text { Variáveis } \\
\text { Doehlert }\end{array}$} & \multicolumn{2}{|c|}{$\begin{array}{l}\text { Variáveis } \\
\text { Reais }\end{array}$} & \multicolumn{2}{|c|}{$\begin{array}{c}\text { Variáveis } \\
\text { Normalizadas }\end{array}$} \\
\hline & $i$ & $\Delta C_{s}^{0}$ & $\begin{array}{c}i \\
\left(A \cdot m^{-2}\right)\end{array}$ & $\begin{array}{c}\Delta C_{s}^{0} \\
\left(\mathbf{k g} \cdot \mathbf{m}^{-3}\right)\end{array}$ & $i$ & $\Delta C_{s}^{0}$ \\
\hline & $X_{1}$ & $\mathbf{X}_{2}$ & $\mathrm{U}_{1}$ & $\mathbf{U}_{2}$ & $X_{1}^{\prime}$ & $\mathrm{X}_{2}$ \\
\hline $1^{\prime}$ & 0 & 0 & 175 & 38,0 & 0 & $-0,017$ \\
\hline $1 r^{\prime}$ & 0 & 0 & 175 & 37,7 & 0 & 0,057 \\
\hline $2^{\prime}$ & 1 & 0 & 275 & 38,8 & 1 & -0.004 \\
\hline $3^{\prime}$ & 0,5 & 0,866 & 225 & 51,4 & 0,5 & 0,743 \\
\hline $4^{\prime}$ & -1 & 0 & 75 & 38,7 & -1 & $-0,008$ \\
\hline 5 & $-0,5$ & $-0,866$ & 125 & 24,9 & $-0,5$ & $-0,785$ \\
\hline $6^{\prime}$ & 0,5 & $-0,866$ & 225 & 24,0 & 0,5 & $-0,809$ \\
\hline 7 & $-0,5$ & 0,866 & 125 & 51,6 & $-0,5$ & 0,768 \\
\hline
\end{tabular}




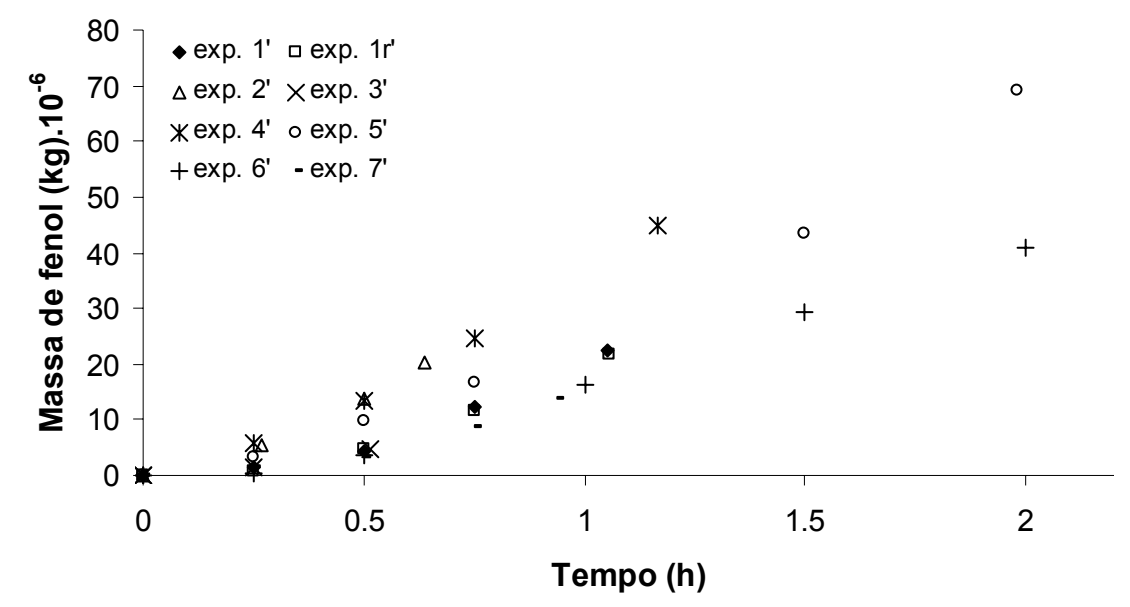

Figura 18 - Variação da massa de fenol no concentrado versus tempo para diferentes concentrações iniciais de sal e densidades de corrente.

Observa-se que o transporte de fenol através das membranas apresenta um atraso no início do experimento (entre 0 e 30 minutos aproximadamente) que tende a mudar aparentemente para uma variação linear após esse período.

Por razões práticas considerou-se que a contribuição à transferência de massa do fenol durante esse primeiro período, que corresponde a um período transiente, pode ser desprezada. Num contexto industrial, o transporte do fenol provavelmente obedeceria ao segundo tipo de comportamento, observado após 30 minutos de experimento, considerando um processo em batelada sem procedimentos de limpeza entre os tratamentos do efluente, assim como para um processo contínuo. Algumas hipóteses podem ser feitas para justificar a existência desse período transiente; uma delas é que o fenol pode interagir com a superfície da membrana, ou seja, pode ser adsorvido, e conseqüentemente uma perda do poluente é verificada durante certo período. Por essa razão, o procedimento experimental foi modificado para minimizar tal efeito. Os experimentos apresentados a seguir foram realizados com circulação de 1 hora das soluções a serem tratadas antes do acionamento da corrente elétrica. 
A perda de fenol pode ser estimada por um balanço de massa e expressa por seu valor percentual, como apresentado pela Equação 23, em função do tempo para as diferentes condições experimentais apresentadas na Tabela 5 (Figura 19).

$\%$ Perda_fenol $=\left(\frac{\left(m_{d}^{0}+m_{c}^{0}\right)-\left(m_{d}^{t}+m_{c}^{t}\right)}{\left(m_{d}^{0}+m_{c}^{0}\right)}\right) .100$

em que $m^{0}$ e $m^{t}$ são as massa de fenol para os diferentes compartimentos no tempo 0 e $t$; e os subscritos $d$ e $c$ representam respectivamente os compartimentos do diluído e concentrado.

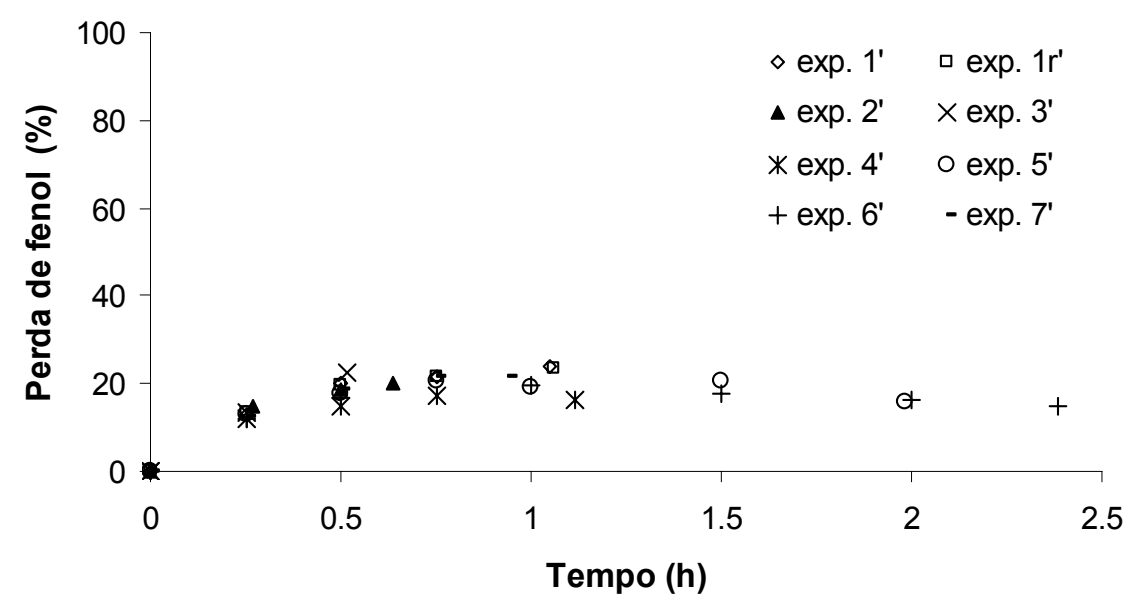

Figura 19 - Perda de fenol em função do tempo.

Pode-se observar que a perda de fenol aumenta durante os primeiros 30 minutos da operação. Após esse período passa a ser aproximadamente constante considerando o erro experimental.

Além disto, a Figura 19 sugere que o transporte de fenol depende da intensidade da corrente; quanto maior a densidade de corrente aplicada, maior a velocidade de transferência do mesmo. No entanto, os resultados desses experimentos não foram utilizados para o ajuste de correlações. 


\subsubsection{Planejamento Experimental}

Para todos os experimentos, as quantidades de soluto e solvente transportadas foram avaliadas segundo a variação de concentração dos solutos e volume nos compartimentos com o tempo. Como resultado, os fluxos de água, sal e fenol, $J_{w}(\mathrm{~m} / \mathrm{s})$, $J_{s}\left(\mathrm{~kg} / \mathrm{s} . \mathrm{m}^{2}\right)$ e $J_{p}\left(\mathrm{~kg} \mathrm{C} / \mathrm{s} . \mathrm{m}^{2}\right)$, foram obtidos pela inclinação das curvas $d V / d t, d m_{s} / d t$, $d m_{p} / d t$ respectivamente, para diferentes condições experimentais. Utilizou-se concentração de fenol de $100 \mathrm{ppm} \mathrm{C}\left(0,13 \mathrm{~kg} / \mathrm{m}^{3}\right)$ no diluído e foram consideradas como área ativa total de membrana, $0,2 \mathrm{~m}^{2}, S_{1}$, para o transporte de sal, e $0,4 \mathrm{~m}^{2}, S_{2}$, para a transferência de água e fenol. O sal é transportado na forma iônica $\left(\mathrm{Na}^{+}\right.$e $\left.\mathrm{Cl}^{-}\right)$através das membranas, e portanto parte é transferido pelas MTCs e parte pelas MTAs, já a água e o fenol são transferidos através das duas membranas.

Os fluxos foram obtidos pela vazão volumétrica e mássica como indicado na Equação 24.

$J=\frac{j}{S}$

A Tabela 6 apresenta os resultados e as condições experimentais, similarmente à Tabela 5. A concentração inicial de sal varia mais em relação aos experimentos prévios uma vez que uma maior quantidade de sal e da água é transferida enquanto as soluções circulam pelo sistema por 1 hora sem corrente elétrica, além do tempo de ajuste da corrente. 
Tabela 6 - Condições experimentais de eletrodiálise baseadas na matriz Doehlert e resultados.

\begin{tabular}{cccccccccc}
\hline & \multicolumn{2}{c}{$\begin{array}{c}\text { Variáveis } \\
\text { Doehlert }\end{array}$} & \multicolumn{2}{c}{$\begin{array}{c}\text { Variáveis } \\
\text { normalizadas }\end{array}$} & \multicolumn{2}{c}{$\begin{array}{c}\text { Variáveis } \\
\text { reais }\end{array}$} & \multicolumn{3}{c}{ Respostas } \\
\cline { 2 - 10 } & $\boldsymbol{I}$ & $\Delta C_{s}^{0}$ & $\boldsymbol{I}$ & $\Delta C_{s}^{0}$ & $\begin{array}{c}\boldsymbol{I} \\
\left(\mathbf{A} / \mathbf{m}^{2}\right)\end{array}$ & $\begin{array}{c}\Delta C_{s}^{0} \\
\left(\mathbf{k g} / \mathbf{m}^{3}\right)\end{array}$ & $\begin{array}{c}J_{w} \cdot 10^{-7} \\
(\mathbf{m} / \mathbf{s})\end{array}$ & $\begin{array}{c}J_{s} \cdot 10^{-5} \\
\left(\mathbf{k g} / \mathbf{s . m}^{2}\right)\end{array}$ & $\begin{array}{c}J_{p} \cdot 10^{-8} \\
\left(\mathbf{k g} / \mathbf{s . m} \mathbf{m}^{2}\right)\end{array}$ \\
\cline { 2 - 10 } & $\mathbf{X}_{\mathbf{1}}$ & $\mathbf{X}_{\mathbf{2}}$ & $\mathbf{X}_{\mathbf{1}}^{\prime}$ & $\mathbf{X}_{\mathbf{2}}^{\prime}$ & $\mathbf{U}_{\mathbf{1}}$ & $\mathbf{U}_{\mathbf{2}}$ & $\mathbf{Y}_{\mathbf{1}}$ & $\mathbf{Y}_{\mathbf{2}}$ & $\mathbf{Y}_{\mathbf{3}}$ \\
\hline 1 & 0 & 0 & 0 & $-0,453$ & 175 & 32,2 & 1,78 & 9,60 & 1,87 \\
2 & 1 & 0 & 1 & 0,043 & 275 & 40,8 & 2,78 & 15,06 & 2,56 \\
$2 \mathrm{r}$ & 1 & 0 & 1 & $-0,416$ & 275 & 32,8 & 2,92 & 15,13 & 2,39 \\
3 & 0,5 & $-0,866$ & 0,5 & $-1,030$ & 225 & 22,2 & 2,36 & 12,78 & 2,21 \\
4 & 0,5 & 0,866 & 0,5 & 0,441 & 225 & 47,6 & 2,33 & 13,58 & 2,25 \\
5 & $-0,5$ & 0,866 & $-0,5$ & 0,577 & 125 & 50,0 & 1,31 & 7,64 & 1,66 \\
6 & -1 & 0 & -1 & $-0,176$ & 75 & 37,0 & 0,78 & 4,61 & 1,28 \\
7 & 0,5 & $-0,866$ & $-0,5$ & $-0,850$ & 125 & 25,3 & 1,27 & 7,67 & 1,65 \\
\hline
\end{tabular}

A metodologia de superfície de resposta foi utilizada para avaliar a relação entre os fatores experimentais controlados $\left(\Delta C_{s}^{0}\right.$ e $\left.i\right)$ e os resultados observados $\left(J_{w}, J_{s}, J_{p}\right)$. Equações com o formato apresentado a seguir (25) foram ajustadas a cada resposta, y, em função dos dois fatores $X_{1}$ e $X_{2}$, supondo-se correlação linear entre a resposta, $y$, e cada fator, além da interação linear entre os dois fatores:

$y=a X_{1}+b X_{2}+c X_{1} X_{2}$

em que os coeficientes experimentais $a b$ e $c$ foram estimados pelo método dos mínimos quadrados.

Os coeficientes relacionados aos fatores de contribuições dos fluxos do solvente e dos solutos são representados resumidamente na Figura 20 por um diagrama de Pareto; que apresenta os módulos dos coeficientes dos fatores em função de sua contribuição relativa a cada resposta. As equações das superfícies de resposta obtidas para cada componente, assim como as representações gráficas correspondentes, são apresentadas no Anexo 1. 


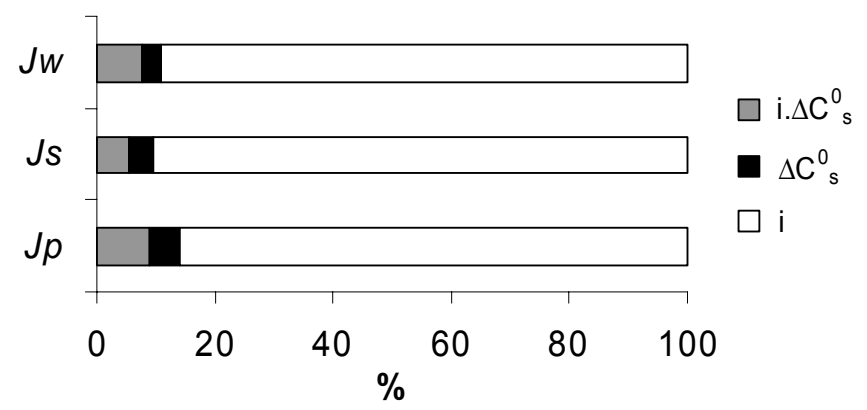

Figura 20 - Diagrama de Pareto normalizado para as contribuições dos fluxos.

Os resultados mostram que a diferença de concentração inicial de sal entre os compartimentos $\left(\Delta \mathrm{C}_{\mathrm{s}}^{0}\right)$ e sua interação com a densidade de corrente $(i)$ tem efeito desprezível em relação à densidade de corrente, especialmente para o fluxo de sal, $J_{s}$. Além disso, nos experimentos realizados sem aplicação de corrente a presença de $\mathrm{NaCl}$ não teve influência significativa no transporte difusivo do fenol.

Nestes experimentos, o desvio máximo observado para o balanço de massa foi de $2,4 \%$. Os resultados serão discutidos mais detalhadamente nas seções a seguir.

\subsubsection{Transporte de sal e água}

Os transportes de solvente e dos solutos foram analisados nos experimentos realizados com e sem aplicação de corrente elétrica. Uma vez que a concentração inicial de sal no sistema foi considerada um fator desprezível nas condições estudadas, os diferentes fluxos foram relacionados à densidade de corrente.

A Figura 21 apresenta a variação de volume de solução no compartimento do concentrado em função do tempo para diferentes correntes aplicadas. O fluxo da água ocorre em sentidos opostos em operações sem e com corrente. A diminuição de volume observada na ausência de corrente é devida à osmose que direciona o solvente do compartimento menos concentrado (concentrado) para o mais concentrado (diluído). Quando existe um gradiente de potencial elétrico aplicado ao sistema o fluxo do solvente 
se dá praticamente devido à eletro-osmose e é orientado na mesma direção do fluxo de sal, do diluído para o concentrado. Conseqüentemente, o volume do concentrado aumenta. A contribuição significativa da eletro-osmose ao transporte de água confirma as observações apresentadas anteriormente na literatura (Bailly et al., 2001). Além disso, quando é aplicada corrente, o volume varia linearmente com o tempo, indicando que o fluxo de água é constante. $\mathrm{O}$ fluxo de água aumenta com a corrente.

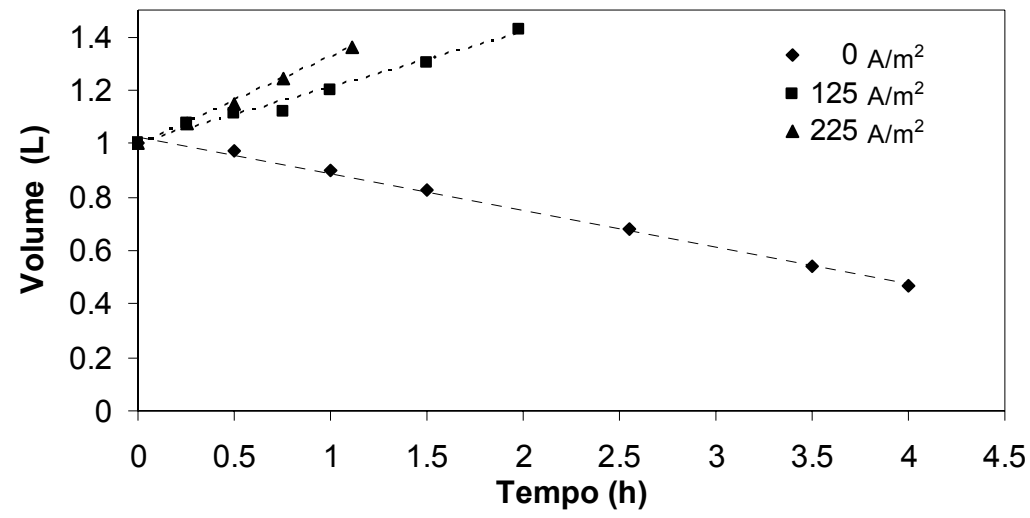

Figura 21 - Volume do compartimento do concentrado em função do tempo para diferentes valores de densidade de corrente aplicadas; $\left[\Delta C_{s}^{0} \approx 55 \mathrm{~kg} \cdot \mathrm{m}^{-3} ; \Delta C_{p}^{0}=100 \mathrm{ppm}\right.$ C].

Em relação ao transporte de sal, a Figura 22 apresenta a massa de sal no concentrado em função do tempo. A contribuição da difusão quando $\mathrm{I}=0$ pode ser considerada desprezível quando comparada à migração. De fato, quando corrente é aplicada, o transporte de sal é significativamente maior em comparação aos experimentos de difusão (fluxo aproximado de $6,4 \cdot 10^{-3} \mathrm{~kg} / \mathrm{h} \cdot \mathrm{m}^{2}$ (i=0)). Além disso, o fluxo de massa de sal pode ser considerado aproximadamente constante, pois os pontos no gráfico encontram-se aparentemente alinhados em cada experimento. 


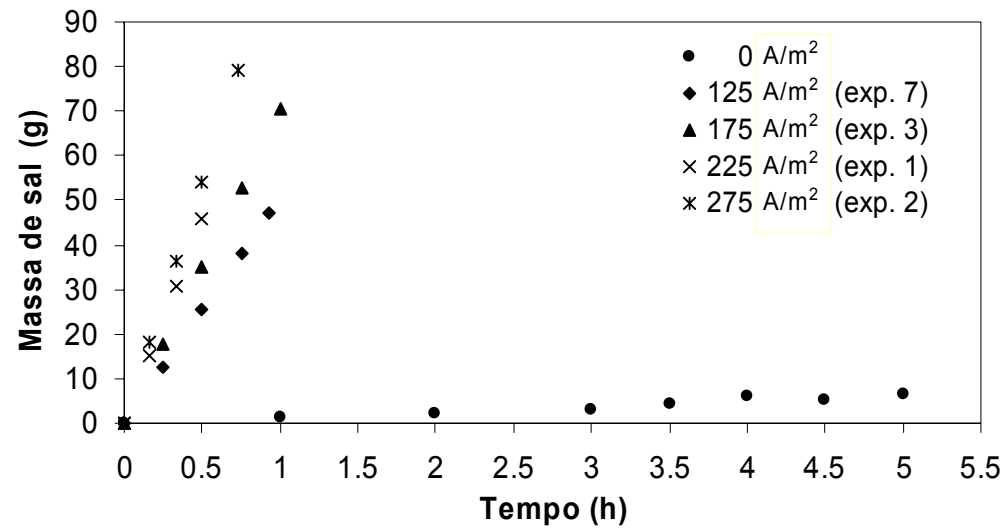

Figura 22 - Massa de $\mathrm{NaCl}$ no compartimento do concentrado em função do tempo para diferentes densidades de corrente.

Os resultados experimentais sugerem para as condições de ED, ou seja, quando corrente elétrica é aplicada, que os fluxos de sal e água podem ser considerados dependentes somente da intensidade de corrente. Portanto, foram correlacionados à densidade de corrente por regressão linear, como apresentado na Figura 23(a) e 23(b), com coeficiente de correlação igual a 0,998 e 0,990, respectivamente, o que confirma a suposição de que as contribuições da difusão ao fluxo de sal assim como da osmose ao fluxo da água são desprezíveis.

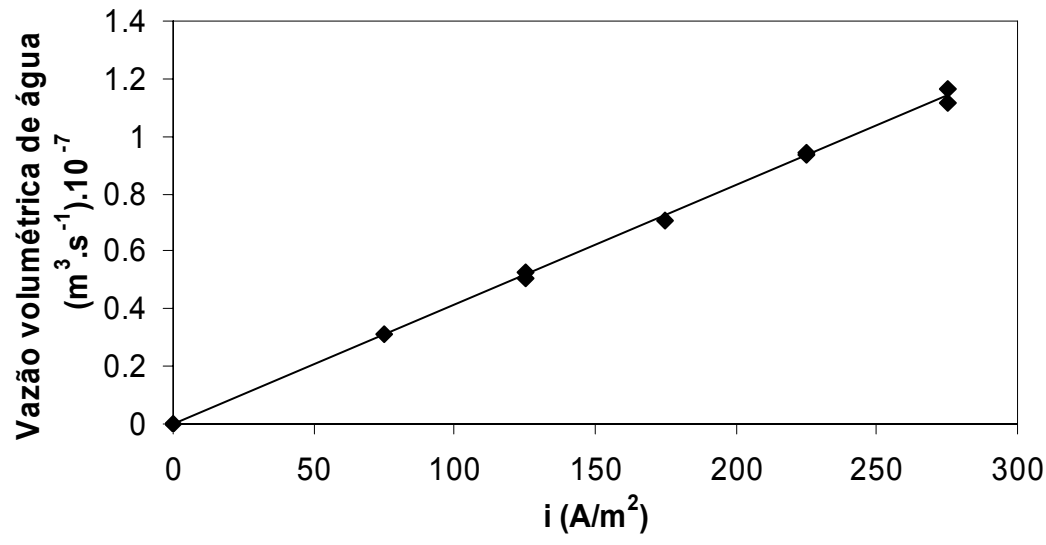

(a) 


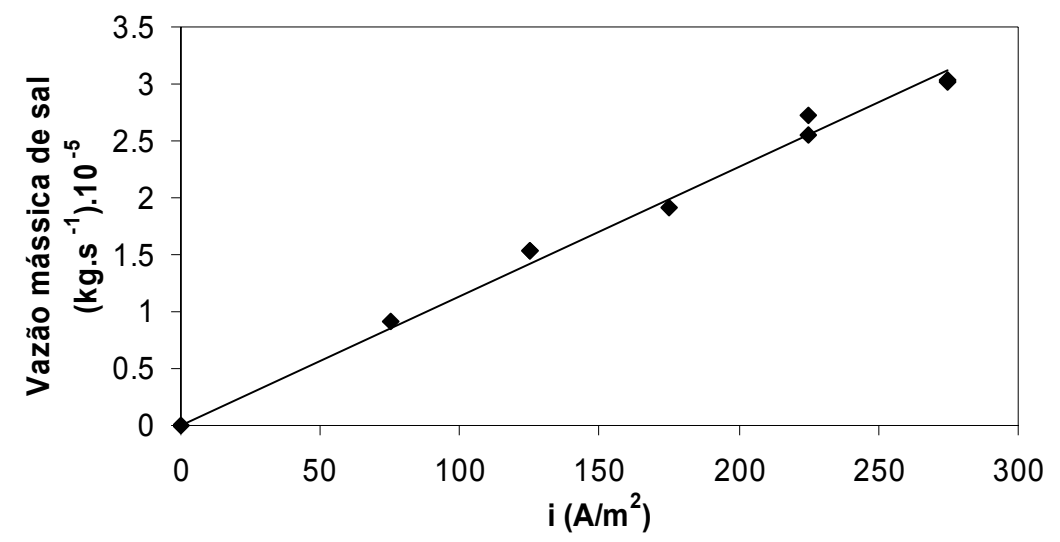

(b)

Figure 23 - Vazão de água (a) e de sal (b) em função da densidade de corrente.

Para as condições avaliadas neste estudo, as seguintes relações foram adotadas:

$J_{w}=\alpha i$

$J_{s}=\beta i$

sendo $\alpha$ igual a $(1,04 \pm 0,02)^{*} \times 10^{-9} \mathrm{~m}^{3} / \mathrm{s}$. A e $\beta$ igual a $(5,5 \pm 0,5)^{1} \times 10^{-7} \mathrm{~kg} / \mathrm{s}$.A.

A partir dos valores obtidos de $J_{s}$ e $J_{w}$ o número de moles de água transportados por mol de íon, $T w$, pode ser calculado. Este parâmetro foi apresentado anteriormente na seção 2.1.4 (Equação 15) e pode ser expresso pela Equação 28.

$$
T_{w}=\frac{j_{w} \cdot N_{w}}{\sum_{i} \frac{j_{i}}{M_{i}}}=\frac{j_{w} \cdot N_{w}}{\frac{j_{N a^{+}}}{M_{N a^{+}}}+\frac{j_{C l^{-}}}{M_{C l^{-}}}}=\frac{j_{w} \cdot N_{w}}{2 \cdot\left(\frac{j_{\mathrm{NaCl}}}{M_{\mathrm{NaCl}}}\right)}
$$

Para uma vazão mássica de sal de 19,7 g/h.A (0,36 mol/h.A total de íons) e vazão de água de 4,3 mol/h, $T_{w}$ é igual a 5,8 moles de água por mol de íons. Neste cálculo adotou-se: massa molecular do $\mathrm{NaCl}, M_{s}$, igual a $58,4 \mathrm{~g} / \mathrm{mol}, N_{w}$ igual a $57,1.10^{-3}$ $\mathrm{mol} / \mathrm{m}^{3}$, e densidade da água igual a $1.027,15 \mathrm{~kg} / \mathrm{m}^{3}$, para uma salinidade de $40 \mathrm{~g} / \mathrm{L}$

* $95 \%$ intervalo de confiança 
(valor médio das condições estudadas) a $25^{\circ} \mathrm{C}$. A Tabela 7 apresenta alguns valores de $T_{w}$ citados na literatura por Singlande (2006) e o encontrado neste estudo.

Tabela 7 - Comparação do número de transferência deste estudo com outros reportados.

\begin{tabular}{c|cccccc}
\hline Composto & $\begin{array}{c}\text { Este } \\
\text { Estudo }\end{array}$ & $\begin{array}{c}\text { [Singlande } \\
2006]\end{array}$ & $\begin{array}{c}\text { [David } \\
2001]\end{array}$ & $\begin{array}{c}\text { [Binder } \\
2002]\end{array}$ & $\begin{array}{c}\text { [Zhou } \\
2000]\end{array}$ & $\begin{array}{c}\text { [Rutgers } \\
1962]\end{array}$ \\
\hline $\mathrm{Na}^{+}$ & - & - & 1,66 & 5,9 & 3,6 & 13 \\
\hline $\mathrm{Cl}^{-}$ & - & - & 0 & $?$ & 3,6 & 5 \\
\hline $\mathrm{NaCl}$ & 5,8 & 7 & 1,66 & 5,9 & 7,2 & 18 \\
\hline
\end{tabular}

Pode-se constatar que o número de hidratação obtido está muito próximo ao apresentado por Binder (2002) e da mesma ordem de grandeza dos reportados por Singlande (2006) e por Zhou (2000).

Considerando que a vazão molar dos íons $\mathrm{Na}^{+}$e $\mathrm{Cl}^{-}$possuem mesmo valor por causa da eletroneutralidade e por serem monovalentes, o número de transferência apresentado neste trabalho refere-se ao valor total para ambos os íons, que não são iguais devido às diferentes camadas de hidratação de cada íon.

Quanto ao grau de hidratação dos íons, uma primeira classificação foi proposta considerando a capacidade de certos íons precipitarem proteínas. Esta classificação foi completada posteriormente por diferentes estudos (Chaplin, 2004 e Lopez-Leon, 2003 apud Singlande, 2006). A Figura 24 apresenta uma representação esquemática da classificação de certos íons quanto ao seu fator de hidratação.

Fortemente Hidratado Pouco Hidratado

$\begin{array}{ll}\text { Ânions } & \text { Citrato }^{3-}>\mathrm{SO}_{4}{ }^{2-}>\mathrm{HPO}_{4}{ }^{2-}>\text { Acetato }^{2} \mathrm{Cl}^{-}>\mathrm{Br}^{-}>\mathrm{I}^{-}>\mathrm{NO}_{3}>\mathrm{ClO}_{4}{ }^{-} \\ \text {Cátions } & \mathrm{Al}^{3+}>\mathrm{Mg}^{2+}>\mathrm{Ca}^{2+}>\mathrm{H}^{+}>\mathrm{Na}^{+}>\mathrm{K}^{+}>\mathrm{Rb}^{+}>\mathrm{Cs}^{+} \mathrm{NH}_{4}{ }^{+}>\mathrm{N}\left(\mathrm{CH}_{3}\right)_{4}{ }^{+}\end{array}$

Figura 24 - Classificação de alguns íons quanto ao seu fator de hidratação (Singlande, 2006). 
A Figura 24 sugere que o $\mathrm{Na}^{+}$e o $\mathrm{Cl}^{-}$possuem graus de hidratação medianos frente a outros íons, sendo o $\mathrm{Na}^{+}$mais hidratado que o $\mathrm{Cl}^{-}$. É válido ressaltar que o número de transferência do $\mathrm{NaCl}$ pode ser fortemente afetado em presença de outros íons. Na presença de íons fortemente hidratados, a camada de hidratação de outras espécies diminui. Essa diminuição da camada de hidratação aumenta o coeficiente de transferência das espécies através da membrana. Singlande (2006) reportou um aumento de 5 vezes no coeficiente de transferência do $\mathrm{NaCl}$ em presença de sulfato de sódio $\left(\mathrm{Na}_{2} \mathrm{SO}_{4}\right)$ em relação ao composto puro em solução.

\subsubsection{Transporte de fenol}

As contribuições para o transporte de fenol, expressas na Equação 29 (apresentada novamente a seguir) na seção 2.1.4, foram analisadas experimentalmente sob as condições apresentadas na Tabela 8.

$$
J_{p}=J_{p}^{\text {diff }}+J_{p}^{\text {conv }}=P_{p} \Delta C_{p}+\bar{C}_{p}(1-\sigma) J_{w}
$$

Tabela 8 - Condições operacionais (densidade de corrente e concentração de fenol) e resultados (fluxo de fenol) dos experimentos realizados para avaliar as diferentes contribuições ao transporte de fenol.

\begin{tabular}{|c|c|c|c|c|}
\hline Experimentos & $\begin{array}{c}i \\
\left(\mathrm{~A} / \mathrm{m}^{2}\right)\end{array}$ & $\begin{array}{c}\Delta C_{p}^{0} \\
(\mathbf{p p m} \mathbf{C})\end{array}$ & $\begin{array}{c}\Delta C_{s}^{0} \\
\left(\mathbf{k g} / \mathbf{m}^{3}\right)\end{array}$ & $\begin{array}{c}\boldsymbol{J}_{\boldsymbol{p}} \cdot 10^{-8} \\
\left(\mathrm{~kg} / \mathbf{m}^{2} . \mathbf{s}\right)\end{array}$ \\
\hline \multirow{8}{*}{ Difusão } & 0 & 359 & 0 & 3,86 \\
\hline & 0 & 306 & 0 & 3,20 \\
\hline & 0 & 231 & 0 & 2,43 \\
\hline & 0 & 140 & 0 & 1,63 \\
\hline & 0 & 87 & 0 & 0,95 \\
\hline & 0 & 81 & 0 & 0,93 \\
\hline & 0 & 73 & 0 & 0,85 \\
\hline & 0 & 71 & 0 & 0,65 \\
\hline \multirow{2}{*}{ Adicionais } & 175 & 256 & 35 & 8,21 \\
\hline & 275 & 256 & 35 & 9,64 \\
\hline
\end{tabular}

Para as soluções de fenol sem $\mathrm{NaCl}$ a variação do fluxo de fenol pela diferença de concentração do composto entre os compartimentos é apresentada na Figura 25. Com base na dependência linear, de acordo com a Equação 29, o coeficiente de 
permeabilidade do fenol, $P_{p}$, foi estimado em $8,4 \times 10^{-8} \mathrm{~m} / \mathrm{s}$, com coeficiente de correlação igual a 0,997 .

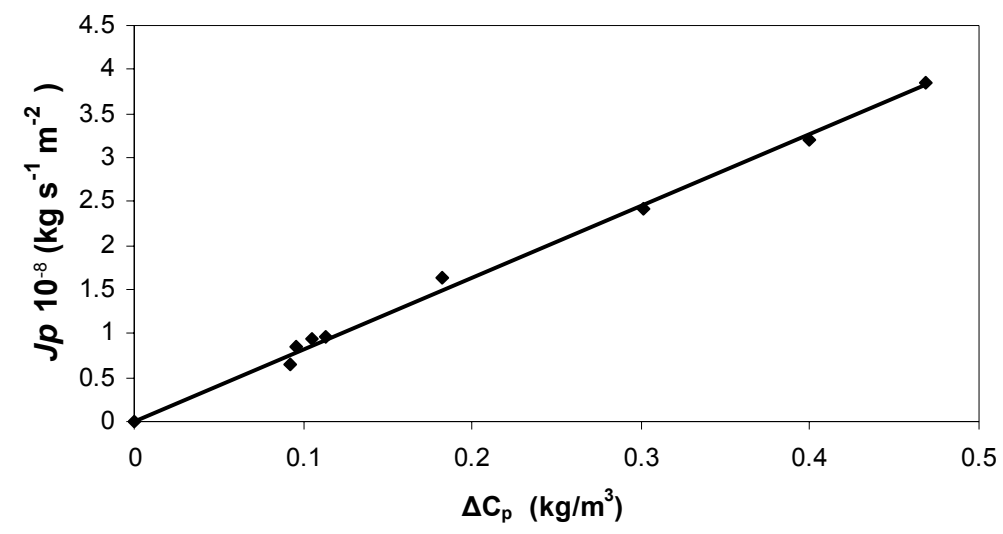

Figura 25 - Variação do fluxo de fenol versus diferença de concentração inicial entre os compartimentos - experimentos sem corrente elétrica.

O efeito da presença de sal na contribuição da difusão ao transporte de fenol foi avaliado. A Figura 26 apresenta a variação de massa do fenol no concentrado com o tempo para diferentes concentrações de sal. Na faixa investigada de concentração do composto, a concentração inicial de $\mathrm{NaCl}$ não influenciou significativamente o fluxo de fenol. Assim, o valor do coeficiente de permeabilidade de fenol determinado foi suposto válido para a faixa de concentração de sal e fenol investigada. 


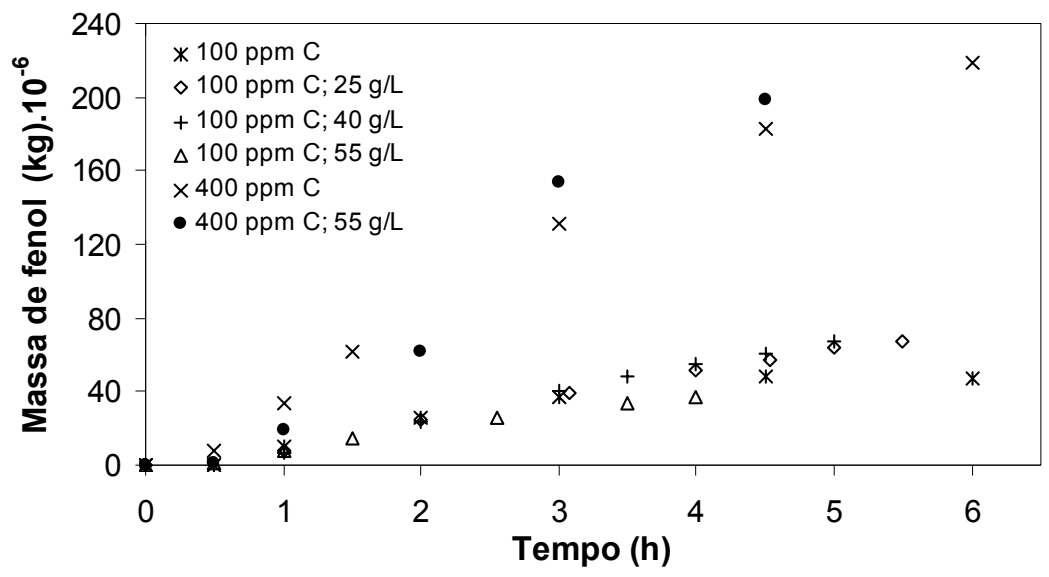

Figura 26 - Variação de massa de fenol no concentrado pelo tempo - influência da concentração inicial de sal e fenol - experimentos sem corrente elétrica.

A Figura 27 apresenta a variação de massa de fenol no concentrado com o tempo no processo de ED. Embora o fenol não seja um composto iônico, sua transferência é afetada pela corrente elétrica. O fluxo de fenol aumenta com o aumento da corrente de 1,5 para 5,5 A. Para $i=275 \mathrm{~A} / \mathrm{m}^{2}$ o fluxo de fenol é aproximadamente 2,5 vezes maior que para $i=0$. Portanto, uma contribuição convectiva pode ser atribuída ao transporte do fenol nas condições estudadas.

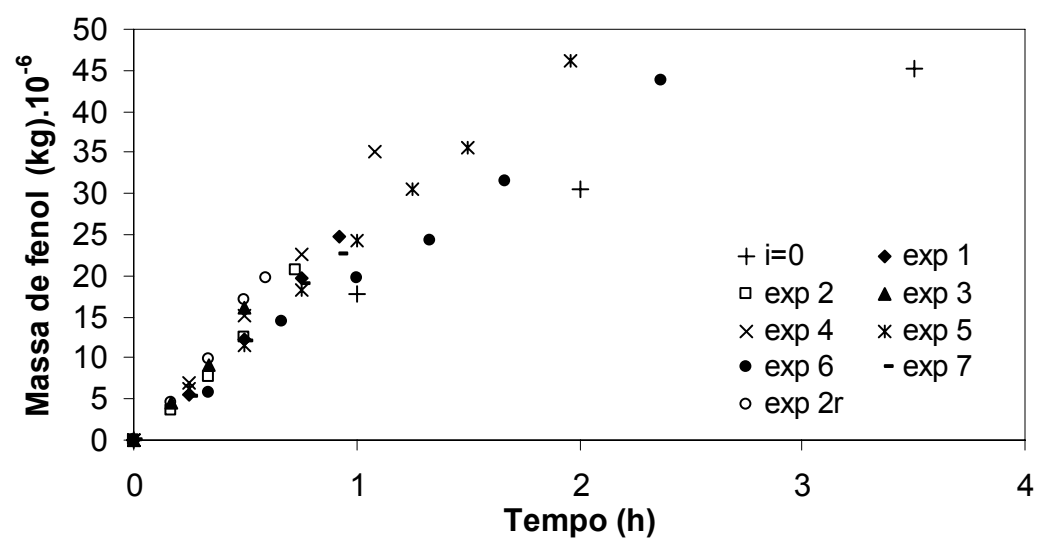

Figura 27 - Variação da massa de fenol com o tempo no concentrado influência da corrente elétrica $-\Delta C_{p}^{0} \approx 100 \mathrm{ppm} \mathrm{C}$. 
Como descrito anteriormente pela Equação 29 o fluxo de fenol resulta de duas contribuições: um fluxo difusivo, que depende da diferença de concentração do componente entre os compartimentos $\left(\Delta C_{p}\right)$ multiplicada por um coeficiente de permeabilidade, e um segundo termo nomeado fluxo convectivo. Este último termo está diretamente relacionado com o fluxo da água, que depende, como mencionado anteriormente, da densidade de corrente aplicada e das restrições da membrana em relação à passagem do fenol. Nos experimentos realizados, a diferença de concentração de fenol entre os compartimentos variou menos de $15 \%$, considerada pequena em relação às outras variáveis. Supondo que a diferença de concentração é aproximadamente constante, a contribuição da difusão ao transporte de fenol pode ser considerada constante em função do tempo. Tal hipótese foi validada posteriormente com base no ajuste obtido entre os resultados experimentais do fluxo de fenol com o tempo, sem corrente elétrica, por um modelo linear. Da mesma maneira, a concentração inicial de fenol na alimentação (diluído). $C_{p_{d}}^{0}$, pode ser considerada aproximadamente igual à diferença de concentração entre os compartimentos, $\Delta C_{p}^{0}$. De fato, observou-se que as concentrações nos dois compartimentos não apresentaram variações significativas ao longo dos experimentos. Considerando essas hipóteses, o fluxo de fenol no processo de ED pode ser descrito pela Equação 30:

$$
J_{p}=P_{p} \Delta C_{p}^{0}+(1-\sigma) C_{p_{d}}^{0} J_{w}
$$

Podem-se ajustar os valores experimentais do fluxo de fenol, $J_{p}$, a $\Delta C_{p}^{0}$ e $\left(C_{p_{d}}^{0} J_{w}\right)$ por um modelo linear e estimar o valor do coeficiente de reflexão $\sigma$. Para as condições testadas, o valor de $0.24 \pm 0.02 *$ foi obtido, e portanto a membrana retem cerca de $24 \%$ de fenol transportado por convecção. O parâmetro $P_{p}$ foi estimado em $\left(8,4 \pm 0,8^{*}\right)$ X $10^{-8} \mathrm{~m} / \mathrm{s}$, valor semelhante ao obtido anteriormente pelo ajuste dos resultados experimentais sem corrente elétrica. O modelo linear possui bom ajuste com os resultados experimentais $\left(\mathrm{R}^{2}=0,995\right)$, como ilustrado na Figura 28, que apresenta os

\footnotetext{
* $95 \%$ confidence intervalo
} 
resultados experimentais versus os resultados calculados pela Equação 25. O modelo linear descrito pela equação correlaciona o fluxo mássico de fenol com a diferença de concentração inicial entre os compartimentos e com o fluxo de água. Com base no comportamento do sistema os parâmetros $P_{p}$ e $\sigma$ podem ser estimados.

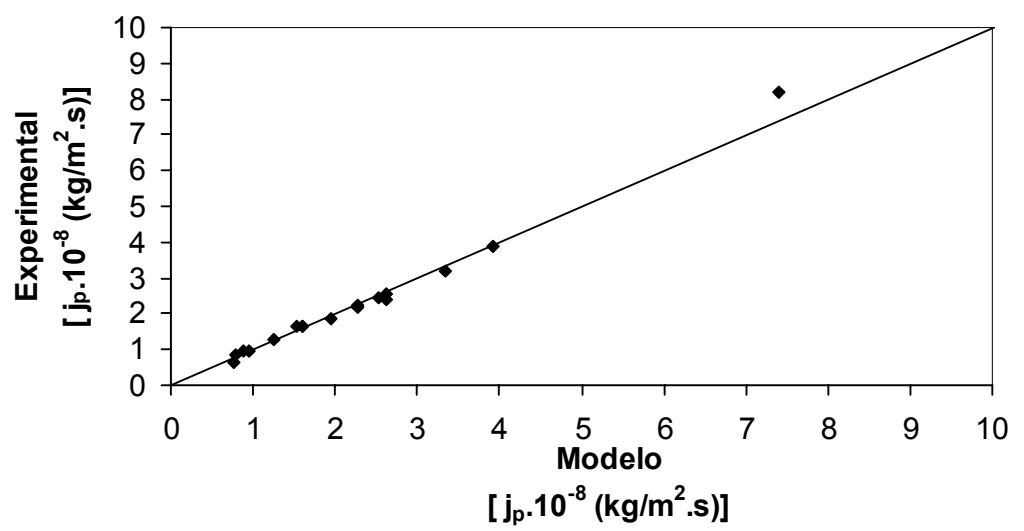

Figura 28 - Resultados experimentais versus calculados do fluxo de fenol.

\subsubsection{Difusão de fenol através das MTCs e MTAs}

Experimentos foram realizados na célula de difusão descrita anteriormente na seção 3.1.2 para a avaliação do transporte difusivo através das MTCs e MTAs separadamente. A Figura 29 apresenta a variação de massa de fenol transportado através das diferentes membranas em função do tempo. 


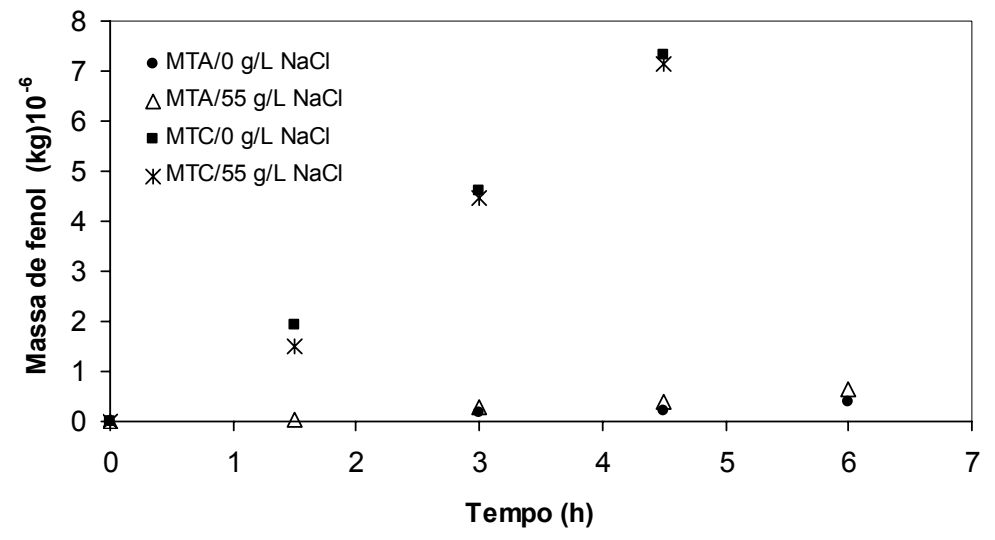

Figura 29 - Massa de fenol em função do tempo através da MTC e MTA em solução aquosa com e sem a adição de $\mathrm{NaCl}\left[\Delta C_{p}^{0}=400\right.$ ppm $\left.\mathrm{C} ; I=0\right]$.

Os resultados sugerem que o transporte de fenol através da MTC é significativamente mais importante do que através da MTA. Sob as condições estudadas, a adição de sal não influencia significativamente o fluxo de fenol através das membranas.

\subsubsection{Tratamento dos resultados experimentais}

A partir dos resultados obtidos, os parâmetros das Equações 22, 23 e 25 foram estimados pelo método dos mínimos quadrados. Esses parâmetros são específicos para a solução e sistema de ED operado. Para condições diferentes daquelas adotadas neste estudo, seus valores devem ser estimados pela metodologia apresentada. Para o sistema investigado neste estudo, os valores destes parâmetros são apresentados na Tabela 9.

Tabela 9 - Coeficientes de transporte obtidos nos experimentos de ED.

\begin{tabular}{cccc}
\hline Transporte de Água & Transporte de Sal & \multicolumn{2}{c}{ Transporte de Fenol } \\
\hline$\alpha \times 10^{-9}$ & $\beta \times 10^{-7}$ & $P_{p} \times 10^{-8}$ & $\sigma$ \\
$\left(\mathrm{m}^{3} \mathrm{~s}^{-1} A^{-1}\right)$ & $\left(\mathrm{kg} \mathrm{s}^{-1} A^{-1}\right)$ & $\left(\mathrm{m} \mathrm{s}^{-1}\right)$ & \\
\hline $1.04 \pm 0.02^{*}$ & $5.5 \pm 0.5^{*}$ & $8.4 \pm 0.8^{*}$ & $0.24 \pm 0.02^{*}$ \\
$S_{I}=0.4 \mathrm{~m}^{2}$ & $S_{2}=0.2 \mathrm{~m}^{2}$ & \multicolumn{2}{c}{$S_{I}=0.4 \mathrm{~m}^{2}$} \\
\hline
\end{tabular}


As variações de concentração de sal e fenol experimentais e calculadas foram comparadas. A maior diferença encontrada entre esses valores foi menor que $10 \%$ para todas as condições investigadas.

As variações de concentração de sal e fenol nos compartimentos no processo de desmineralização por ED podem ser obtidas por balanço de massa em cada compartimento. A Equação 31 relaciona $m_{s}^{0}$ e $m_{s}^{t}$, as massas de sal no início e no tempo $t$ respectivamente, para o compartimento do concentrado, considerando a vazão mássica de sal, $j_{s}$, constante.

$m_{s}^{t}-m_{s}^{0}=C_{s}^{t} V_{c}^{t}-C_{s}^{0} V_{c}^{0}=j_{s} t$

em que $V_{c}^{0}$ é o volume inicial e $V_{c}^{t}$ é o volume no compartimento do concentrado no tempo $t$. Considerando a densidade da solução constante, o transporte de água do diluído para o concentrado provoca um aumento no volume, descrito pela Equação 32.

$V_{c}^{t}=V_{c}^{0}+\Delta V_{c}$

em que $\Delta V_{c}$ é o volume transportado de água do diluído durante o período considerado. A velocidade do aumento do volume de água foi considerada constante e igual a $j_{w}$, vazão volumétrica de água, e portanto:

$V_{c}^{t}-V_{c}^{0}=j_{w} . t$

A Equação 31 pode então ser reformulada, resultando na Equação 34:

$C_{s}^{t}=\frac{j_{s} t+C_{s}^{0} V_{c}^{0}}{V_{c}^{t}}$

Considerando os coeficientes de transporte $\alpha$ e $\beta$ (Equações 22 e 23) e a áreas de membrana $S_{1}$ e $S_{2}$, as Equações 33 e 34 podem ser combinadas, resultando na Equação 35.

$C_{s}^{t}=\frac{\beta i S_{2} t+C_{s}^{0} V_{c}^{0}}{\left(\alpha i S_{1} t+V_{c}^{0}\right)}$

A partir dessas hipóteses, o transporte de fenol pode ser descrito pela seguinte relação: 
$C_{p}^{t}=\frac{\left(P_{p} \Delta C_{p}^{0}+(1-\sigma) C_{p_{d}}^{0} \alpha i S_{1}\right) t+C_{p}^{0} V_{c}^{0}}{\left(\alpha i S_{1} t+V_{c}^{0}\right)}$

Para o compartimento do diluído as equações anteriores podem ser reescritas resultando nas Equações 37 e 38 para as concentrações de sal e fenol respectivamente; em que $V_{d}^{0}$ é o volume inicial no compartimento do diluído.

$$
\begin{aligned}
& C_{s}^{t}=\frac{\left(-\beta i S_{2} t\right)+C_{s}^{0} V_{d}^{0}}{\left(\left(-\alpha i S_{1} t\right)+V_{d}^{0}\right)} \\
& C_{p}^{t}=\frac{\left(-\left(P_{p} \Delta C_{p}^{0}+(1-\sigma) C_{p_{d}}^{0} \alpha i S_{1}\right) t\right)+C_{p}^{0} V_{d}^{0}}{\left(\left(-\alpha i S_{1} t\right)+V_{d}^{0}\right)}
\end{aligned}
$$

Essas equações também podem ser utilizadas para avaliar o desempenho da desmineralização por ED, que é caracterizado pela perda de fenol, ou seja, pela quantidade de fenol transferida para o concentrado; assim como pelo fator de desmineralização, representado pela quantidade de sal removido da solução. A Figura 30 apresenta um exemplo de resultados calculados: a variação de concentração de fenol no concentrado versus a concentração de sal no diluído, ou seja, a quantidade de sal residual no efluente fenólico desmineralizado.

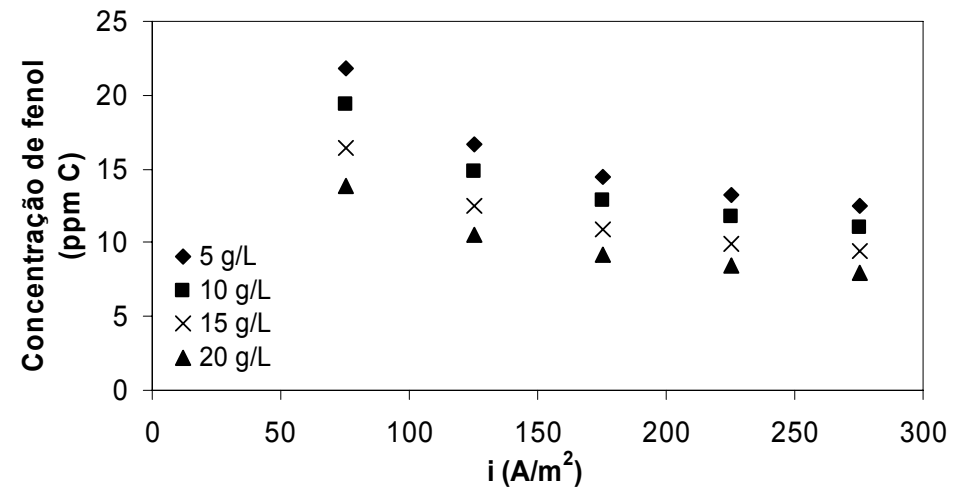

Figura 30 - Concentração final de fenol no concentrado versus densidade de corrente para diferentes valores de concentração final de $\mathrm{NaCl}$ no diluído; $\left[\Delta C_{p}^{0}=100\right.$ $\left.\operatorname{ppm~C;~} \Delta C_{s}^{0}=40 \mathrm{~g} / \mathrm{L}\right]$. 
Para um determinado valor de densidade de corrente, valores decrescentes de concentração residual de sal correspondem a uma maior concentração de fenol no concentrado. Como esperado, quanto maior a desmineralização da solução, o que se traduz pela maior migração de sal, maior o tempo de processo de ED, o que resulta numa maior transferência de fenol. A variação da perda de fenol em função do sal residual em solução é mais pronunciada para valores menores de densidade de corrente. Por outro lado, para uma dada concentração de sal, ou seja, para um determinado fator de desmineralização, a perda de fenol diminui com o aumento da corrente. 


\subsection{POA}

O processo foto-Fenton envolve quatro variáveis principais de operação: concentração do catalisador $\mathrm{Fe}(\mathrm{II})$, concentração de $\mathrm{H}_{2} \mathrm{O}_{2}$, concentração de poluente a ser degradado e intensidade da irradiação UV. No caso deste estudo a concentração de fenol foi fixada em 100 ppm C e a potência da lâmpada em $250 \mathrm{~W}$. Experimentos prévios de actinometria realizados no LSCP, Laboratório de Simulação e Controle de Processos, mostraram que o ganho em termos de incidência de fótons torna-se desvantajoso para lâmpada acima de $250 \mathrm{~W}$ de potência em função do consumo de energia da lâmpada.

\subsubsection{Experimentos exploratórios}

Experimentos exploratórios foram realizados para determinar o plano experimental a ser estudado quanto aos limites de concentração de $\mathrm{Fe}(\mathrm{II})$ e $\mathrm{H}_{2} \mathrm{O}_{2}$. A Figura 31 apresenta gráficos de $\mathrm{COT} / \mathrm{COT}_{0}$ em função do tempo para diferentes valores da concentração de $\mathrm{Fe}(\mathrm{II})$ e da concentração de $\mathrm{H}_{2} \mathrm{O}_{2}$. 


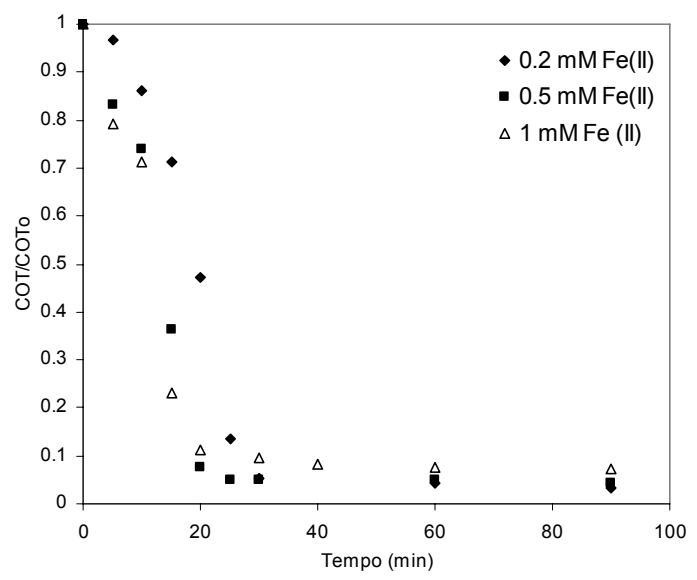

(a)

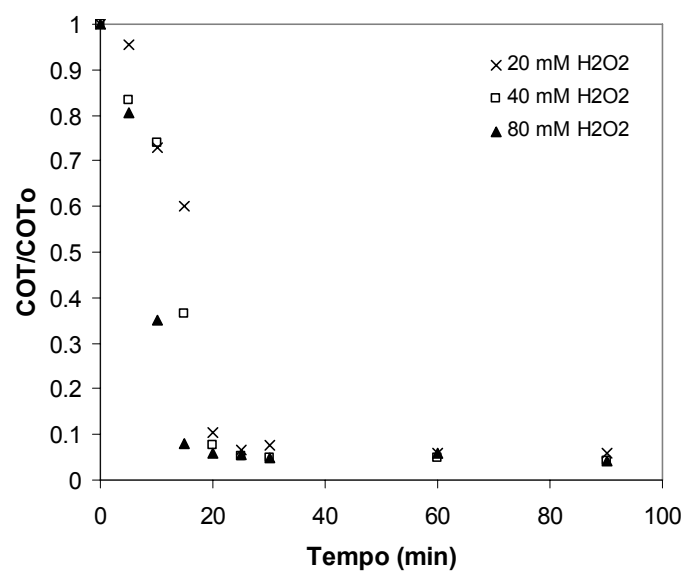

(b)

Figura 31 - Remoção de COT em função do tempo; (a) efeito da concentração de $\mathrm{Fe}(\mathrm{II}),\left[\mathrm{H}_{2} \mathrm{O}_{2}\right]=40 \mathrm{mM}$; (b) Efeito da concentração de $\mathrm{H}_{2} \mathrm{O}_{2}$, [Fe(II)] = 0,5 mM.

De modo geral, os gráficos mostram que os valores de remoção de COT são altos, ultrapassando $95 \%$ para todas as condições. A concentração de $\mathrm{Fe}$ (II) exerce efeito sobre a reação de oxidação de fenol (Figura 31(a)). Nas condições estudadas, a remoção de COT não apresentou diferenças significativas para as concentrações de $\mathrm{Fe}$ (II) de 0,5 e $1 \mathrm{mM}$, apresentando perfis semelhantes, o que pode caracterizar o excesso de $\mathrm{Fe}(\mathrm{II})$ acima de 0,5 mM nesta condição. A velocidade de remoção de COT diminui para a condição de 0,2 mM de $\mathrm{Fe}(\mathrm{II})$ enquanto que a remoção de COT em 25 minutos de reação é praticamente a mesma para todas as condições. Considerando o intervalo entre 5 e 20 minutos a constante cinética $k$ pode ser estimada a partir da inclinação de uma reta traçada neste intervalo para a taxa de decaimento de COT em função do tempo. Para as concentrações de 1 e $0,5 \mathrm{mM}$ os valores da constante são 0,050 e $0,053 \mathrm{~min}^{-1}\left(\mathrm{R}^{2}=\right.$ 0,913 e 0,955); para concentração de Fe(II) de 0,2 mM esta constante diminui para 0,033 $\min ^{-1}\left(\mathrm{R}^{2}=0,967\right)$, cerca de $35 \%$.

No caso da variação da concentração de $\mathrm{H}_{2} \mathrm{O}_{2}$, a velocidade de remoção aumenta com o aumento de concentração da mesma. Em 15 minutos nota-se que as remoções para as diferentes concentrações se distinguem $(40 \%$ para $20 \mathrm{mM}$; $64 \%$ para $40 \mathrm{mM}$; $92 \%$ para $80 \mathrm{mM}$ ). No entanto, não há variação significativa em termos de remoção de COT após 20 minutos para estas condições. 
A eficiência do processo foi testada para diferentes concentrações de $\mathrm{H}_{2} \mathrm{O}_{2}$ e $\mathrm{NaCl}$. Nos experimentos prévios a concentração de Fe(II) foi mantida em $0,2 \mathrm{mM}$, visando verificar o efeito da adição de $\mathrm{NaCl}$ em uma condição na qual o $\mathrm{Fe}(\mathrm{II})$ não está em excesso. A concentração de Fe(II) será estudada posteriormente.

A Figura 32 apresenta a remoção de COT em função do tempo para diferentes tempos de adição de $\mathrm{H}_{2} \mathrm{O}_{2}$ : em 60 e 90 minutos respectivamente. A concentração de $\mathrm{H}_{2} \mathrm{O}_{2}$ também foi variada (20 e $40 \mathrm{mM}$ ).

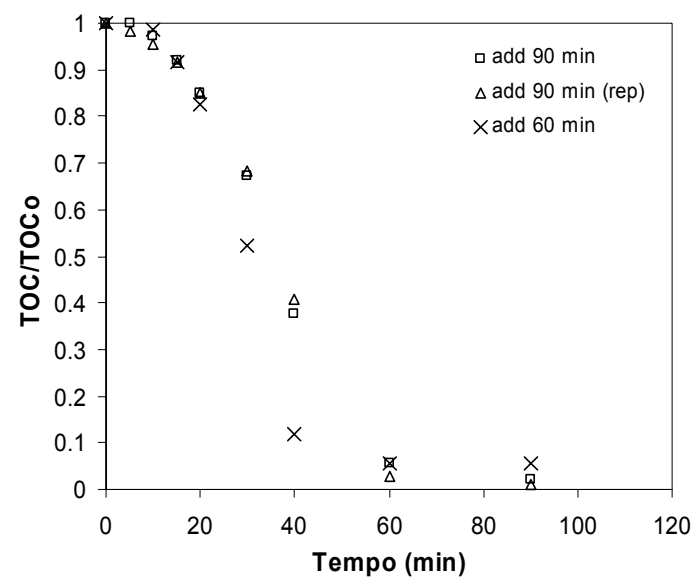

(a)

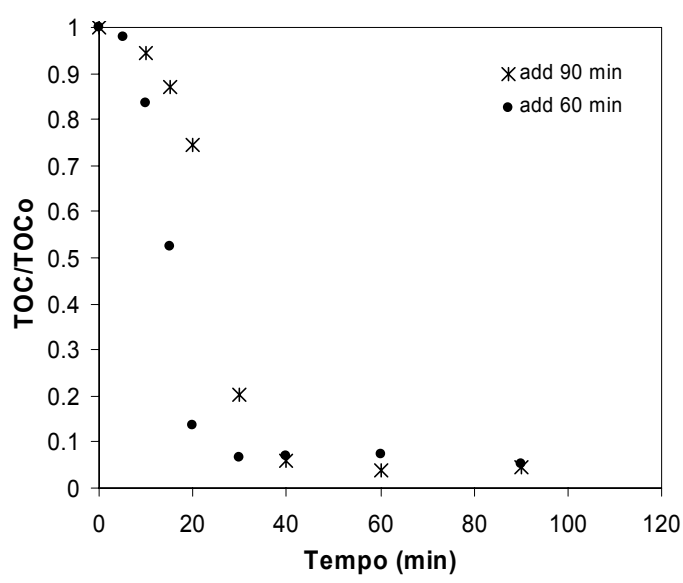

(b)

Figura 32 -Remoção de COT em função do tempo; efeito do tempo de adição da solução de $\mathrm{H}_{2} \mathrm{O}_{2}$ em diferentes concentrações [0,2 mM Fe(II); (a) $20 \mathrm{mM}$ $\mathrm{H}_{2} \mathrm{O}_{2}$; (b) $40 \mathrm{mM} \mathrm{H}_{2} \mathrm{O}_{2}$.

De modo geral, os resultados apresentados na Figura 32(a) e (b) indicam, como visto anteriormente, que a concentração do $\mathrm{H}_{2} \mathrm{O}_{2}$ exerce efeito importante sobre as reações de oxidação do fenol, pois quanto maior a concentração, maior a velocidade de remoção. Por outro lado, os resultados sugerem que esta remoção é ligeiramente mais rápida em 90 minutos de reação para os experimentos em que a solução de $\mathrm{H}_{2} \mathrm{O}_{2}$ foi adicionada em um maior período, para as duas concentrações de peróxido de hidrogênio no reator, 20 e $40 \mathrm{mM}$, indicando então que o tempo de adição de $\mathrm{H}_{2} \mathrm{O}_{2}$ pode influenciar os percentuais de remoção final de COT. A Figura 32(a) apresenta ainda um dos 
experimentos realizados em duplicata, utilizando-se $20 \mathrm{mM}$ de $\mathrm{H}_{2} \mathrm{O}_{2}$, indicando que o erro experimental foi pequeno.

É válido ressaltar que, sendo o COT um parâmetro global para a composição do meio e não se dispõem de medidas de concentração de fenol ao longo do tempo, nada se pode afirmar quanto à remoção deste contaminante. Em outras palavras, é possível que a concentração de fenol varie devido às reações com o radical hidroxila, gerando produtos orgânicos oxidados na solução, sem variação expressiva de COT.

Com base nos comentários anteriores, $\mathrm{o}_{2} \mathrm{O}_{2}$ foi adicionado nos experimentos nos primeiros 90 minutos de reação. No entanto, o tempo de adição do oxidante é um fator importante a ser estudado e que está relacionado à concentração de $\mathrm{H}_{2} \mathrm{O}_{2}$ adicionada.

\subsubsection{Resultados Experimentais}

Os resultados experimentais foram avaliados a partir de diferentes variáveis dependentes (respostas): tempo de inversão da primeira mudança de perfil da curva $\left(t_{1}\right)$, determinado a partir do equacionamento dos dois decaimentos de $\mathrm{COT} / \mathrm{COT}_{0}$, no início do processo e quando a remoção torna-se mais pronunciada; segunda inversão de perfil $\left(t_{2}\right)$, a velocidade de decaimento mais pronunciada $(k)$ entre $t_{1}$ e $t_{2}$; e remoção final em $120 \min \left(\% R_{120}\right)$ segundo a Equação 39 . A remoção em 40 min $\left(\% R_{40}\right)$ também foi utilizada como resposta intermediária para avaliação da eficiência do processo. Um exemplo da obtenção destas respostas é apresentado na Figura 33.

$$
\% R_{120}=\left(1-\left[\frac{C O T_{120}}{C O T_{0}}\right]\right) \cdot 100
$$




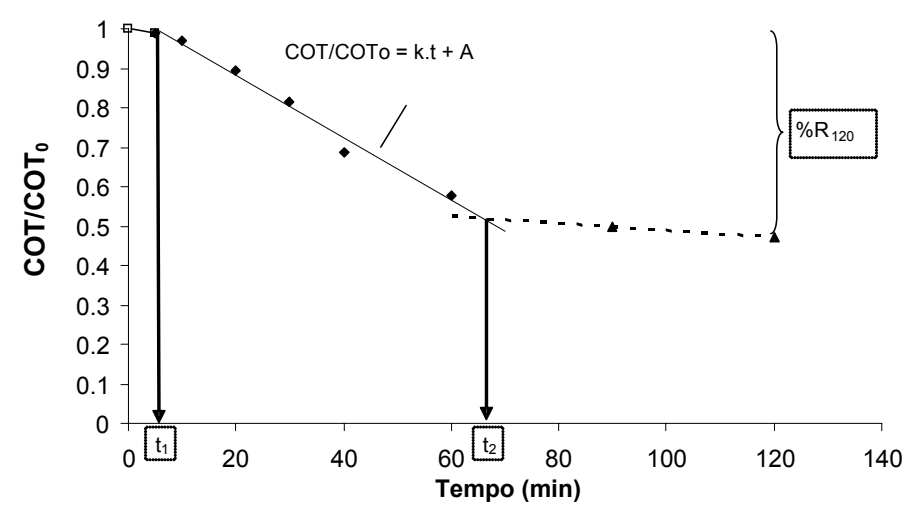

Figura 33 - Exemplificação do método de obtenção das respostas de decaimento de $\mathrm{COT} / \mathrm{COT}_{0}$.

Os resultados do planejamento experimental para o processo foto-Fenton são apresentados na Tabela 10 e as curvas de COT em função do tempo na Figura 34 (a) (d). 
Tabela 10 - Resultados experimentais - processo foto-Fenton.

\begin{tabular}{|c|c|c|c|c|c|c|c|c|c|c|}
\hline \multirow{3}{*}{\multicolumn{2}{|c|}{ Experimento }} & \multicolumn{3}{|c|}{ Fatores } & \multicolumn{6}{|c|}{ Respostas } \\
\hline & & \multirow{2}{*}{$\begin{array}{c}{\left[\mathrm{H}_{2} \mathrm{O}_{2}\right]} \\
(\mathrm{mM})\end{array}$} & \multirow{2}{*}{$\begin{array}{c}\text { [NaCl] } \\
\left(\text { g.L }^{-1}\right)\end{array}$} & \multirow{2}{*}{$\begin{array}{c}\text { [Fe (II)] } \\
(\mathrm{mM})\end{array}$} & \multirow{2}{*}{$\begin{array}{c}t_{1} \\
(\mathrm{~min})\end{array}$} & \multicolumn{2}{|c|}{$C O T / C O T_{o}=k . t+A$} & \multirow{2}{*}{$\begin{array}{c}t_{2} \\
(\mathrm{~min})\end{array}$} & \multirow{2}{*}{$\begin{array}{c}\% R_{120} \\
(\%)\end{array}$} & \multirow{2}{*}{$\begin{array}{c}\% R_{40} \\
(\%)\end{array}$} \\
\hline & & & & & & $k\left(\min ^{-1}\right)$ & $R^{2}$ & & & \\
\hline \multirow{15}{*}{ Central } & $80 \_50$ & 80 & 50 & 0,2 & 6,4 & 0,024 & 0,996 & 45,3 & 98 & 84,2 \\
\hline & $80 \_25$ & 80 & 25 & 0,2 & 5,7 & 0,027 & 0,988 & 40,7 & 99 & 88,9 \\
\hline & $80 \quad 25 \mathrm{r}$ & 80 & 25 & 0,2 & 3,7 & 0,026 & 0,980 & 41,5 & 99 & 91,3 \\
\hline & $80 \_0$ & 80 & 0 & 0,2 & 5,5 & 0,038 & 0,999 & 30,4 & 97 & 95,2 \\
\hline & $40 \_50$ & 40 & 50 & 0,2 & 7,6 & 0,016 & 0,995 & 65,5 & 99 & 60,0 \\
\hline & $40 \_25$ & 40 & 25 & 0,2 & 11,2 & 0,025 & 0,990 & 47,2 & 99 & 81,6 \\
\hline & 40 & 40 & 0 & 0,2 & 10,2 & 0,038 & 0,937 & 35,7 & 95 & 94,1 \\
\hline & $20 \_50$ & 20 & 50 & 0,2 & 17,6 & 0,010 & 0,995 & 102,9 & 93 & 25,1 \\
\hline & $20 \_25$ & 20 & 25 & 0,2 & 13,0 & 0,013 & 0,987 & 79,8 & 96 & 35,0 \\
\hline & 2010 & 20 & 10 & 0,2 & 10,87 & 0,017 & 0,975 & 66,34 & 98 & 52,4 \\
\hline & $20 \_5$ & 20 & 5 & 0,2 & 9,8 & 0,017 & 0,995 & 65,0 & 99 & 60,9 \\
\hline & 200 & 20 & 0 & 0,2 & 12,1 & 0,020 & 0,961 & 63,7 & 98 & 59,2 \\
\hline & $10 \_50$ & 10 & 50 & 0,2 & 34,2 & 0,008 & 0,996 & 155,4 & 74 & 14,3 \\
\hline & $10 \_25$ & 10 & 25 & 0,2 & 29,0 & 0,007 & 0,995 & 158,2 & 75 & 17,5 \\
\hline & $10 \_0$ & 10 & 0 & 0,2 & 13,4 & 0,011 & 0,980 & 97,9 & 97 & 31,0 \\
\hline \multirow{6}{*}{ Estrela } & $20 \_0 \mathrm{e}$ & 20 & 0 & 0,1 & 14,8 & 0,018 & 0,977 & 68,8 & 99 & 49,1 \\
\hline & $80 \_25 \mathrm{e}$ & 80 & 25 & 0,1 & 6,2 & 0,016 & 0,976 & 64,6 & 97 & 41,3 \\
\hline & $20 \_50 \mathrm{e}$ & 20 & 50 & 0,1 & 18,4 & 0,010 & 0,978 & 111,5 & 92 & 18,1 \\
\hline & $40 \quad 0 \mathrm{e}$ & 40 & 0 & 0,5 & 9,1 & 0,042 & 0,996 & 31,1 & 99 & 98,6 \\
\hline & $10 \_25 \mathrm{e}$ & 10 & 25 & 0,5 & 12,2 & 0,008 & 0,973 & 128,8 & 85 & 24,8 \\
\hline & $20 \_50 \mathrm{e}$ & 20 & 50 & 0,5 & 13,6 & 0,019 & 0,924 & 62,0 & 99 & 62,4 \\
\hline
\end{tabular}




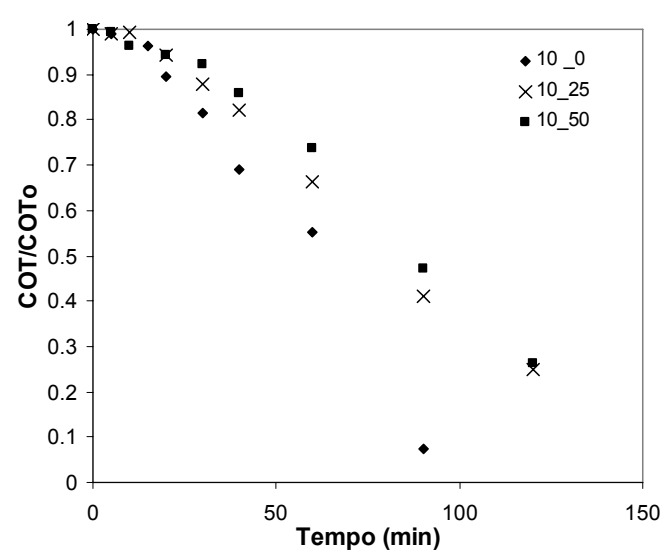

(a)

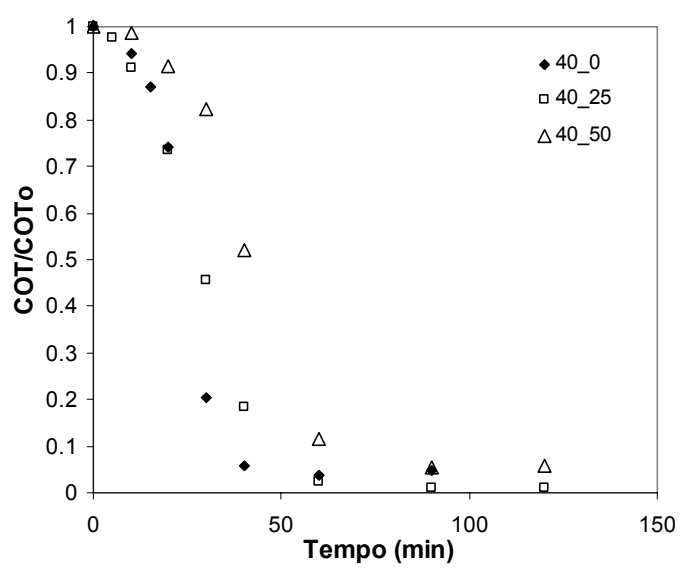

(c)

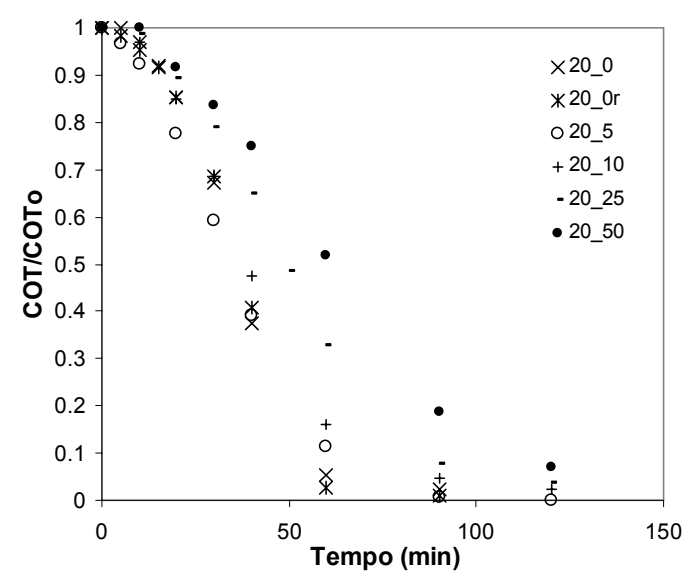

(b)

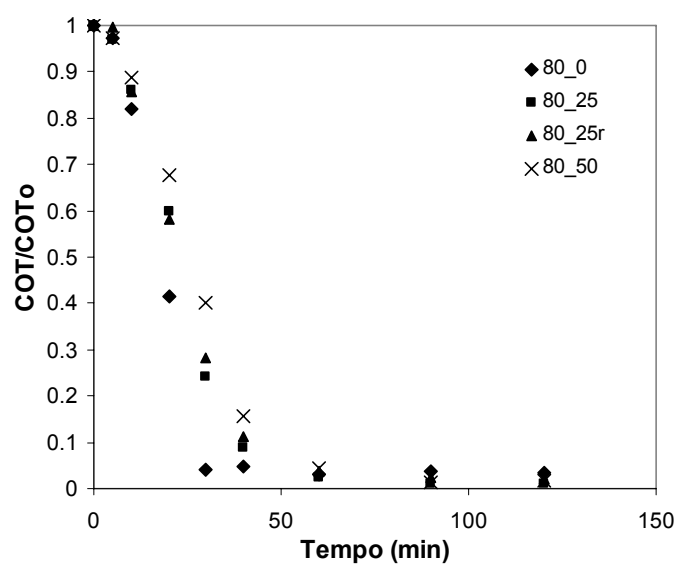

(d)

Figura 34 - Remoção de COT em função do tempo para as condições experimentais no plano central; $0,2 \mathrm{mM} \mathrm{Fe}(\mathrm{II})$ - processo foto-Fenton; $(\mathrm{a})\left[\mathrm{H}_{2} \mathrm{O}_{2}\right]=10$ $\mathrm{mM}$; (b) $\left[\mathrm{H}_{2} \mathrm{O}_{2}\right]=20 \mathrm{mM}$; (c) $\left[\mathrm{H}_{2} \mathrm{O}_{2}\right]=40 \mathrm{mM}$; (d) $\left[\mathrm{H}_{2} \mathrm{O}_{2}\right]=80 \mathrm{mM}$.

Os resultados apresentados na Figura 34 sugerem, como esperado, que o efeito da adição de $\mathrm{NaCl}$ ao processo exerce efeito negativo sobre a velocidade de remoção de COT. No entanto, os decaimentos da remoção de COT são próximos para concentrações de 5 e $10 \mathrm{~g} / \mathrm{L}$ de $\mathrm{NaCl}$ e para as concentrações de 25 e $50 \mathrm{~g} / \mathrm{L}$, sugerindo variação não linear entre a concentração do sal e a remoção de COT. Por outro lado, observa-se nos dois gráficos, Figura 34 (a) e (b), que a adição do sal impõe um limite na remoção final de COT, após 120 minutos, estabilizando a remoção de COT em valores próximos a 
$90 \%$, o que não ocorre nos experimentos sem adição do sal, em que a remoção de COT aproxima-se de $100 \%$. Os decaimentos de COT nos gráficos da Figura 34 mostram também que o efeito da concentração do sal é mais pronunciado para menores concentrações de $\mathrm{H}_{2} \mathrm{O}_{2}$, sugerindo que a diminuição da eficiência do processo pela presença de $\mathrm{NaCl}$ pode ser mitigada pelo aumento da concentração de oxidante.

Quanto às diferentes concentrações de $\mathrm{Fe}(\mathrm{II})$ estudadas pelo planejamento podem-se analisar graficamente algumas condições, como apresentado na Figura 35 (a) e (b). Esses resultados sugerem ligeiro aumento na eficiência de remoção de COT com o aumento da concentração de catalisador.

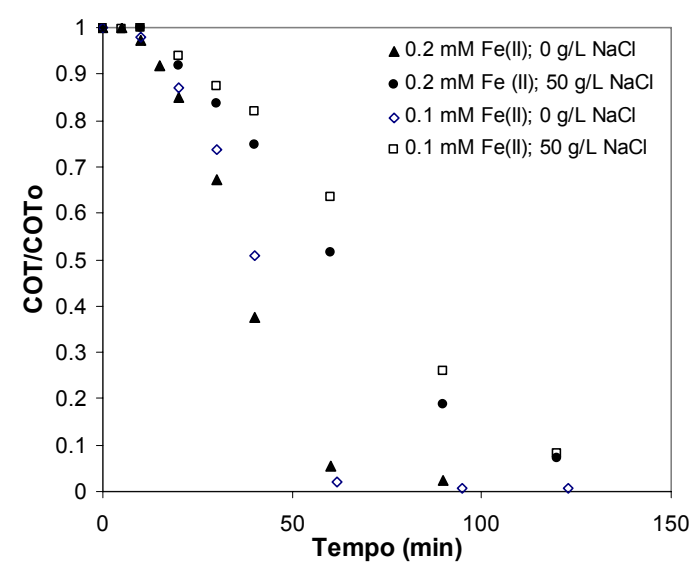

(a)

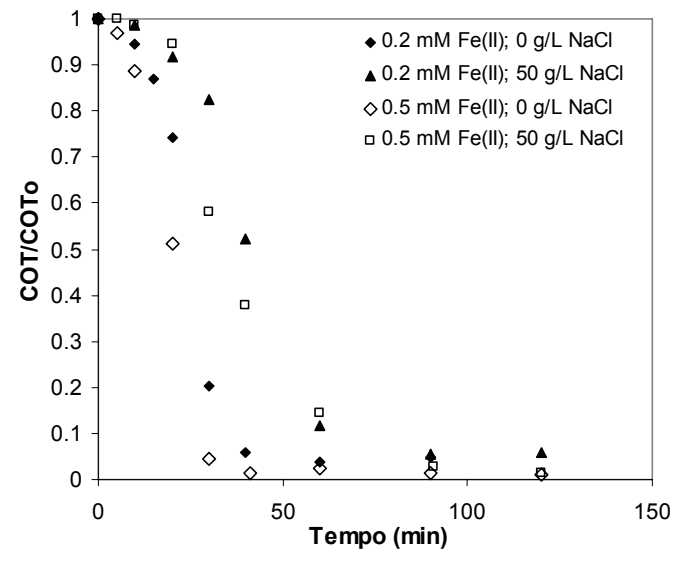

(b)

Figura 35 - Remoção de COT em função do tempo para as condições do planejamento experimental; efeito [Fe(II)] - processo foto-Fenton; (a) $\left[\mathrm{H}_{2} \mathrm{O}_{2}\right]=20 \mathrm{mM}$; $\left[\mathrm{H}_{2} \mathrm{O}_{2}\right]=40 \mathrm{mM} ;\left[\mathrm{H}_{2} \mathrm{O}_{2}\right]$.

Mediante as respostas apresentadas na Tabela 10 e as representações gráficas da Figura 32 (a) - (b) observa-se que as respostas $t_{1}$ e $\% R_{120}$ não possuem variação significativa para a maioria das condições em comparação com as respostas $k, t_{2} \mathrm{e} \% R_{40}$. A Figura 36 (a)-(c) apresenta a variação dessas respostas em função da concentração de $\mathrm{NaCl}$ para diferentes níveis da concentração de $\mathrm{H}_{2} \mathrm{O}_{2}$ para algumas das condições experimentais. 


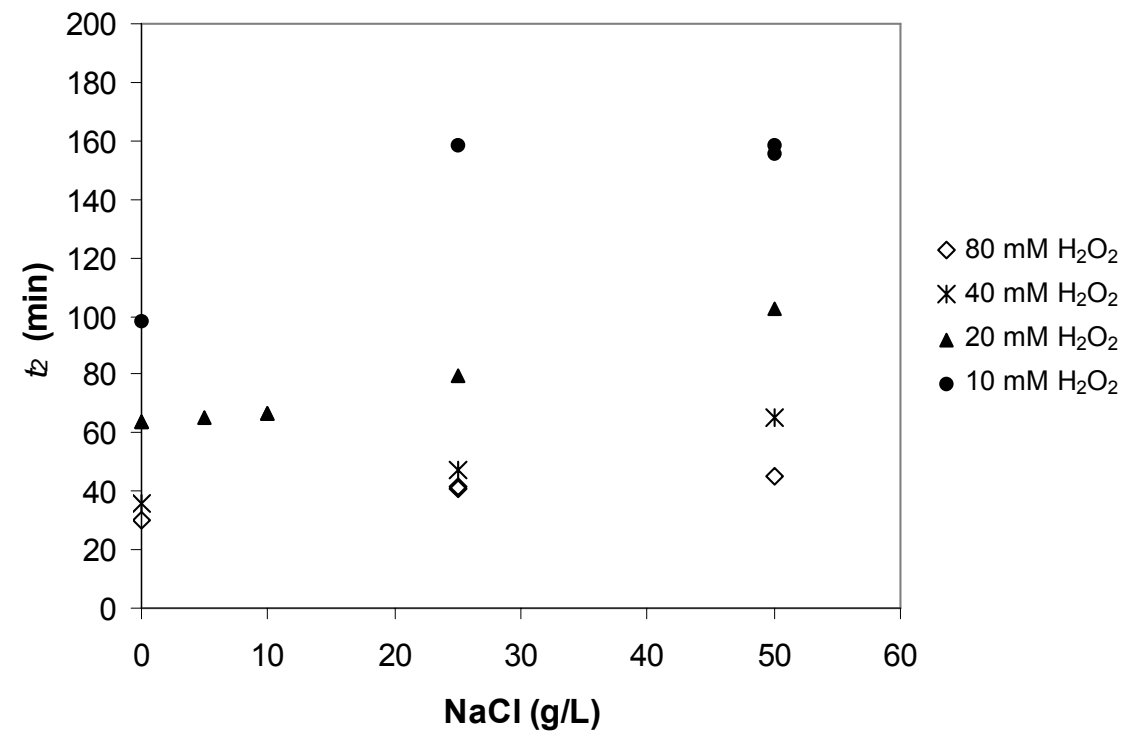

(a)

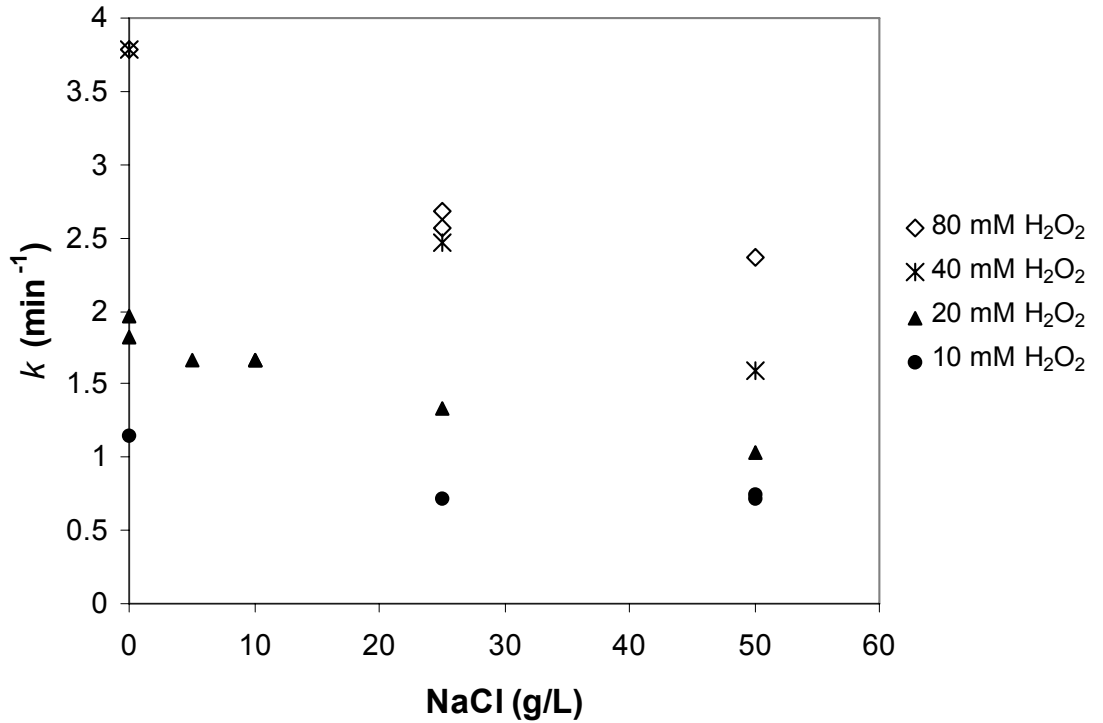

(b) 


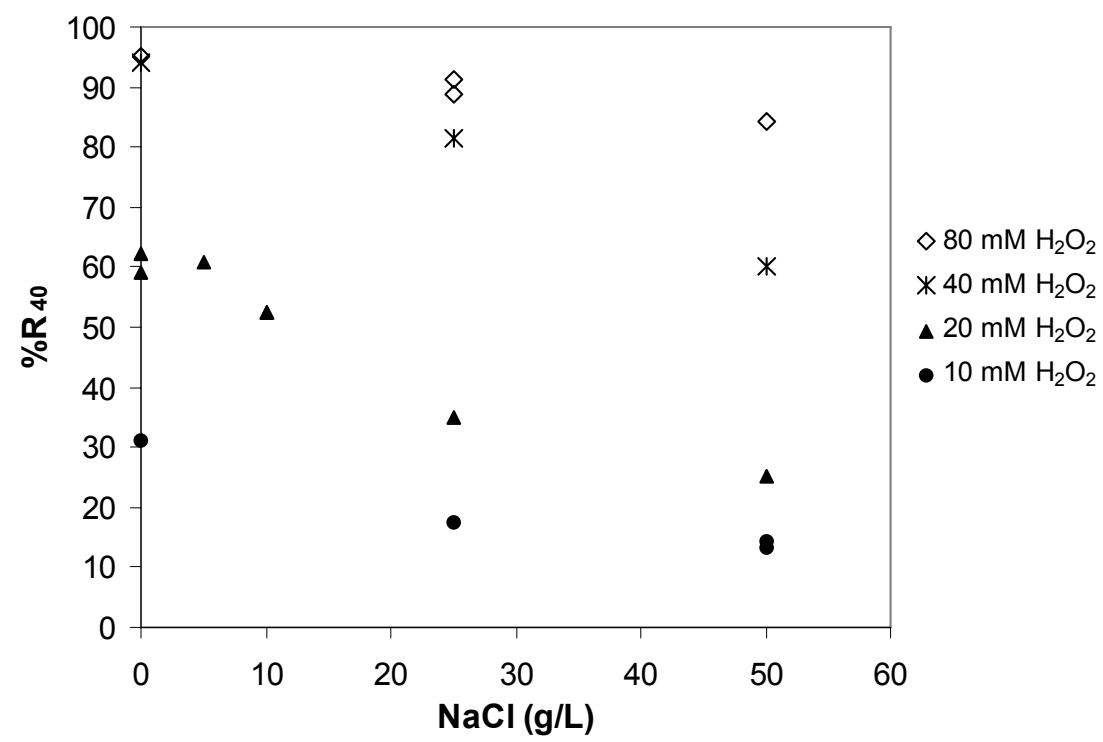

Figura 36 - Respostas em função da concentração de $\mathrm{NaCl}$ para diferentes concentrações de $\mathrm{H}_{2} \mathrm{O}_{2}$ para algumas condições experimentais; (a) $k$; (b) $t_{2}$; (c) $\% R_{40}$.

A partir das Figuras 36 (a)-(c) é possível verificar mais claramente os efeitos da concentração de $\mathrm{NaCl}$ na velocidade de remoção de COT observados nas Figuras 34 (a)(d). Os resultados mostram que a concentração de peróxido de hidrogênio e concentração de $\mathrm{NaCl}$ modificam substancialmente as respostas observadas. No caso de ausência de $\mathrm{NaCl}$ os resultados sugerem que a degradação aumenta gradativamente com o aumento da concentração de $\mathrm{H}_{2} \mathrm{O}_{2}$, atingindo o maior percentual de redução de COT em $40 \mathrm{mM}$, uma vez que não existem variações significativas entre 40 e $80 \mathrm{mM}$, indicando portanto que a partir desse valor o $\mathrm{H}_{2} \mathrm{O}_{2}$ estaria em excesso. No entanto, o valor limite de $\mathrm{H}_{2} \mathrm{O}_{2}$ aumenta significativamente com a adição de $\mathrm{NaCl}$ ao sistema, uma vez que íons cloreto em solução consomem o oxidante. Os resultados mostram também que o efeito da concentração de $\mathrm{NaCl}$ quanto à diminuição da remoção de COT é significativo para concentrações maiores que aproximadamente $10 \mathrm{~g} / \mathrm{L}$. Apenas para $\% R_{40}$ esse efeito é observado a partir de $5 \mathrm{~g} / \mathrm{L}$. Os resultados indicam ainda que concentrações menores que cerca de $10 \mathrm{~g} / \mathrm{L}$ não interferem significativamente na 
velocidade de remoção de $\mathrm{COT}$. A presença de $\mathrm{NaCl}$ em concentrações maiores que 50 $\mathrm{g} / \mathrm{L}$ apresenta uma tendência de desfavorecer o processo.

De modo geral, os resultados mostram-se coerentes quanto ao efeito da concentração de $\mathrm{NaCl}$ e $\mathrm{H}_{2} \mathrm{O}_{2}$ na remoção de COT.

Posteriormente um modelo empírico utilizando os resultados do planejamento experimental do processo foto-Fenton foi desenvolvido com o intuito de descrever matematicamente o comportamento da remoção de COT em função do tempo e integrálo com o processo de eletrodiálise

\subsubsection{Comparação com outros POAs}

O desempenho do processo foto-Fenton foi comparado com outros POAs em alguns experimentos utilizando os processos $\mathrm{UV} / \mathrm{H}_{2} \mathrm{O}_{2}$ e $\mathrm{UV} / \mathrm{TiO}_{2}$.

$\mathrm{O}$ processo $\mathrm{UV} / \mathrm{TiO}_{2}$ não apresentou resultados razoáveis de degradação de COT em relação aos outros processos avaliados, conforme mostrado na Figura 37. Já o processo $\mathrm{UV} / \mathrm{H}_{2} \mathrm{O}_{2}$ apresentou comportamento semelhante ao processo foto-Fenton quanto ao efeito negativo da presença de $\mathrm{NaCl}$ no decaimento do COT. No entanto, a remoção de COT é menor no processo $\mathrm{UV} / \mathrm{H}_{2} \mathrm{O}_{2}$. O processo foi avaliado a partir de um planejamento de dois fatores, em que os níveis das variáveis estudadas variaram entre 50 e $80 \mathrm{mM}$ para $\left[\mathrm{H}_{2} \mathrm{O}_{2}\right]$ e entre 0 e $50 \mathrm{~g} / \mathrm{L}$ para $[\mathrm{NaCl}]$. 


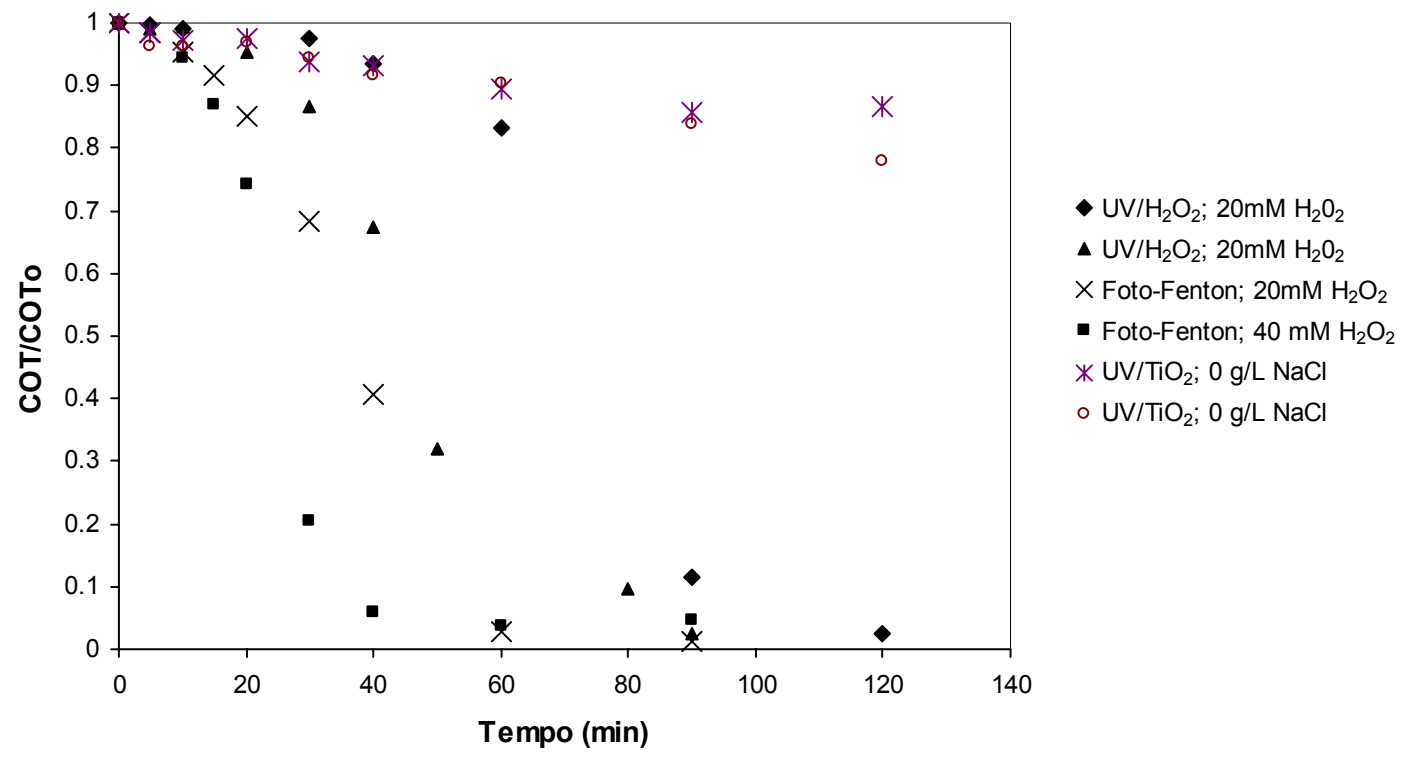

Figura 37 - Remoção de COT em função do tempo para algumas condições estudadas dos diferentes processos avaliados; $[\mathrm{Fe}(\mathrm{II})]=0,2 \mathrm{mM} ;\left[\mathrm{TiO}_{2}\right]=1 \mathrm{~g} / \mathrm{L}$. 


\section{Capítulo 5: MODELAGEM}

- Eletrodiálise

o Modelo Piloto

o Modelo Contínuo - estado estacionário

o Modelo Contínuo com Reciclo

- POA

o $\mathrm{RNA}_{1}$

o $\mathrm{RNA}_{2}$

o Modelo Contínuo

- Integração dos processos 
Os processos de eletrodiálise e foto-Fenton foram modelados matematicamente a partir dos parâmetros experimentais obtidos anteriormente. O objetivo dessa etapa é avaliar os processos em diferentes cenários, principalmente em modo contínuo. 


\subsection{Eletrodiálise}

O sistema de eletrodiálise foi descrito por um modelo genérico permitindo o estudo de diferentes configurações do processo, incluindo o modo contínuo, utilizandose os parâmetros de fluxo de solvente e solutos obtidos experimentalmente. A Figura 38 apresenta o esquema representativo utilizado e a nomenclatura das variáveis (vazões molares das correntes, $F$, e frações molares dos componentes, $X$ ). O subscrito $i$ representa os diferentes solutos e solvente, que serão representados posteriormente por $s$ para o $\mathrm{NaCl}, p$ para o fenol e $w$ para a água.

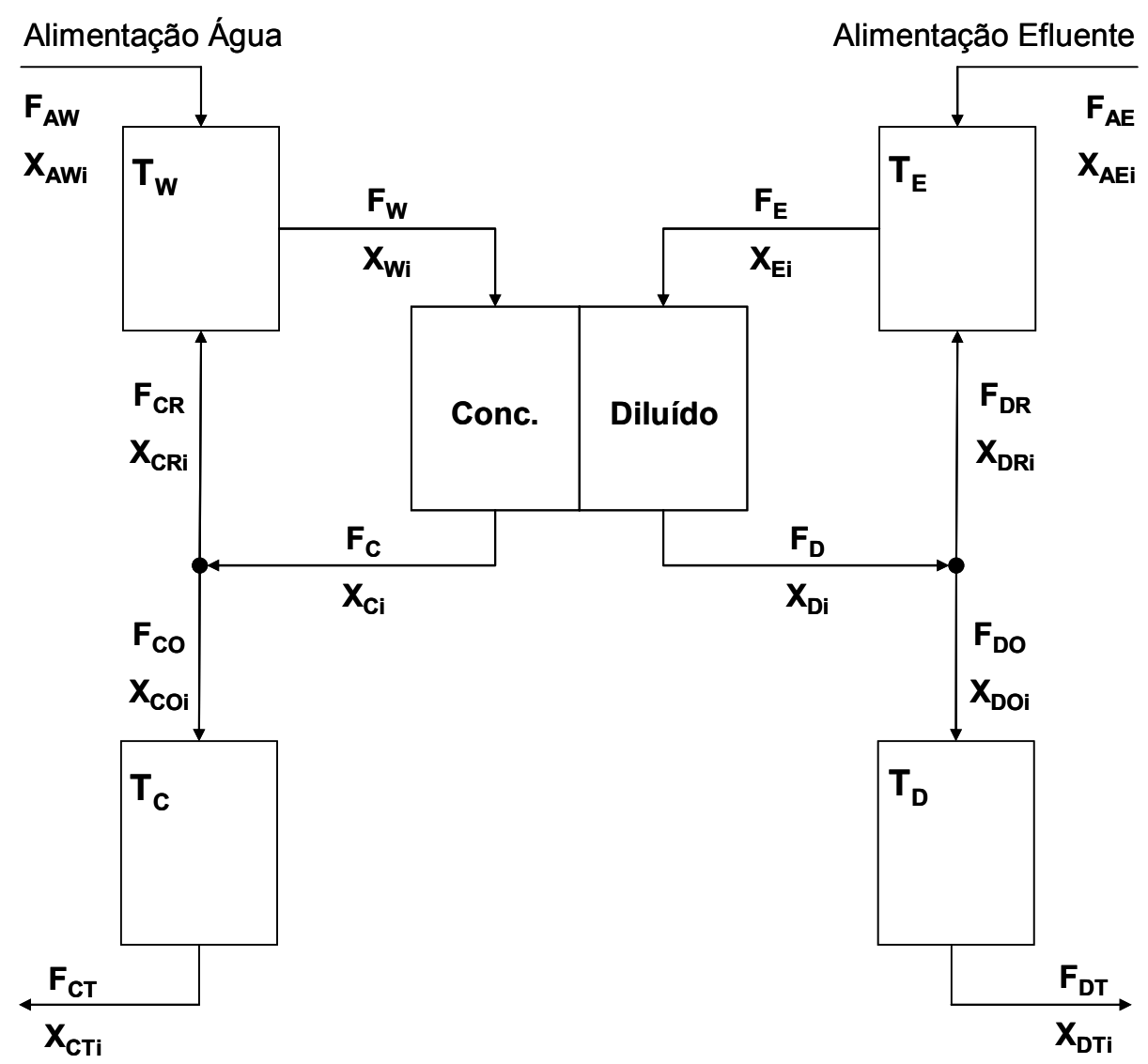

Figura 38 - Esquema do modelo desenvolvido para o processo de eletrodiálise; $F$ : fluxo molar; $X$ : fração molar; $T$ : tanque; subscrito $i$ : fenol, sal ou água. 
Considerando o sistema isotérmico, a densidade constante das correntes e os tanques perfeitamente agitados, as variações número de moles, $N$, e das frações molares, de sal; fenol e água com o tempo podem ser obtidas por balanço de molar para os compartimentos e as correntes representadas na Figura 38.

A Equação 40 apresenta o balanço molar total do sistema.

$F_{A W}+F_{A E}=F_{C T}+F_{D T}$

Iniciando pelo tanque $T_{W}$, sua variação de moles pode ser descrita pela Equação diferencial 41, em que $N_{W}$ é a quantidade de moles do tanque:

$\frac{d N_{W}}{d t}=F_{A W}+F_{C R}-F_{W}$

A Equação 42 apresenta a variação da quantidade para os diferentes componentes, $i$, sal, fenol e água, com o tempo em $T_{W}$.

$\frac{d X_{W i} N_{W}}{d t}=F_{A W} X_{A W i}+F_{C R} X_{C R i}-F_{W} X_{W i}$

A Equação 42 combinada com a Equação 41 resulta em:

$\frac{d X_{W i}}{d t}=\frac{1}{N_{W}}\left(F_{A W} X_{A W i}+F_{C R} X_{C R i}-F_{A W} X_{W i}-F_{C R} X_{W i}\right)$

Analogamente, as Equações 44 e 45 apresentam as variações de número de moles e fração molar no tanque $T_{E}$ :

$\frac{d N_{E}}{d t}=F_{A E}+F_{D R}-F_{E}$
$\frac{d X_{E i}}{d t}=\frac{1}{N_{E}}\left(F_{A E} X_{A E i}+F_{D R} X_{D R i}-F_{A E} X_{E i}-F_{D R} X_{E i}\right)$

Considerando o volume de soluções nos dois compartimentos da unidade de ED constante, a vazão molar de saída do compartimento do diluído pode ser expressa pela Equação 46 , em que $\dot{J}_{i}$ é o fluxo molar dos componentes e supondo $\dot{J}_{w}$ o fluxo molar da água.

$F_{D}=F_{E}-2 \dot{J}_{W} A-\left(\dot{J}_{s}+\dot{J}_{p}\right) A$ 
As concentrações de sal e fenol na célula são representadas pelas Equações 47 e 48.

$$
\begin{aligned}
& \frac{d X_{D s}}{d t}=\frac{1}{N_{E D}}\left(F_{E} X_{E s}-\dot{J}_{s} A-F_{D} X_{D s}\right) \\
& \frac{d X_{D p}}{d t}=\frac{1}{N_{E D}}\left(F_{E} X_{E p}-2 \dot{J}_{p} A-F_{D} X_{D p}\right)
\end{aligned}
$$

Vale ressaltar que o fluxo de fenol se dá através dos dois tipos de membranas, MTC e MTA. Já o sal atravessa cada tipo de membrana dissociado, por isso o fluxo é multiplicado pela área total de cada tipo de membrana, $A$.

As variações no compartimento do concentrado na célula resultam similarmente nas equações:

$$
\begin{aligned}
& F_{C}=F_{W}+2 \dot{J}_{W} A+\left(\dot{J}_{s}+\dot{J}_{p}\right) A \\
& \frac{d F_{C s}}{d t}=\frac{1}{N_{E D}}\left(F_{W} X_{W s}+\dot{J}_{s} A-F_{C} X_{C s}\right) \\
& \frac{d X_{C p}}{d t}=\frac{1}{N_{E D}}\left(F_{W} X_{W p}+2 \dot{J}_{p} A-F_{C} X_{C p}\right)
\end{aligned}
$$

As correntes de reciclo do sistema podem ser definidas pelas Equações 52 e 55, em que $R_{C}$ e $R_{D}$ correspondem às razões de reciclo dos compartimentos do concentrado e do diluído respectivamente.

$$
\begin{aligned}
& F_{C R}=R_{C} F_{C} \\
& F_{D R}=R_{D} F_{D}
\end{aligned}
$$

Com isto, as correntes de entrada dos tanques $T_{C}$ e $T_{D}$ resultam em:

$$
\begin{aligned}
& F_{C O}=F_{C}-F_{C R} \\
& F_{D O}=F_{D}-F_{D R}
\end{aligned}
$$

Para o tanque $T_{C}$ valem as equações:

$$
\frac{d N_{C}}{d t}=F_{C O}-F_{C T}
$$




$$
\begin{aligned}
& \frac{d X_{C T s}}{d t}=\frac{1}{N_{C}}\left(F_{C O} X_{C O S}-F_{C O} X_{C T s}\right) \\
& \frac{d X_{C T p}}{d t}=\frac{1}{N_{C}}\left(F_{C O} X_{C O p}-F_{C O} X_{C T p}\right)
\end{aligned}
$$

E finalmente para o tanque $T_{D}$ :

$$
\begin{aligned}
& \frac{d N_{D}}{d t}=F_{D O}-F_{D T} \\
& \frac{d X_{D T s}}{d t}=\frac{1}{N_{D}}\left(F_{D O} X_{D O s}-F_{D O} X_{D T s}\right) \\
& \frac{d X_{D T p}}{d t}=\frac{1}{N_{D}}\left(F_{D O} X_{D O p}-F_{D O} X_{D T p}\right)
\end{aligned}
$$

O valor de $1 \mathrm{~mm}$ foi utilizado como espaçamento típico entre as membranas de uma célula (Strathmann, 2004) para o cálculo do volume $\left(V_{E D}\right)$ para cada compartimento da célula de ED (diluído e concentrado). Assim, o volume de 0,0002 $\mathrm{m}^{3}$ foi adotado para $V_{E D}$ (correspondente a 10 compartimentos, com área de cada membrana igual a $0,02 \mathrm{~m}^{2}$ ). O número de moles na célula de ED nos compartimentos do diluído e concentrado, $N_{D}$ e $N_{C}$, respectivamente, foi calculado simplificadamente a partir do número de moles de água, uma vez que o número de moles de sal e fenol no compartimento podem ser desprezíveis em relação a esse componente.

O conjunto das equações apresentadas foi utilizado na elaboração de um algoritmo de simulação do sistema, com um programa escrito em código Matlab para a simulação de diferentes configurações do processo (o Anexo 2 apresenta os códigos utilizados para as simulações). Os diferentes cenários foram avaliados por praticidade em termos das variações das vazões volumétricas das correntes, $Q$, das concentrações mássicas dos componentes, $C$, e dos volumes dos tanques, $V$, utilizando as mesmas notações dos subscritos apresentados na Figura 38.

A influência das variáveis do modelo foi avaliada por análise de sensibilidade. Definindo $Y(x)$ como o resultado do modelo utilizando o valor $x$ do parâmetro, uma medida de sensibilidade conveniente pode ser representada pela Equação 62 (USEPA, 2001). 
Sensibilidade $=\frac{Y(x+0,1 x)-Y(x)}{0,1 Y(x)}$

A Equação 64 utiliza o resultado de uma determinada condição, que pode ser chamado de caso base, e a variação da resposta quando o parâmetro aumenta $10 \%$.

Quando o valor de sensibilidade é igual a 1, existe uma relação de um para um entre o valor do parâmetro e o resultado do modelo. Já quando o valor se aproxima de zero, o modelo é relativamente insensível ao parâmetro e quando é maior que 1, é muito sensível.

\subsubsection{Modelo Piloto}

O primeiro cenário representa a piloto de ED que foi utilizada nos experimentos, permitindo além da variação de alguns parâmetros envolvidos, a validação do modelo.

A planta piloto opera em batelada e, com reciclo total e vazão das correntes de entrada igual a zero (Figura 39).

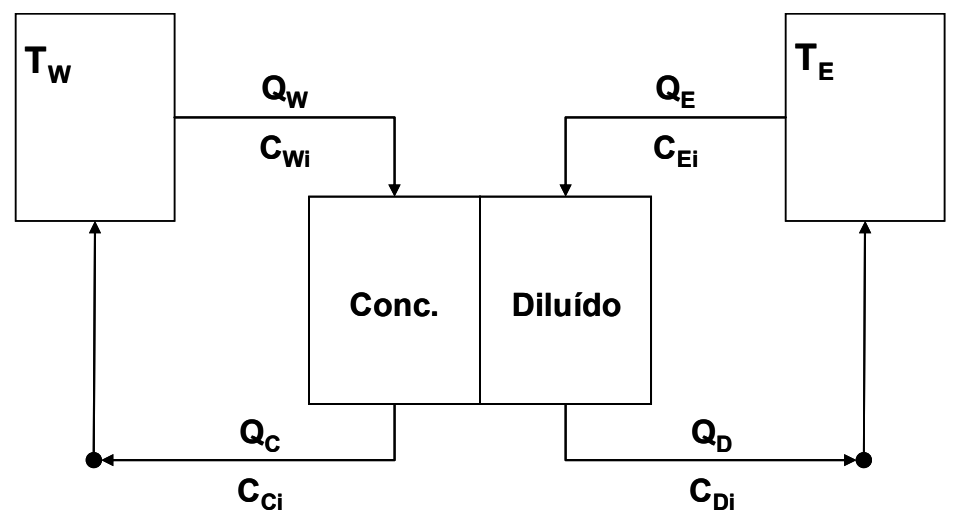

Figura 39 - Esquema da configuração do modelo piloto; $Q$ : vazão das correntes; $C$ : concentração dos componentes; subscrito $i$ : fenol e sal.

Os gráficos apresentados na Figura 40 foram utilizados na validação do modelo e apresentam a variação de volume (40(a)), concentração de sal (40(b)) e de fenol (40(c)) em 1 hora nos tanques $T_{E}$ e $T_{W}$ obtida pelo modelo e os pontos experimentais obtidos na 
mesma condição, ou seja: $\mathrm{i}=275 \mathrm{~A} / \mathrm{m}^{2} ; Q_{W}=Q_{E}=0,18 \mathrm{~m}^{3} / \mathrm{h}$; condições iniciais: $C_{W_{S}}=0$ $\mathrm{kg} / \mathrm{m}^{3}, C_{W_{P}}=0 \mathrm{~kg} / \mathrm{m}^{3}, C_{E_{S}}=50 \mathrm{~kg} / \mathrm{m}^{3}, C_{E_{P}}=0,087 \mathrm{~kg} / \mathrm{m}^{3}, C_{C_{S}}=0 \mathrm{~kg} / \mathrm{m}^{3}, C_{C_{P}}=0 \mathrm{~kg} / \mathrm{m}^{3}$, $C_{D_{S}}=50 \mathrm{~kg} / \mathrm{m}^{3}, \quad C_{D_{P}}=0,087 \mathrm{~kg} / \mathrm{m}^{3}, \quad V_{W}=V_{E}=0,002 \mathrm{~m}^{3}$ (volume de $T_{E}$ e $T_{W}$ respectivamente).

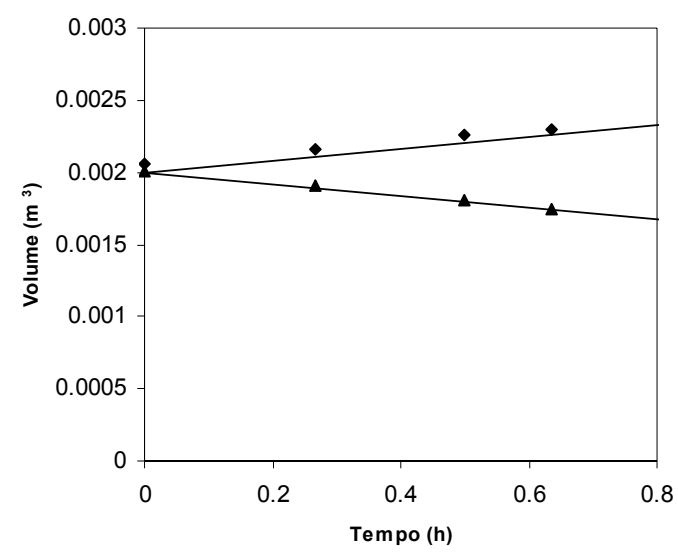

(a)

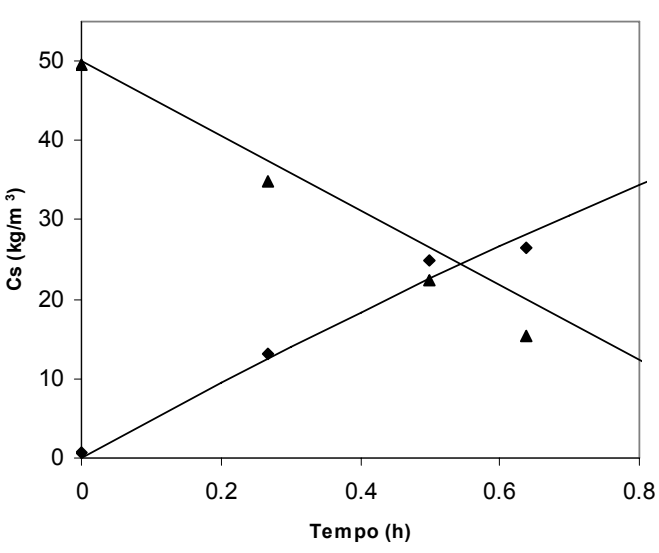

(b)

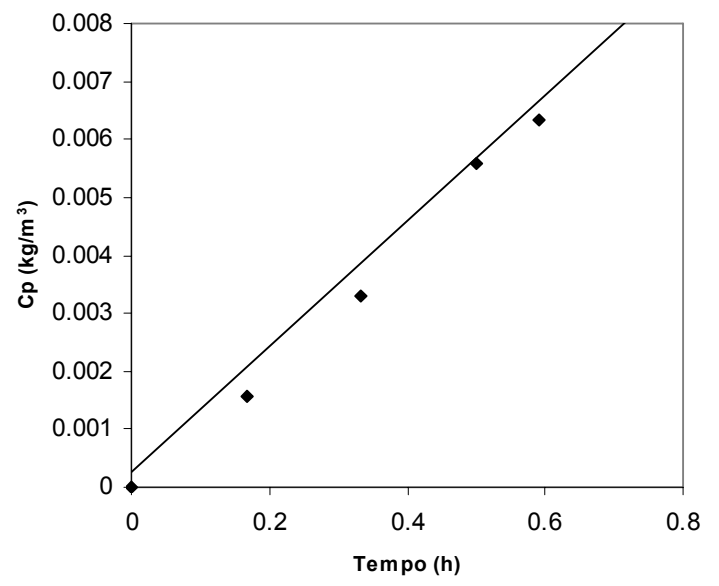

(c)

Figura 40 - Variação do volume (a), concentração de sal (b) e fenol (c) com o tempo nos tanques $T_{E}$ e $T_{W}$; predição modelo e valores experimentais; $i=275 \mathrm{~A} / \mathrm{m}^{2}$. 
Avaliando a sensibilidade do modelo em relação às vazões $Q_{W}$ e $Q_{E}$ e utilizando como resposta $C_{W_{P}}$, que é atrelada à perda de fenol para o concentrado, observa-se que o modelo é relativamente insensível em relação a esses parâmetros, pois foram obtidos os valores de $1.10^{-7}$ e $1.10^{-9}$ para a sensibilidade em relação a $Q_{W}$ e $Q_{E}$ respectivamente (Equação 64).

Esse resultado confirma o observado experimentalmente, pois não foram observadas mudanças significativas nos valores de $C_{W_{P}}$ ao se dobrarem os valores de $Q_{W}$ e $Q_{E}$ nas condições estudadas. No entanto, o tempo de residência é um fator importante a ser considerado nos processos de dessalinização por ED. Se as vazões de diluído e concentrado através da célula são relativamente altas a eficiência do processo é menor (Strathmann, 2004).

A sensibilidade do modelo em relação à densidade de corrente, $i$, e à área de membrana, $A$, é mostrada em termos da variação de $C_{W_{P}}$ e $C_{E_{S}}$ para diferentes valores dos parâmetros na Figura 41. O gráfico foi gerado a partir de simulações do modelo em diferentes condições.

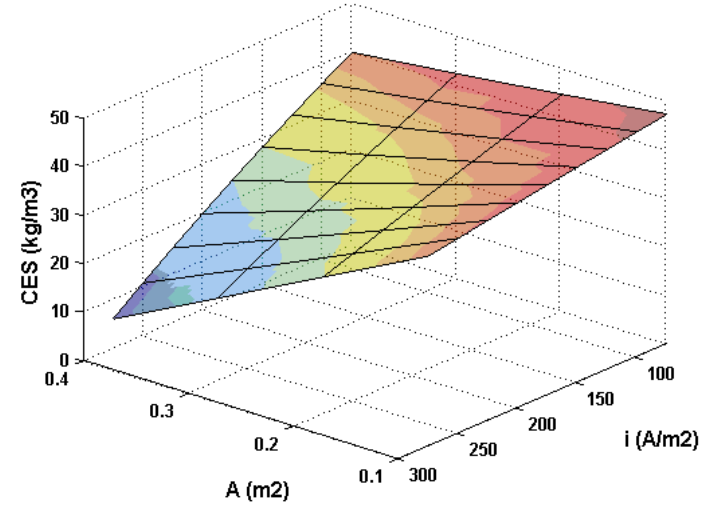

(a)

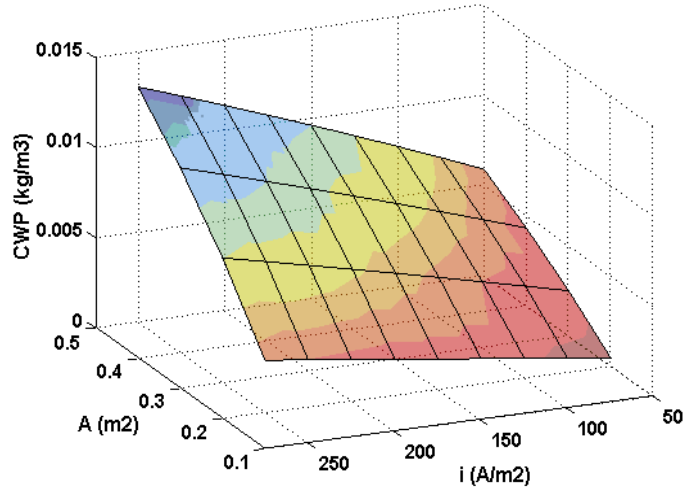

(b)

Figura 41 - Superfície de resposta para $C_{E_{S}}$ (a) e $C_{W_{P}}$ (b) em 30 minutos de operação em função da área de membrana, $A$, e da densidade de corrente, $i$. 
Como esperado, as superfícies de resposta das Figuras 41(a) e 41(b) indicam que nas condições estudadas a densidade de corrente e a área afetam significativamente as respostas $C_{E_{S}}$ e $C_{W_{P}}$, que representam a quantidade de sal removida e a perda de fenol para o concentrado. Na Figura 42 (a) e (b) é mostrado que o efeito da área da membrana é mais pronunciado para maiores valores de densidade de corrente.

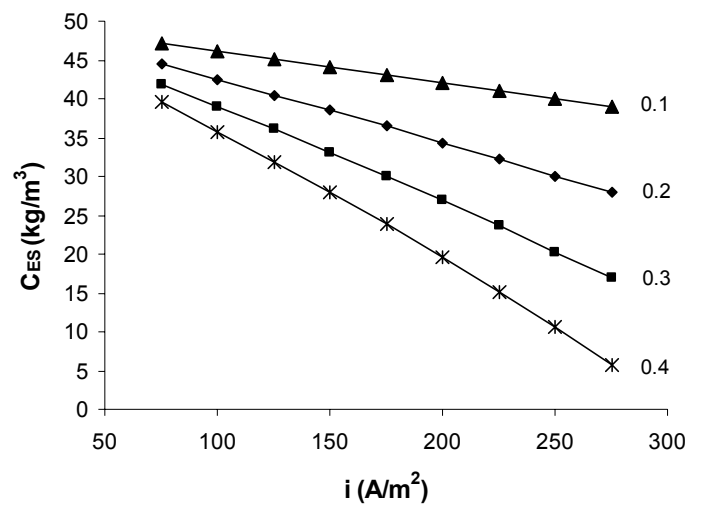

(a)

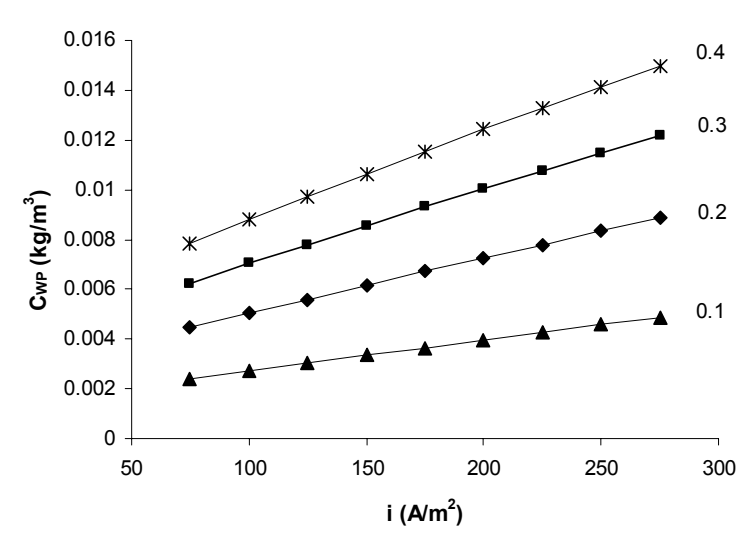

(b)

Figura 42 - Variação de $C_{W_{P}}$ (a) e $C_{E_{S}}$ (b) em função da densidade de corrente para diferentes valores de área de membrana $\left(\mathrm{m}^{2}\right)$ em 30 minutos de operação.

A análise de sensibilidade do modelo mostrou que $C_{W_{P}}$ é mais sensível às variações de área de membrana e densidade de corrente do que $C_{E_{S}}$ (Tabela 11).

Tabela 11 - Resultados da análise de sensibilidade de $C_{E_{S}}$ e $C_{W_{P}}$ em relação à área de membrana e densidade de corrente.

\begin{tabular}{|c|c|c|c|c|c|}
\hline \multirow{2}{*}{$Y$} & \multirow{2}{*}{$\begin{array}{c}\text { Caso base } \\
\begin{array}{c}i=175 \mathrm{~A} / \mathrm{m}^{2} \\
A=0,2 \mathrm{~m}^{2}\end{array}\end{array}$} & \multicolumn{2}{|c|}{ Variações } & \multirow{2}{*}{$\begin{array}{c}\text { Sensibilidade } \\
\text { A }\end{array}$} & \multirow{2}{*}{$\begin{array}{c}\text { Sensibilidade } \\
\text { i }\end{array}$} \\
\hline & & $A=0,22 \mathrm{~m}^{2}$ & $i=192,5 \mathrm{~A} / \mathrm{m}^{2}$ & & \\
\hline$C_{E_{S}}$ & 36,4 & 35,1 & 35,0 & $-0,35$ & $-0,40$ \\
\hline$C_{W_{P}}$ & 0,0067 & 0,0073 & 0,0071 & 0,83 & 0,57 \\
\hline
\end{tabular}




\subsubsection{Modo Contínuo - estado estacionário}

A operação da unidade de ED foi simulada em modo contínuo, com a configuração apresentada na Figura 43.

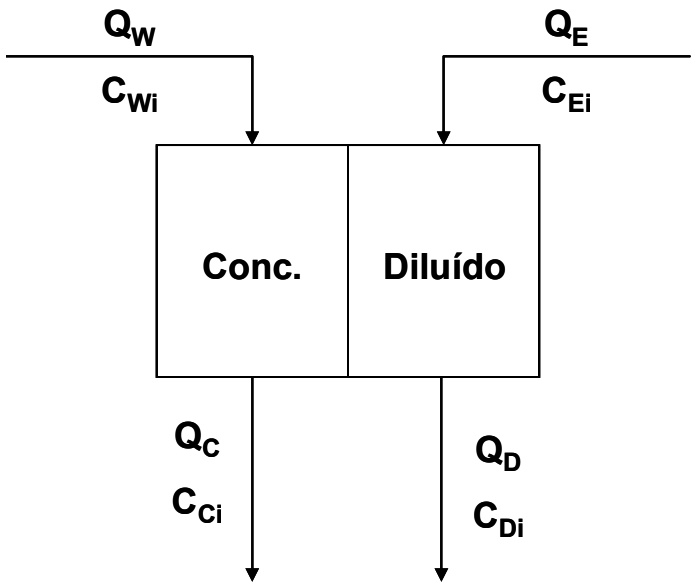

Figura 43 - Configuração para operação contínua em regime estacionário; $Q$ : vazão das correntes; $C$ : concentração; subscrito $i$ : fenol e sal.

A operação em estado estacionário possui dois parâmetros importantes de projeto, a área de membrana, $A$, e a densidade de corrente aplicada ao sistema, $i$. Neste contexto, foi avaliado o efeito da variação de $A$ e $i$ para a obtenção de diferentes percentuais de dessalinização, 60, 80 e 98\%, o que corresponde às seguintes concentrações de $\mathrm{NaCl}$ na corrente do diluído $\left(C_{D_{S}}\right)$ respectivamente: 20,10 e $1 \mathrm{~kg} / \mathrm{m}^{3}$. Os resultados obtidos são apresentados graficamente na Figura 44. 


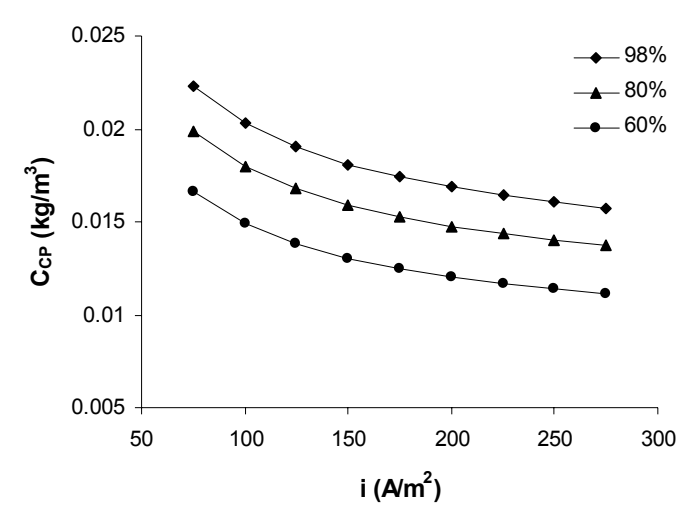

(a)

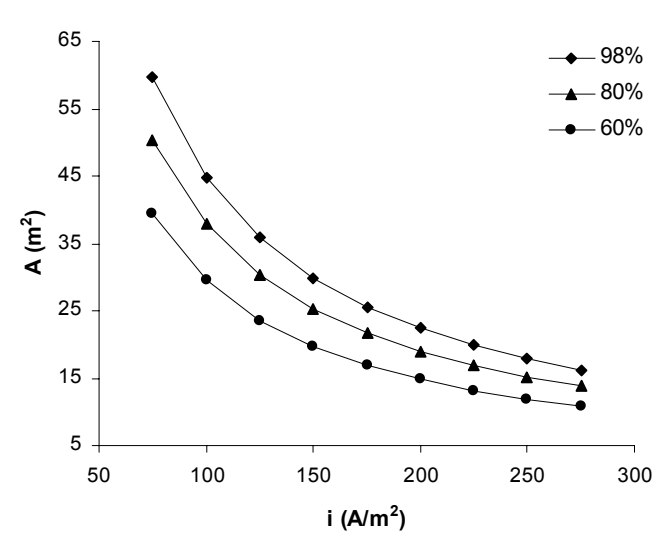

(b)

Figura 44 - Variação de (a) $C_{C_{P}}$ e $A$ (b) em função da densidade de corrente para diferentes percentuais de dessalinização.

De acordo com a Figura 44(a) a perda de fenol, $C_{C_{P}}$, é maior para densidades de correntes mais baixas. A partir de $150 \mathrm{~A} / \mathrm{m}^{2}$ o efeito não é tão pronunciado. A Figura 44(b) indica que a área das membranas para a dessalinização em diferentes percentuais é afetada significativamente pela densidade de corrente aplicada, $i$. O gráfico mostra a tendência do efeito tender assintoticamente a zero para altos valores de $i$.

$\mathrm{O}$ efeito de $A$ e $i$ nas principais respostas do processo, $C_{C_{P}}$ e $C_{D_{S}}$ pode ser também avaliado por análise de sensibilidade conforme apresentado na Tabela 12 . Conforme a análise, a dessalinização do efluente é significativamente sensível igualmente a $A$ e $i$. Já a perda de fenol, $C_{C_{P}}$, mostrou-se mais sensível à área de membranas do sistema do que à corrente aplicada. Foi utilizado como caso base 175 $\mathrm{A} / \mathrm{m}^{2}$ e $20 \mathrm{~m}^{2}$ para os valores de $i$ e $A$. 
Tabela 12 - Resultados da análise de sensibilidade de $C_{C_{P}}$ e $C_{D_{S}}$ em relação à área de membrana e densidade de corrente.

\begin{tabular}{|c|c|c|c|c|c|}
\hline \multirow{2}{*}{$\boldsymbol{Y}$} & Caso base & \multicolumn{2}{|c|}{ Variações } & \multirow{2}{*}{$\begin{array}{c}\text { Sensibilidade } \\
A\end{array}$} & $\begin{array}{c}\text { Sensibilidade } \\
i\end{array}$ \\
\cline { 2 - 4 } & $\begin{array}{c}i=175 \mathrm{~A} / \mathrm{m}^{2} \\
A=20 \mathrm{~m}^{2}\end{array}$ & $A=22 \mathrm{~m}^{2}$ & $i=192,5 \mathrm{~A} / \mathrm{m}^{2}$ & & \\
\hline$C_{C_{P}}$ & 0,014 & 0,016 & 0,015 & 0,80 & 0,54 \\
\hline$C_{D_{S}}$ & 13,5 & 9,1 & 9,1 & $-3,23$ & $-3,23$ \\
\hline
\end{tabular}

\subsubsection{Modelo Contínuo com Reciclo}

Finalmente, o efeito da razão de reciclo da corrente do concentrado, $R_{C}$, foi estudada no modelo em modo contínuo e estacionário segundo a Figura 45.

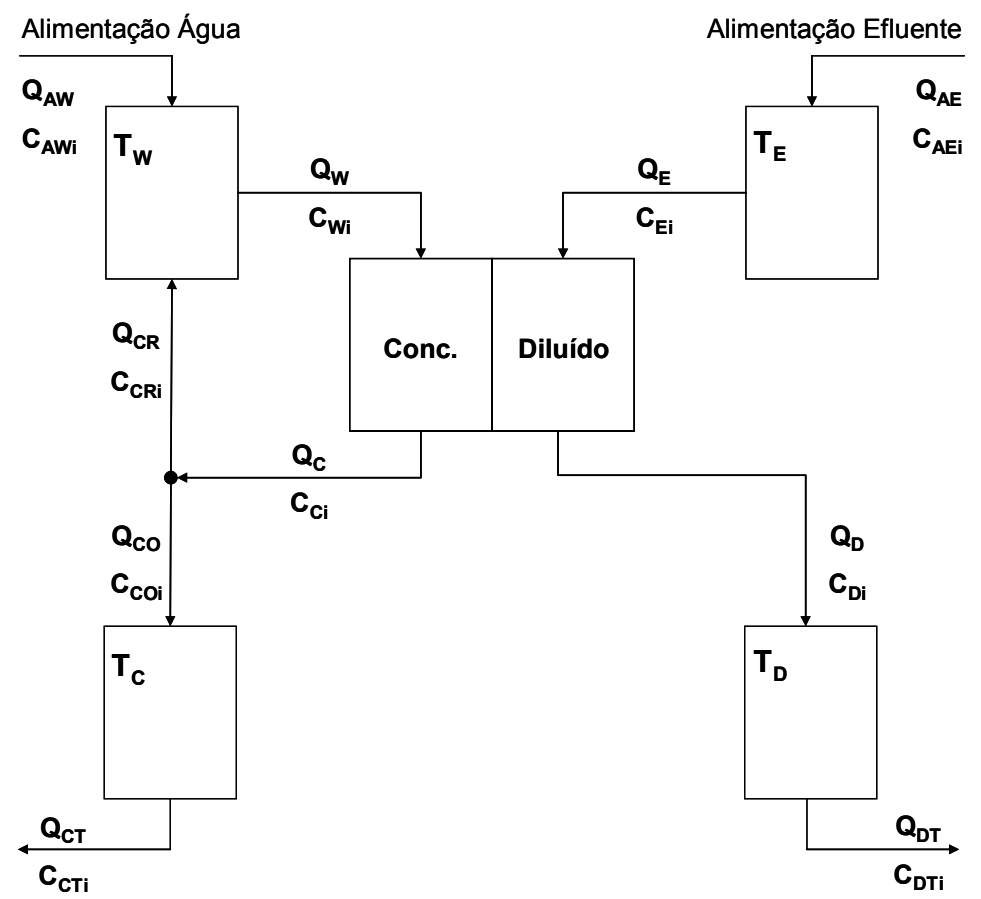

Figura 45 - Configuração do modelo contínuo com reciclo no concentrado; $Q$ : vazão das correntes; $C$ : concentração; subscrito $i$ : fenol e sal. 
O sistema de ED estudado pode apresentar vantagens com a reciclagem da corrente do concentrado, $Q_{C}$, uma vez que o consumo de água da alimentação, $Q_{W}$, e o vazão de efluente salino a ser tratado, $Q_{C T}$, diminuem com o aumento do percentual reciclado. Por outro lado, a concentração de fenol na saída do compartimento, $C_{C p}$, aumenta com o reciclo.

A concentração de sal da corrente do concentrado possui um limite de operação em função da solubilidade do sal, pois sua precipitação durante o processo pode danificar o sistema (solubilidade do $\mathrm{NaCl}$ em água é de aproximadamente 35,9 g/100 $\mathrm{mL}\left(25^{\circ} \mathrm{C}\right.$ e $\left.1 \mathrm{~atm}\right)$ (Perry e Green, 1999)), e a fim de evitar um fluxo 'retrodifusivo', em que o fluxo de sal devido à migração é menor que o fluxo difusivo do compartimento do concentrado para o diluído. Nas condições estudadas obteve-se um fluxo difusivo de aproximadamente $6,4 \cdot 10^{-3} \mathrm{~kg} / \mathrm{m}^{2} . \mathrm{h}$ para uma concentração de $55 \mathrm{~kg} / \mathrm{m}^{3}$.

A Figura 46 apresenta a variação da concentração de sal e fenol na corrente de saída do concentrado para diferentes percentuais de reciclo. A figura foi gerada a partir de simulações utilizando-se $175 \mathrm{~A} / \mathrm{m}^{2}$ e $20 \mathrm{~m}^{2}$ de área de membrana; o que resulta em $73 \%$ de dessalinização da corrente de alimentação em estado estacionário e um fluxo de sal de $0,347 \mathrm{~kg} / \mathrm{m}^{2} . \mathrm{h}$.

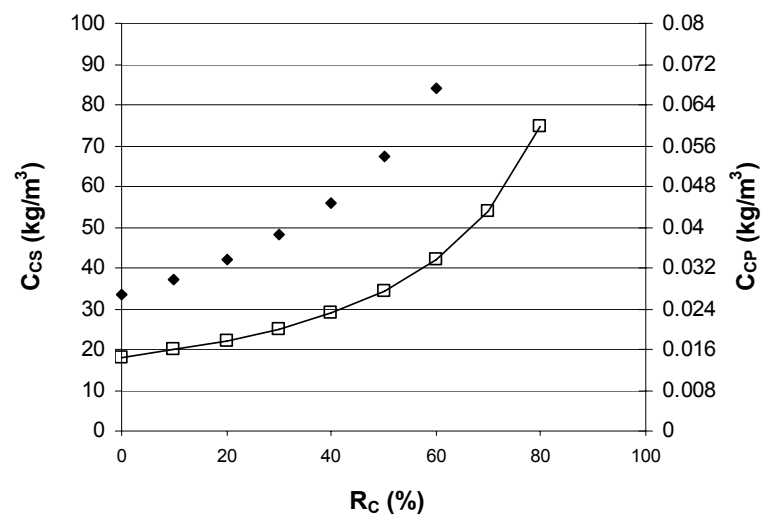

Figura 46 - Variação da concentração de sal (pontos) e fenol (linha e retângulos) em função do percentual reciclado - compartimento concentrado; $i=175 \mathrm{~A} / \mathrm{m}^{2}, A=20$

$$
\mathrm{m}^{2} \text {. }
$$


Como previsto, observa-se um aumento da concentração de sal e fenol no compartimento, conseqüência do acúmulo do modo de operação com reciclo.

Observa-se que, a partir de 50\% de reciclo, as variações dessas concentrações tornam-se mais pronunciadas. No entanto, os parâmetros do modelo foram obtidos para concentrações menores que $55 \mathrm{~kg} / \mathrm{m}^{3}$ no concentrado, portanto nada se pode dizer das predições maiores que esse valor. O modelo considerou apenas o fluxo devido à migração do sal, e nesse caso o fluxo difusivo deve ser considerado, pois torna-se uma variável significativa para o fluxo total de sal através das membranas.

A vazão de alimentação e conseqüente vazão de descarte diminuem proporcionalmente em função do percentual de reciclo. Para valores de reciclo, $R_{C}$, de 20 e $40 \%$ as vazões $Q_{A W}$ e $Q_{C T}$ sofrem redução de 4 e $8 \%$ respectivamente.

Observa-se, nas simulações, que o aumento da razão de reciclo do concentrado diminui o fluxo de fenol através das membranas, o que é favorável para o processo, já que a perda de fenol para o concentrado é menor. Como mencionado anteriormente, o modelo considerou duas contribuições para o fluxo do fenol: difusiva e convectiva, e foram descritas no modelo segundo a Equação 63 (seguindo as notações de concentração de fenol apresentadas na Figura 38.

$$
J_{p}=J_{p}^{\text {diff }}+J_{p}^{\text {conv }}=P_{p}\left(C_{D_{P}}-C_{C_{P}}\right)+C_{D p}(1-\sigma) J_{w}
$$

O fluxo difusivo é afetado pelo aumento da concentração de fenol no concentrado; já o fluxo convectivo, que depende da concentração de fenol no diluído, não sofre alterações consideráveis. As variações desses fluxos e das concentrações de fenol pertinentes são apresentadas na Figura 47(a) e (b).

Pode-se observar que em estado estacionário o fluxo de fenol diminui cerca de $2 \%$ para um percentual de reciclo de $30 \%$. 


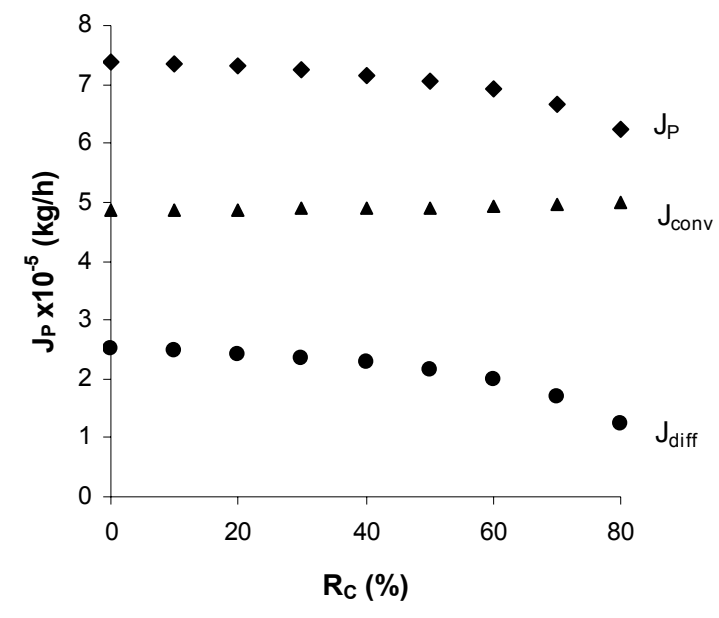

(a)

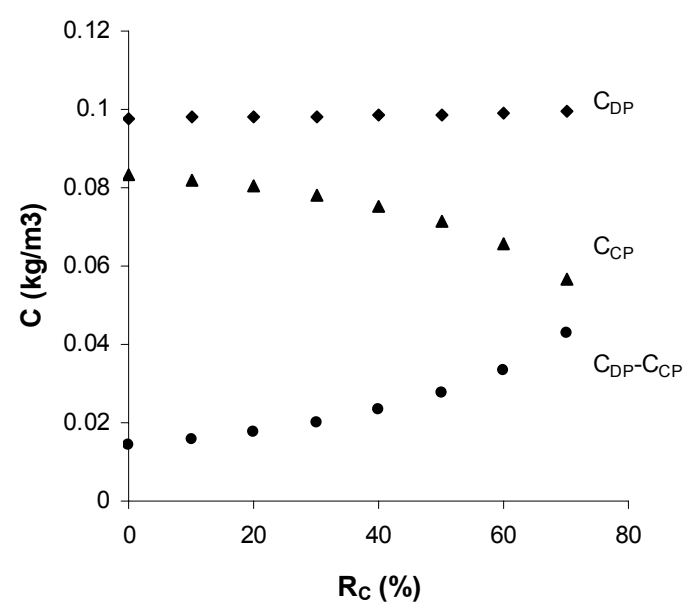

(b)

Figura 47 - (a) Fluxos de fenol: total, $J_{P}$, convectivo, $J_{\text {conv }}$, e difusivo, $J_{\text {diff }}$, (b) Concentrações de fenol no diluído, $C_{D_{P}}$, concentrado, $C_{C_{P}}$, e diferença entre elas, $\left(C_{D_{P}}-C_{C_{P}}\right)$, versus percentual reciclado - compartimento concentrado; $i=175 \mathrm{~A} / \mathrm{m}^{2}$,

$$
A=20 \mathrm{~m}^{2} \text {. }
$$

O efeito da razão de reciclo nas principais respostas do processo, $C_{C_{S}}$ e $C_{C_{p}}$ pode ser também avaliado por análise de sensibilidade conforme apresentado na Tabela 13. Conforme a análise, as duas variáveis são sensíveis ao reciclo da corrente do concentrado, apresentando praticamente uma variação de um para um. Foi utilizado como caso base a operação sem reciclo, $R_{C}=0$, e $175 \mathrm{~A} / \mathrm{m}^{2}$ e $20 \mathrm{~m}^{2}$ para os valores de $i$ e $A$.

Tabela 13 - Resultados da análise de sensibilidade de $C_{C_{S}}$ e $C_{C_{P}}$ em relação ao percentual de reciclo.

\begin{tabular}{|c|c|c|c|}
\hline \multirow{2}{*}{$\boldsymbol{Y}$} & Caso base & Variações & \multirow{2}{*}{ Sensibilidade } \\
\cline { 2 - 4 } & $\% R_{C}=0$ & $\% R_{C}=10$ & \\
\hline$C_{C_{S}}$ & 33,6 & 37,3 & 1,11 \\
\hline$C_{C_{P}}$ & 0,014 & 0,016 & 1,05 \\
\hline
\end{tabular}




\subsection{POA}

Um modelo baseado em redes neurais foi desenvolvido para simular a taxa de degradação de poluente com base no ajuste dos dados experimentais com o processo Foto-Fenton. Primeiramente foi ajustada uma rede neural aos dados de COT versus tempo, com a obtenção de um modelo para simulação dos experimentos no reator fotoquímico em batelada. Esse modelo foi usado na geração de perfis "suavizados" de COT versus tempo, os quais foram usados para obtenção de valores da taxa de degradação para cada condição experimental. Esses valores foram usados no ajuste de um segundo modelo de rede neural, para estimativa da taxa de reação em função das variáveis de processo consideradas. Esse modelo de taxa de degradação foi usado nas simulações do processo em diferentes configurações. A abordagem utilizada é apresentada no diagrama da Figura 48.

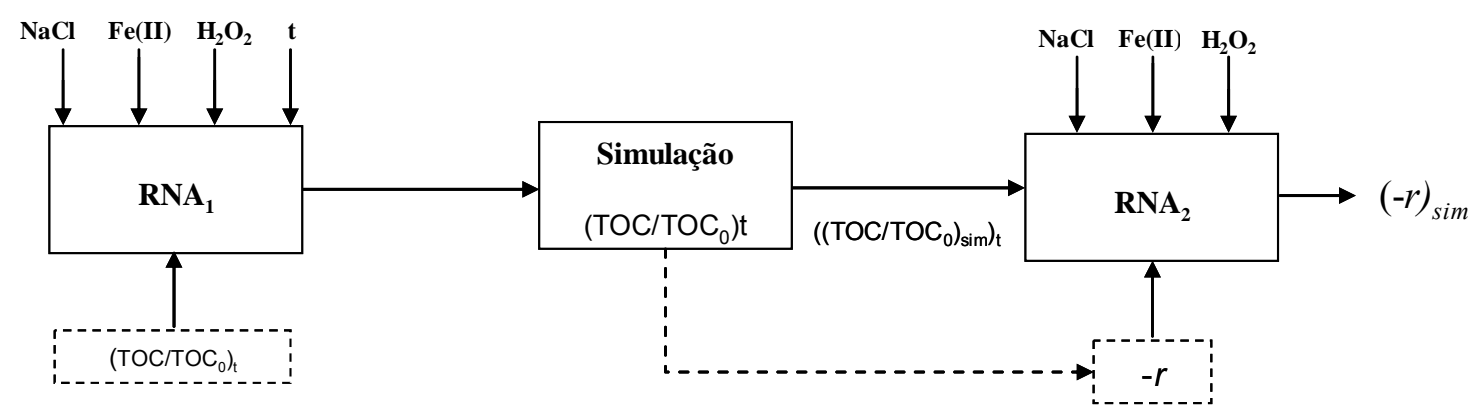

Figura 48 - Diagrama ilustrativo do modelo de redes neurais para estimativa da taxa de degradação $(-r)_{\text {sim }}$.

O objetivo do primeiro modelo de rede neural $\left(\mathrm{RNA}_{1}\right)$ é simular o que foi obtido experimentalmente, a variação do decaimento de COT (COT/COT $)$ com o tempo em função da concentração de $\mathrm{NaCl}, \mathrm{H}_{2} \mathrm{O}_{2}$ e $\mathrm{Fe}(\mathrm{II})$. A resposta ou variável de saída da $\mathrm{RNA}_{1}$ é $C O T / C O T_{0}$ em um determinado tempo: $\left(C O T / C O T_{0}\right)_{t}$.

A partir da $\mathrm{RNA}_{1}$ foi possível simular o $C O T / C O T_{0}$ no tempo experimental ( 0 a $120 \mathrm{~min})$ em diferentes condições para obter $\left(\left(C O T / C O T_{0}\right)_{t}\right)_{s i m}$. Com os valores 
simulados a taxa de reação foi calculada para cada valor de $\left.\left(\left(C O T / C O T_{0}\right)\right)_{t}\right)_{\operatorname{sim}}$ segundo a Equação 64:

$$
r=\frac{\left(C O T / C O T_{0}\right)_{t_{i}}-\left(C O T / C O T_{0}\right)_{t_{i-1}}}{t_{i}-t_{i-1}}
$$

Os itens a seguir descrevem o procedimento para a obtenção dos modelos de $\mathrm{RNA}_{1}, \mathrm{RNA}_{2}$.

\subsubsection{RNA $_{1}$}

O programa para ajuste e simulação das redes neurais utilizadas neste trabalho foi desenvolvido pelo Laboratório de Simulação e Controle de Processos (LSCP) da Escola Politécnica da Universidade de São Paulo. O programa gera um arquivo de saída com o relatório do ajuste e um arquivo de simulação, que contem os pesos da rede.

Após o tratamento dos dados experimentais, em que dados anômalos foram eliminados, o conjunto de dados foi separado em dois grupos: conjunto de aprendizado (LS), Learning Set, contendo cerca de $80 \%$ dos dados, e conjunto de teste (TS), Test Set. O LS é utilizado para o treinamento da rede em si, ou seja, ajuste dos parâmetros da rede, devendo conter um número de dados que constitua uma amostra representativa. Já o TS verifica a capacidade de predição da rede sob condições reais de utilização. O treinamento da rede tem como objetivo minimizar o erro médio quadrático entre os dados experimentais e modelados, modificando os pesos sinápticos da rede iterativamente.

O conjunto de dados da $\mathrm{RNA}_{1}$ possuia 200 pontos experimentais. As variáveis de entrada foram normalizadas entre 0,1 e 0,9 . Os valores mínimos e máximos das variáveis de entrada da $\mathrm{RNA}_{1}$, tempo de reação $(t)$, concentração de peróxido de hidrogênio total $\left(\left[\mathrm{H}_{2} \mathrm{O}_{2}\right]\right)$, concentração de cloreto de sódio ([NaCl]), concentração de $\mathrm{Fe}(\mathrm{II})([\mathrm{Fe}(\mathrm{II})])$, são apresentados na Tabela 14: 
Tabela 14 - Valores máximos e mínimos de entrada da RNA .

\begin{tabular}{|c|c|c|c|c|}
\hline \multirow{2}{*}{ Variáveis } & \multicolumn{4}{|c|}{ Entradas } \\
\cline { 2 - 5 } & $\begin{array}{c}\boldsymbol{t} \\
(\mathbf{m i n})\end{array}$ & $\begin{array}{c}{\left[\mathbf{H}_{\mathbf{2}} \mathbf{O}_{\mathbf{2}}\right]} \\
(\mathbf{m M})\end{array}$ & $\begin{array}{c}{[\mathbf{N a C l}]} \\
(\mathbf{g} / \mathbf{L})\end{array}$ & $\begin{array}{c}{[\mathbf{F e}(\mathbf{I I})]} \\
(\mathbf{m M})\end{array}$ \\
\hline Mínimo & 0 & 10 & 10 & 0,1 \\
\hline Máximo & 120 & 80 & 50 & 0,5 \\
\hline
\end{tabular}

O conjunto de dados foi dividido aleatoriamente nos grupos LS e TS e a rede foi treinada, variando-se o número de neurônios na camada oculta $(\mathrm{NH})$, o número de apresentações e parâmetros de treinamento (como a taxa de atualização dos pesos, por exemplo).

Os relatórios de ajuste dos diversos modelos obtidos foram observados por diferentes critérios:

- variação do erro quadrático do TS;

- comparação dos resultados modelados e experimentais para o LS e o TS;

- avaliação dos resultados simulados.

Este último critério foi adotado na decisão final da escolha da rede, pois é possível observar diretamente o desempenho do modelo.

Os modelos com 4 a 12 neurônios na camada oculta apresentaram melhor ajuste. A Figura 49 apresenta a variação da raiz quadrada do erro quadrático médio do Test set, RMSTT, em função do número de apresentações. Observa-se que, a partir de 10 neurônios, o RMSTT não apresentou diminuição significativa e que a rede com NH = 12 apresentou maior erro quadrático do que com $\mathrm{NH}=11$. 


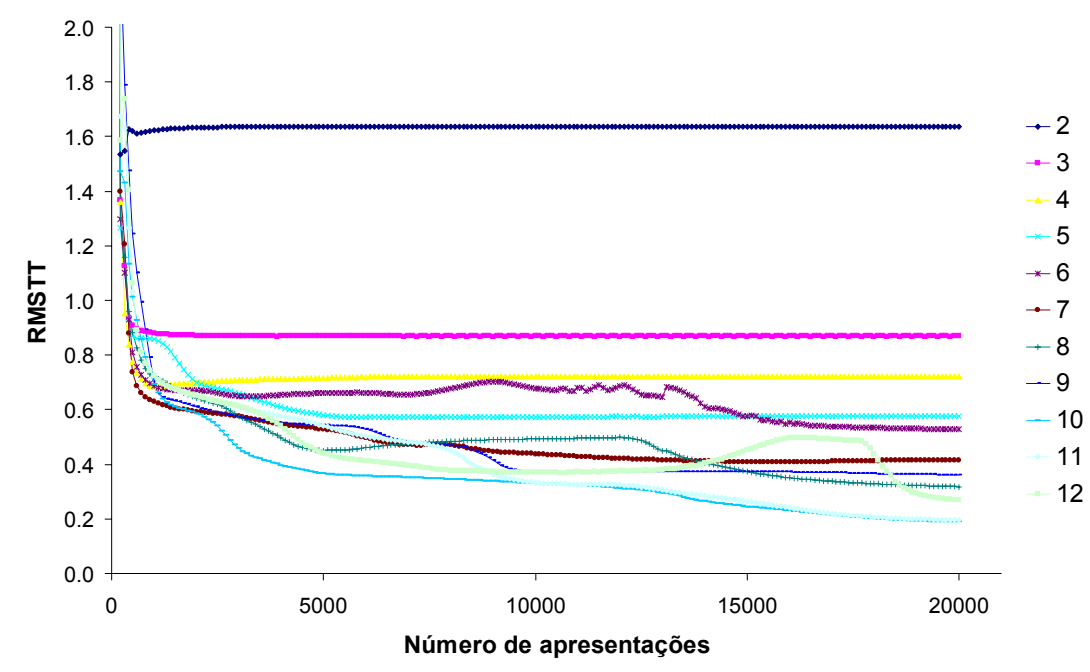

Figura 49 - RMSTT (Test set) em função do número de apresentações para a $\mathrm{RNA}_{1}$ para diferentes números de neurônios.

Analisando as simulações das diferentes redes, foram observados efeitos de sobreajuste nas redes com NH a partir de 5. Para alguns períodos de tempo de reação e determinadas condições, os valores de COT aumentaram com o tempo. Com isso, a configuração da $\mathrm{RNA}_{1}$ selecionada foi de $\mathrm{NH}$ igual a 4, que apresentou bom ajuste. A Figura 50 apresenta a comparação entre os valores de $C O T / C O T_{0}$ calculados pelo modelo e os dados experimentais para o LS e o TS (coeficientes de correlação iguais a 0,966 e 0,965 , respectivamente). 


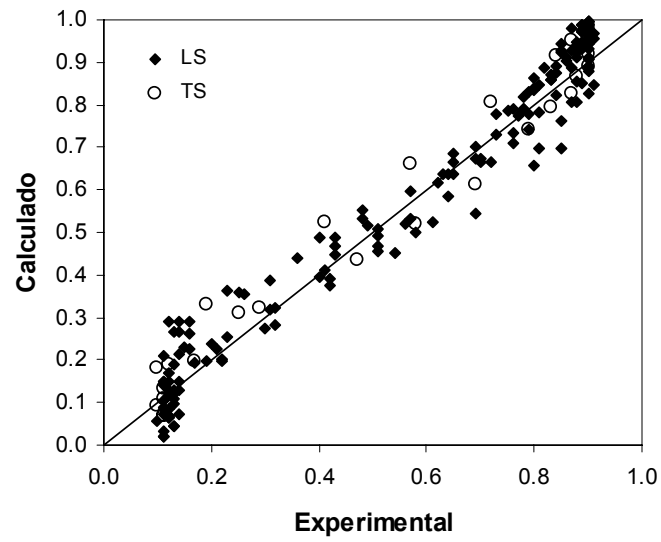

Figura 50 - Resultados experimentais versus calculados de $C O T / C O T_{0}$ para $\mathrm{RNA}_{1}$.

A Figura 51 apresenta uma comparação entre resultados experimentais de $C O T / C O T_{0}$ em função do tempo de reação com resultados calculados pelo modelo para experimentos do Test set. Observa-se que modelo ajustado reproduz o comportamento observado experimentalmente.

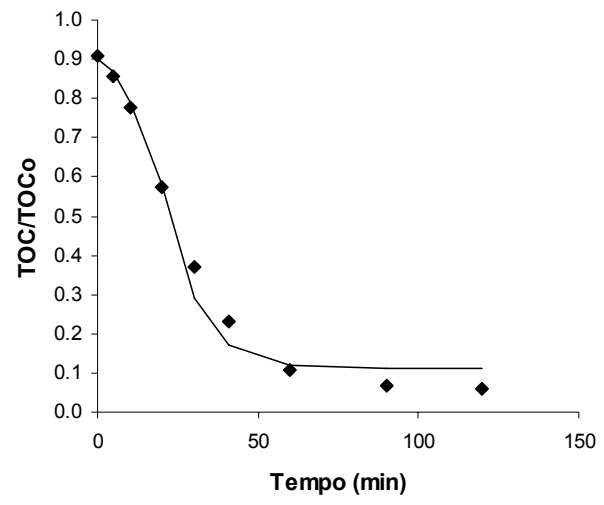

(a)

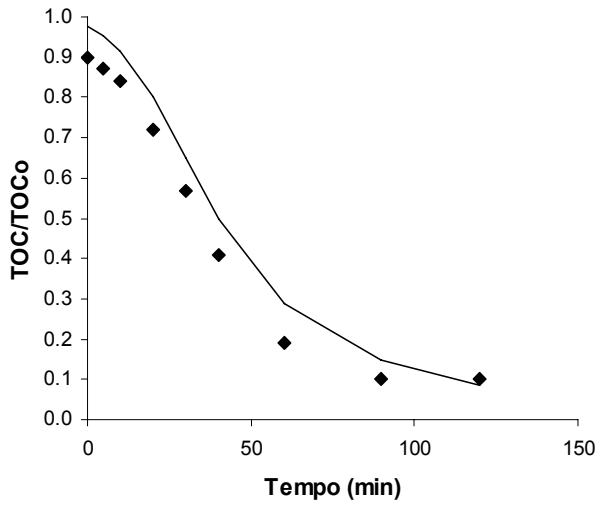

(b) 


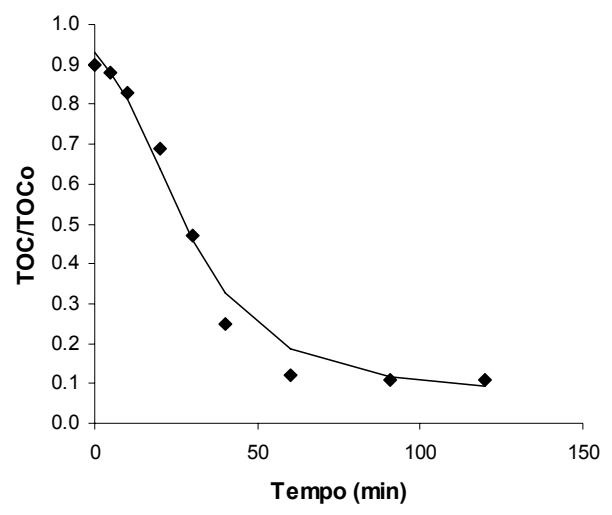

(c)

Figura 51 - Resultados experimentais (pontos) e calculados (linha cheia) para experimentos do Test set; (a) $\left[\mathrm{H}_{2} \mathrm{O}_{2}\right]=80 \mathrm{mM},[\mathrm{NaCl}]=25 \mathrm{~g} \mathrm{~L}^{-1},[\mathrm{Fe}(\mathrm{II})]=0,2 \mathrm{mM}$; (b) $\left[\mathrm{H}_{2} \mathrm{O}_{2}\right]=20 \mathrm{mM},[\mathrm{NaCl}]=5 \mathrm{~g} / \mathrm{L},[\mathrm{Fe}(\mathrm{II})]=0,2 \mathrm{mM}$; (c) $\left[\mathrm{H}_{2} \mathrm{O}_{2}\right]=40 \mathrm{mM},[\mathrm{NaCl}]=25 \mathrm{~g} / \mathrm{L}$, $[\mathrm{Fe}(\mathrm{II})]=0,2 \mathrm{mM}$;

A análise do modelo obtido para $\mathrm{RNA}_{1}$ também pode ser feita observando a remoção de COT em diferentes tempos de reação, 30 e 40 minutos, como apresentado na Figura 52.

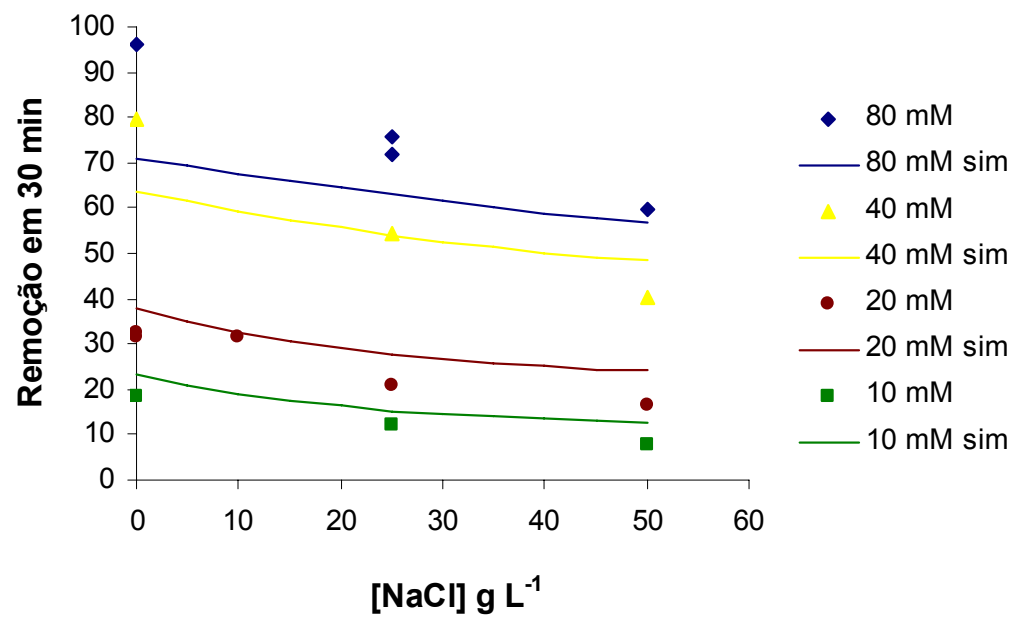

(a) 


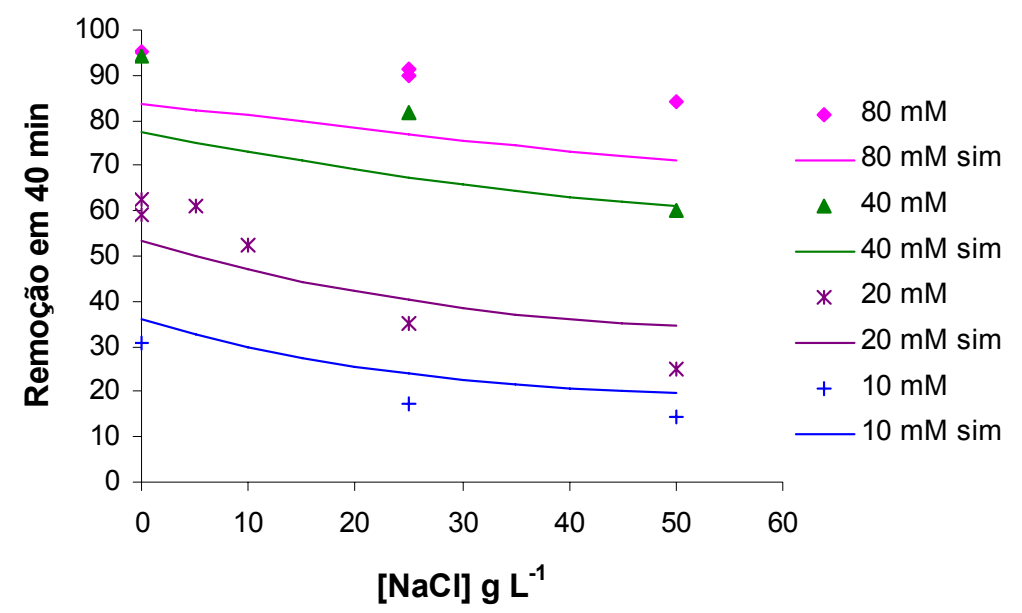

(b)

Figura 52 - Remoção de COT em 30 minutos (a) e 40 minutos (b) de reação em função da concentração de $\mathrm{NaCl}$ para diferentes concentrações de $\mathrm{H}_{2} \mathrm{O}_{2} ;[\mathrm{Fe}(\mathrm{II})]=0,2$ $\mathrm{mM}$.

O modelo apresenta as mesmas tendências observadas experimentalmente, embora com desvios em alguns casos. Em relação ao peróxido, o modelo representa adequadamente $o$ fato que a concentração de peróxido de hidrogênio afeta substancialmente a resposta observada; o ajuste é melhor para baixas concentrações. Para concentrações maiores de $\mathrm{H}_{2} \mathrm{O}_{2}$, o efeito de excesso da concentração a partir de 80 $\mathrm{mM}$ é previsto pelo modelo, uma vez que não existem variações significativas entre $40 \mathrm{e}$ $80 \mathrm{mM}$.

Quanto ao efeito da concentração de $\mathrm{NaCl}$, observa-se que o seu aumento na solução prejudica a remoção de COT. Experimentalmente, o efeito do sal foi significativo para concentrações maiores que aproximadamente $10 \mathrm{~g} / \mathrm{L}$. Já a estabilização do efeito negativo da presença de $\mathrm{NaCl}$ para concentrações maiores que 50 g/L pode ser observada no modelo.

Considerando os limites da representação de um processo complexo e dos possíveis erros experimentais, o modelo representa apropriadamente o decaimento de COT em função do tempo. 
A Tabela 15 apresenta a matriz de pesos da $\mathrm{RNA}_{1}$, em que $\mathrm{W}_{1}$ representa os pesos entre a camada de entrada e a camada oculta e $\mathrm{W}_{2}$ os pesos entre a camada oculta e a camada de saída.

Tabela 15 - Pesos da RNA 1 .

\begin{tabular}{|c|c|c|c|c|c|c|c|}
\hline \multicolumn{6}{|l|}{$\mathbf{W}_{1}$} & \multicolumn{2}{|l|}{$\mathbf{W}_{2}$} \\
\hline Neurônio & $\begin{array}{c}\mathbf{x}_{1} \\
{\left[\mathbf{H}_{2} \mathbf{O}_{2}\right]}\end{array}$ & $\begin{array}{c}\mathbf{x}_{2} \\
{[\mathrm{NaCl}]}\end{array}$ & $\begin{array}{c}x_{3} \\
{[\mathrm{Fe}(\mathrm{II})]}\end{array}$ & $\begin{array}{l}x_{4} \\
(t)\end{array}$ & Bias & Neurônio & Pesos \\
\hline 1 & $-0,148$ & 1,758 & $-4,593$ & 1,635 & 0,409 & 1 & 3,421 \\
\hline 2 & $-1,290$ & 0,358 & 0,479 & 6,216 & 0,041 & 2 & 10,142 \\
\hline 3 & $-3,550$ & $-0,344$ & 0,815 & $-1,577$ & 0,437 & 3 & 9,823 \\
\hline \multirow[t]{2}{*}{4} & 1,788 & 2,990 & 3,679 & $-1,991$ & 0,931 & 4 & 4,439 \\
\hline & & & & & & Bias & 0,231 \\
\hline $\begin{array}{c}\sum_{\text {(valores }} \\
\text { absolutos) }\end{array}$ & 6,776 & 5,450 & 9,566 & & & & \\
\hline
\end{tabular}

\subsection{2. $\mathrm{RNA}_{2}$}

A RNA 2 modela a taxa de reação, $-r$, em função das seguintes variáveis:

- $\quad$ concentração de COT na forma de $\left(C O T / C O T_{0}\right)_{s i m}$;

- concentração de peróxido de hidrogênio total $\left(\left[\mathrm{H}_{2} \mathrm{O}_{2}\right]\right)$;

- concentração de cloreto de sódio ([NaCl]);

- concentração de $\mathrm{Fe}(\mathrm{II})$ ([Fe(II)]);

Os valores de $\left(C O T / C O T_{0}\right)_{s i m}$ foram obtidos a partir de simulações da $\mathrm{RNA}_{1}$. A rede gerou valores para diferentes combinações das seguintes condições: $\left[\mathrm{H}_{2} \mathrm{O}_{2}\right](\mathrm{mM})$ $=10,20,40,80 ;[\mathrm{NaCl}](\mathrm{g} / \mathrm{L})=0: 5: 50 ;[\mathrm{Fe}(\mathrm{II})](\mathrm{mM})=0,1 ; 0,2 ; 0,5$ para tempo de reação de 120 minutos, em intervalos de 10 minutos; o que resultou em 3600 pontos. Os valores do tempo zero foram removidos. Com isto, os valores calculados da taxa simulada (segundo a equação 64, item 5.2), concentrações de $\mathrm{H}_{2} \mathrm{O}_{2}$, sal e $\mathrm{Fe}$ (II) foram utilizados como entrada da segunda rede, $\mathrm{RNA}_{2}$. 
A rede com $\mathrm{NH}=10$ foi escolhida, pois apresentou menor erro quadrático (Figura 53) e melhor ajuste comparando os resultados calculados e experimentais (Figura 54; coeficiente de correlação igual a 0,960).

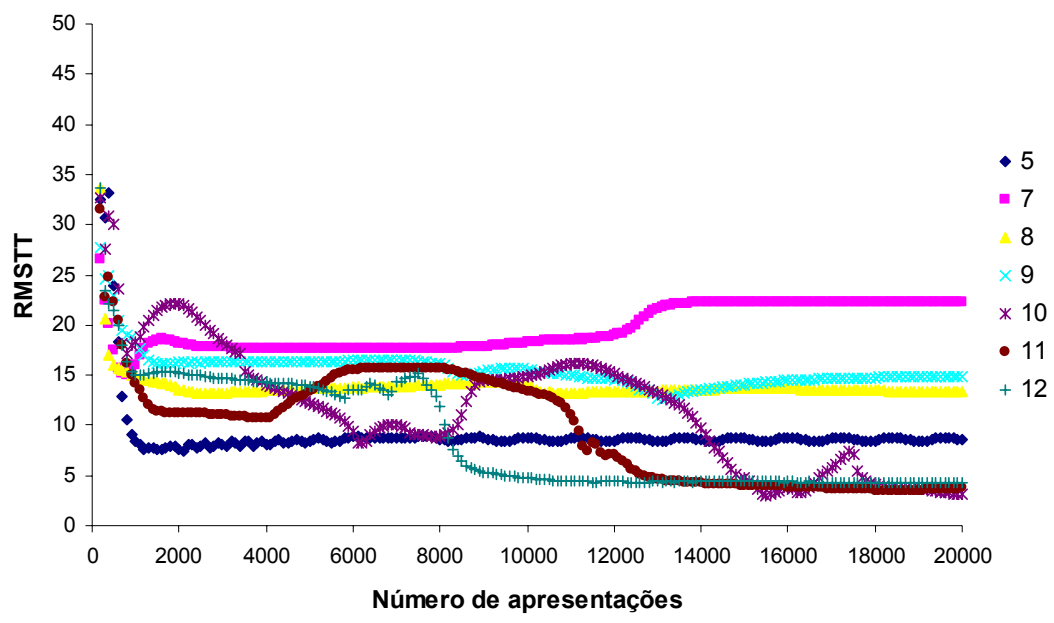

Figura 53 - RMSTT (Test set) em função do número de apresentações para a $\mathrm{RNA}_{2}$.

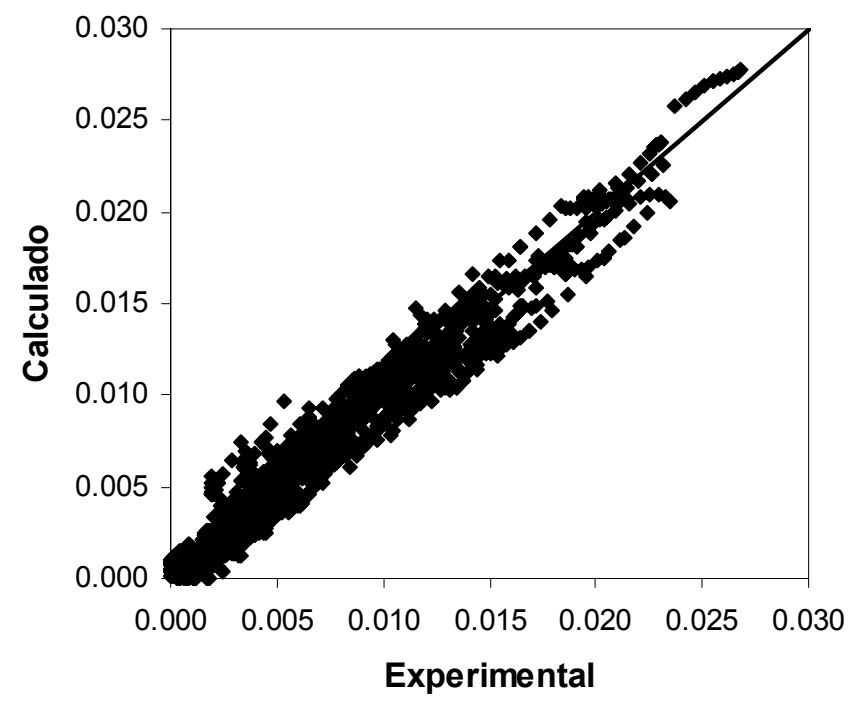

Figura 54 - Resultados experimentais versus calculados do módulo da taxa de reação para $\mathrm{RNA}_{2}$. 
A Tabela 16 apresenta a matriz de pesos da $\mathrm{RNA}_{2}$, em que $\mathrm{W}_{1}$ representa os pesos entre a camada de entrada e a camada oculta e $\mathrm{W}_{2}$ os pesos entre a camada oculta e a camada de saída.

Tabela 16 - Pesos da RNA 2 .

\begin{tabular}{|c|c|c|c|c|c|c|c|}
\hline \multicolumn{6}{|l|}{$\mathbf{W}_{1}$} & \multicolumn{2}{|l|}{$\mathbf{W}_{2}$} \\
\hline Neurônio & $\begin{array}{c}\mathbf{X}_{1} \\
\left(\mathbf{H}_{2} \mathbf{O}_{2}\right) \\
\end{array}$ & $\begin{array}{c}\mathbf{x}_{2} \\
(\mathrm{NaCl}) \\
\end{array}$ & $\begin{array}{c}\mathbf{X}_{3} \\
(\mathrm{Fe}(\mathrm{II}))\end{array}$ & $\begin{array}{c}\mathbf{x}_{4} \\
\left(C O T / C O T_{0}\right)\end{array}$ & Bias & Neurônio & Pesos \\
\hline 1 & 1,230 & 0,756 & 1,365 & 0,051 & 0,734 & 1 & $-7,139$ \\
\hline 2 & $-0,224$ & 2,092 & 1,759 & 0,649 & 0,899 & 2 & $-9,603$ \\
\hline 3 & 6,267 & 0,765 & $-4,096$ & $-0,282$ & 0,759 & 3 & 3,490 \\
\hline 4 & 1,168 & 0,426 & 2,842 & $-3,376$ & 0,119 & 4 & 4,611 \\
\hline 5 & $-0,872$ & 0,429 & 5,718 & $-1,554$ & 0,379 & 5 & 6,014 \\
\hline 6 & 0,271 & $-0,452$ & 5,744 & 0,871 & 0,057 & 6 & $-8,330$ \\
\hline 7 & $-2,936$ & $-1,338$ & 7,462 & 3,986 & 0,414 & 7 & $-3,342$ \\
\hline 8 & $-0,673$ & 0,692 & $-0,018$ & 4,463 & 0,855 & 8 & 19,580 \\
\hline 9 & 0,086 & 1,094 & $-1,944$ & $-4,643$ & 0,211 & 9 & $-13,142$ \\
\hline \multirow[t]{2}{*}{10} & $-3,398$ & 0,071 & $-1,697$ & 8,128 & 0,228 & 10 & $-1,486$ \\
\hline & & & & & & Bias & 0,168 \\
\hline $\begin{array}{c}\sum_{\text {(valores }} \\
\text { absolutos) }\end{array}$ & 13,727 & 8,044 & 30,948 & 19,875 & 4,426 & & \\
\hline
\end{tabular}




\subsubsection{Modelo Contínuo}

A partir da $\mathrm{RNA}_{2}$ um modelo foi desenvolvido para o processo Foto-Fenton nas condições estudadas, para sistema em escoamento.

Uma aproximação foi realizada com um reator Tubular ("Plug Flow") utilizando a taxa de reação da $\mathrm{RNA}_{2}$ em uma equação diferencial ordinária (64):

$$
\frac{d(C O T)_{z}}{d V}=-\frac{r}{q}
$$

em que $V$ é o volume do reator, e $q$ a vazão de fluido no reator.

O modelo descreve a variação de COT em um reator tubular em função do volume e das condições de operação, concentração de sal, $\mathrm{Fe}(\mathrm{II})$ e $\mathrm{H}_{2} \mathrm{O}_{2}$. O algoritmo para simulação foi organizado de forma a possibilitar o dimensionamento do reator (estimativa de $V$ ) para um dado conjunto de condições de processo e uma taxa de remoção de COT especificada. A Figura 55 apresenta resultados de simulações com o modelo para o volume do reator fotoquímico em função da concentração de sal para diferentes concentrações de $\mathrm{H}_{2} \mathrm{O}_{2}$ para a remoção de $70 \%$ do poluente em termos de COT. Utilizou-se a mesma vazão experimental de $0,09 \mathrm{~m}^{3} / \mathrm{h}$.

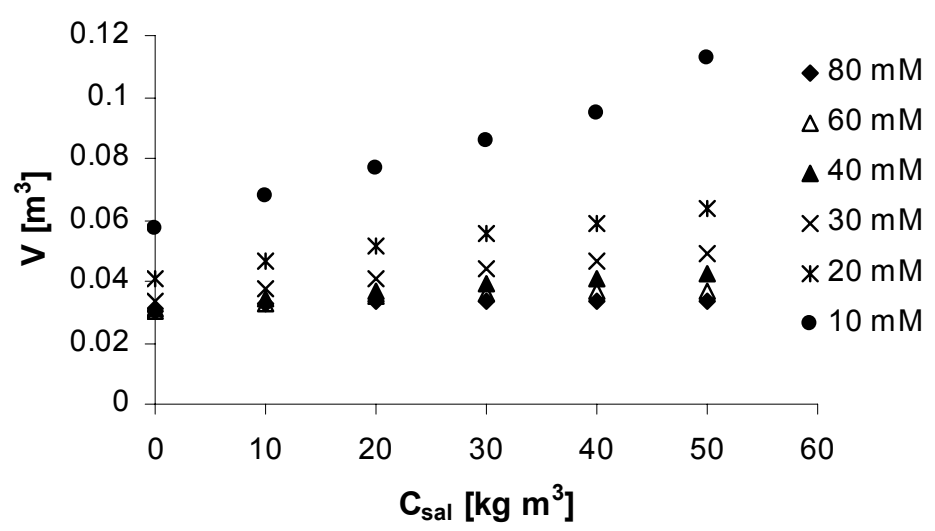

Figura 55 - Volume do reator fotoquímico versus concentração de sal para diferentes concentrações de $\mathrm{H}_{2} \mathrm{O}_{2}$ para remoção de COT de $70 \%$. 
Observa-se que, nas condições estudadas, a concentração de $\mathrm{H}_{2} \mathrm{O}_{2}$ exerce um efeito importante no volume do reator, sendo o efeito de $C_{s a l}$ maior para menores valores de $\left[\mathrm{H}_{2} \mathrm{O}_{2}\right]$. As melhores condições foram obtidas para concentrações maiores que 30 $\mathrm{mM}$ de $\mathrm{H}_{2} \mathrm{O}_{2}$. Por outro lado, valores maiores que $40 \mathrm{mM}$ não aumentam a degradação significativamente e a mitigação do efeito negativo do sal na solução pode ser observada para concentrações maiores que $30 \mathrm{~kg} / \mathrm{m}^{3}$. Para $\left[\mathrm{H}_{2} \mathrm{O}_{2}\right]$ menor que cerca de $40 \mathrm{mM}$, o aumento da concentração de sal de 0 para $50 \mathrm{~kg} / \mathrm{m}^{3}$ aumenta o volume do reator em aproximadamente $40 \%$, o que afeta negativamente o processo do ponto de vista econômico.

A Figura 56 apresenta resultados de simulações com o modelo para o volume do reator fotoquímico em função da concentração de sal para diferentes percentuais de remoção de COT para uma $\left[\mathrm{H}_{2} \mathrm{O}_{2}\right]$ de $40 \mathrm{mM}$.

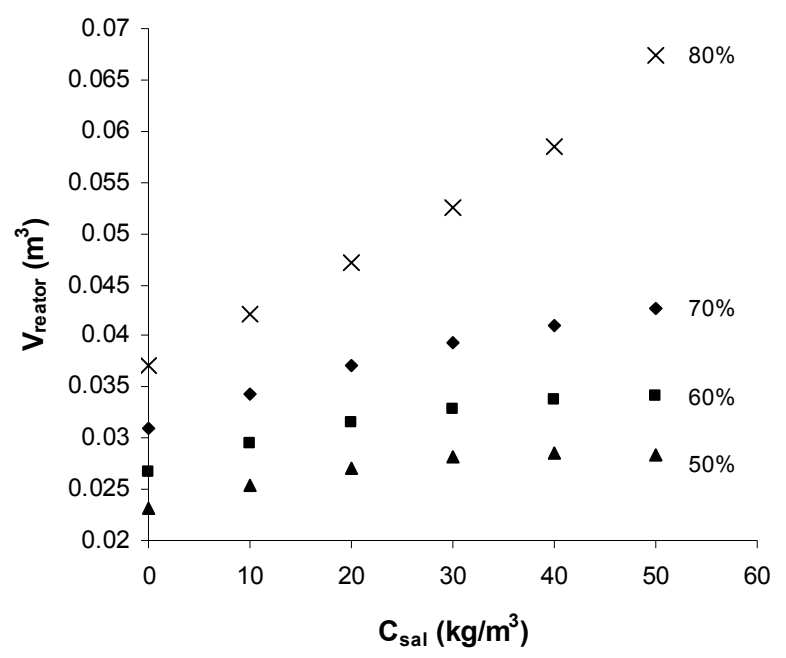

Figura 56 - Volume de reator necessário em função da concentração de $\mathrm{NaCl}$ da solução para diferentes percentuais de remoção de COT; $\left[\mathrm{H}_{2} \mathrm{O}_{2}\right]=40 \mathrm{mM}$; $[\mathrm{Fe}(\mathrm{II})]=0,2$ $\mathrm{mM}$.

Observa-se que o percentual de remoção de COT também exerce como esperado um efeito importante no volume do reator. Nesse caso o aumento da concentração de $\mathrm{NaCl}$ influi significativamente no volume do reator necessário, principalmente para maiores 
valores de remoção de COT. Para uma remoção de $80 \%$ de COT, o aumento da concentração de sal de 0 para $50 \mathrm{~kg} / \mathrm{m}^{3}$ aumenta o volume do reator em aproximadamente $50 \%$. 


\subsection{Integração dos processos}

Os modelos ajustados para a eletrodiálise e reator fotoquímico foram acoplados de modo a possibilitar simular o processo integrado de remoção de $\mathrm{NaCl}$ seguido pela fotodegradação de efluente. $\mathrm{O}$ algoritmo de simulação foi organizado de forma a calcular área de membranas da unidade de ED e volume do reator fotoquímico, juntamente com as variáveis de processo associadas ao consumo de insumos e de energia. Tais variáveis são relacionadas a custos de investimento e operacionais de unidades industriais. No presente trabalho, não foram atribuídos custos, sendo os resultados apresentados e discutidos com base na área de membranas de ED, volume do reator fotoquímico e consumo energético em ambas as etapas.

A Figura 57 apresenta um esquema simplificado dos processos de ED e oxidativo integrados.

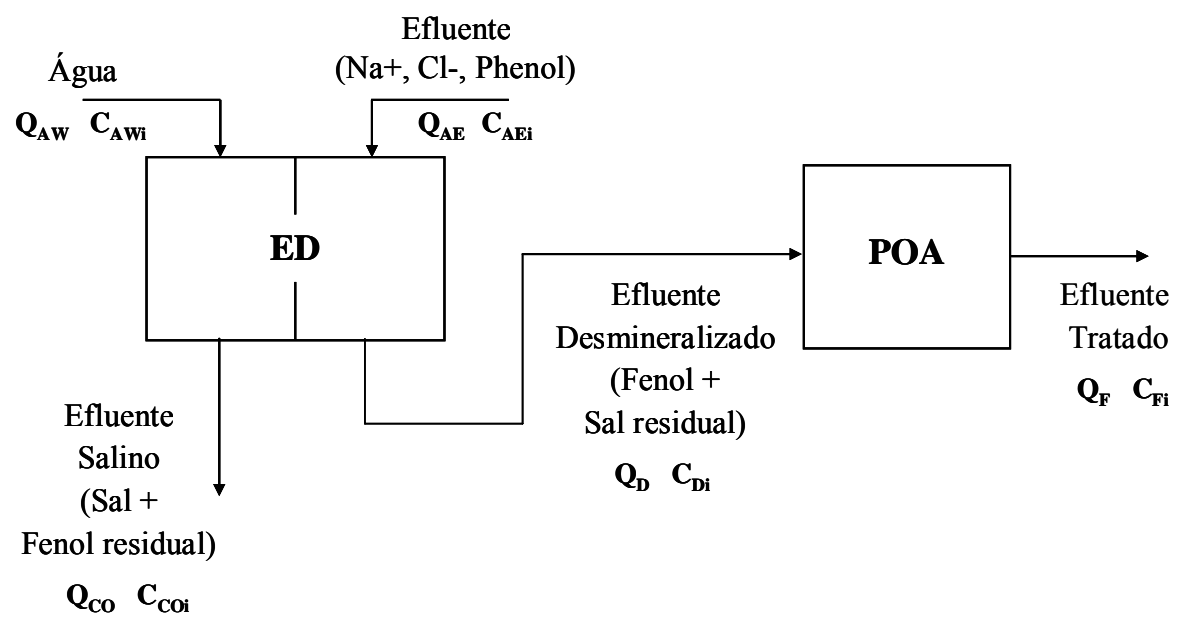

Figura 57 - Esquema do sistema integrado.

Nas condições estudadas, o processo de ED possui dois fatores principais ligados ao custo do processo: 1) intensidade de corrente aplicada, que se reflete no consumo de energia elétrica do sistema, e 2) a área de membranas necessária, relacionada principalmente ao investimento inicial e manutenção. Outro fator importante é a perda de fenol no efluente descartado, na saída do compartimento do concentrado, que gera 
um custo de tratamento adicional ao processo em função desse poluente. Já a etapa de fotodegradação possui diferentes fatores que influenciam na eficiência do processo; como a concentração dos reagentes, peróxido de hidrogênio e Fe (II), e, a concentração de $\mathrm{NaCl}$ da alimentação. No entanto, o consumo de energia pelas lâmpadas é certamente o item que mais afeta o custo do processo. Como exemplo, nos experimentos em escala de laboratório, foi utilizada uma fonte de luz com potência elétrica nominal de $250 \mathrm{~W}$ inserida em um reator com volume de 1 litro. Esse valor representa o limite a partir do qual foi observado excesso de fluxo de fótons em estudos anteriores. $\mathrm{O}$ aumento do volume do reator fotoquímico, portanto, implica o aumento da potência elétrica consumida, desde que mantida a relação potência e volume do reator.

Neste contexto, o processo de ED foi avaliado em função da área de membrana, perda de fenol, e vazão de descarte do concentrado. O processo foto-Fenton foi avaliado em função do volume do reator e diferentes concentrações de $\mathrm{H}_{2} \mathrm{O}_{2}$, conforme apresentado na Tabela 17. Os processos integrados foram avaliados em modo contínuo em diferentes cenários para valores de densidade de corrente entre 75 e $275 \mathrm{~A} / \mathrm{m}^{2}$, e diferentes percentuais de dessalinização (\% Des) do processo de ED, 60, 80 e 98\% ( $C_{C O_{s}}=20,10$ e $1 \mathrm{~kg} / \mathrm{m}^{3}$ respectivamente); considerando-se a concentração inicial de sal de $50 \mathrm{~kg} / \mathrm{m}^{3}$ e de fenol de $0,1 \mathrm{~kg} / \mathrm{m}^{3}$ e a vazões de entrada do processo de $\operatorname{ED}\left(Q_{A W}\right.$ e $Q_{A E}$ ) de $1 \mathrm{~m}^{3} / \mathrm{h}$. A vazão de alimentação do processo oxidativo, igual à vazão de saída da $\operatorname{ED}\left(Q_{D}\right)$, também é apresentada na Tabela 17. A vazão $Q_{D}$ varia em função fluxo de sal através da membrana devido à eletro-osmose. $\mathrm{O}$ efluente dessalinizado pela ED foi avaliado segundo o volume do reator fotoquímico necessário para a remoção de $70 \%$ de COT, utilizando-se $40 \mathrm{mM}$ de $\mathrm{H}_{2} \mathrm{O}_{2}$ e 0,2 de $\mathrm{Fe}(\mathrm{II})$. 
Tabela 17 - Resultados em diferentes cenários do processo integrado.

\begin{tabular}{|c|c|c|c|c|c|c|}
\hline \multirow[b]{3}{*}{ \% Des. } & \multirow[b]{3}{*}{$\begin{array}{c}i \\
\left(\mathrm{~A} / \mathrm{m}^{2}\right)\end{array}$} & \multirow[b]{3}{*}{$\mathbf{U}(\mathbf{V})$} & \multicolumn{4}{|c|}{ Respostas } \\
\hline & & & \multicolumn{3}{|c|}{ ED } & \multirow{2}{*}{$\begin{array}{c}\text { POA } \\
\\
V_{\text {reator }} \\
\text { (L) }\end{array}$} \\
\hline & & & $\begin{array}{c}A \\
\left(\mathrm{~m}^{2}\right)\end{array}$ & $\begin{array}{c}\text { Perda de } \\
\text { fenol } \\
C_{C O_{P}} \\
\left(\mathbf{k g} / \mathbf{m}^{3}\right)\end{array}$ & $\begin{array}{c}Q_{D} \\
\left(\mathbf{m}^{3} / \mathbf{h}\right)\end{array}$ & \\
\hline \multirow{5}{*}{60} & 75 & 6,4 & 218,5 & 0,017 & \multirow{5}{*}{0,81} & \multirow{5}{*}{361,3} \\
\hline & 125 & 8,7 & 131,1 & 0,014 & & \\
\hline & 175 & 11,1 & 93,7 & 0,013 & & \\
\hline & 225 & 13,4 & 72,8 & 0,012 & & \\
\hline & 275 & 15,7 & 59,6 & 0,011 & & \\
\hline \multirow{5}{*}{80} & 75 & 6,4 & 279,9 & 0,020 & \multirow{5}{*}{0,84} & \multirow{5}{*}{321,0} \\
\hline & 125 & 8,7 & 167,9 & 0,017 & & \\
\hline & 175 & 11,1 & 119,9 & 0,015 & & \\
\hline & 225 & 13,4 & 93,3 & 0,014 & & \\
\hline & 275 & 15,7 & 76,3 & 0,013 & & \\
\hline \multirow{5}{*}{98} & 75 & 6,4 & 331,2 & 0,022 & \multirow{5}{*}{0,88} & \multirow{5}{*}{282,5} \\
\hline & 125 & 8,7 & 198,7 & 0,019 & & \\
\hline & 175 & 11,1 & 141,9 & 0,017 & & \\
\hline & 225 & 13,4 & 110,4 & 0,016 & & \\
\hline & 275 & 15,7 & 90,3 & 0,015 & & \\
\hline
\end{tabular}

De modo geral, os resultados da Tabela 17 mostram que os valores da concentração de sal do efluente dessalinizado, alimentação do processo fotoquímico, influenciam significativamente o volume do reator necessário para remoção de $70 \%$ de COT, confirmando, como visto anteriormente, o efeito negativo que a concentração de $\mathrm{NaCl}$ exerce sobre a eficiência do processo oxidativo. Nas condições estudadas, observa-se um aumento de cerca de $22 \%$ do volume do reator fotoquímico com o aumento da concentração de sal da alimentação de 1 para $20 \mathrm{~kg} / \mathrm{m}^{3}$.

No caso da ED, a área de membrana diminui significativamente com o aumento da densidade de corrente. Com o aumento de 75 para $275 \mathrm{~A} / \mathrm{m}^{2}$ nota-se que a área de membrana diminui cerca de $73 \%$. Já a concentração de fenol no efluente salino diminui aproximadamente $35 \%$. 
O processo integrado possui portanto diferentes fatores que influenciam na eficiência geral do processo, que devem ser analisados utilizando-se o custo de cada variável para sua otimização.

O custo do processo integrado pode ser estimado de forma qualitativa utilizandose o consumo energético como componente principal para os dois processos.

Considerando-se estado estacionário e os dados de variação da voltagem experimentais, pode-se obter uma relação entre a densidade de corrente e a voltagem. Nos experimentos a voltagem variou significativamente no início e no final do experimento. Considerando-se os valores médios de voltagem $(U)$ e excluindo-se o primeiro e o último valor registrado, foi possível obter a relação apresentada na Equação 65.

$U=0,046 I+2,9$

Os valores de voltagem para cada cenário segundo a Equação 65 são apresentados na Tabela 17.

A potência elétrica consumida, $P$, na operação de ED pode ser estimada a partir da Equação 66.

$P=U . I . A$

Já a potência elétrica consumida pelo processo oxidativo pode ser estimada a partir da relação utilizada experimentalmente de $250 \mathrm{~W}$ para cada litro de reator, e portanto será proporcional ao volume de reator. A Figura 58 apresenta os resultados de potência consumida no processo de ED e a área de membrana necessária para diferentes densidades de corrente e percentuais de dessalinização. 


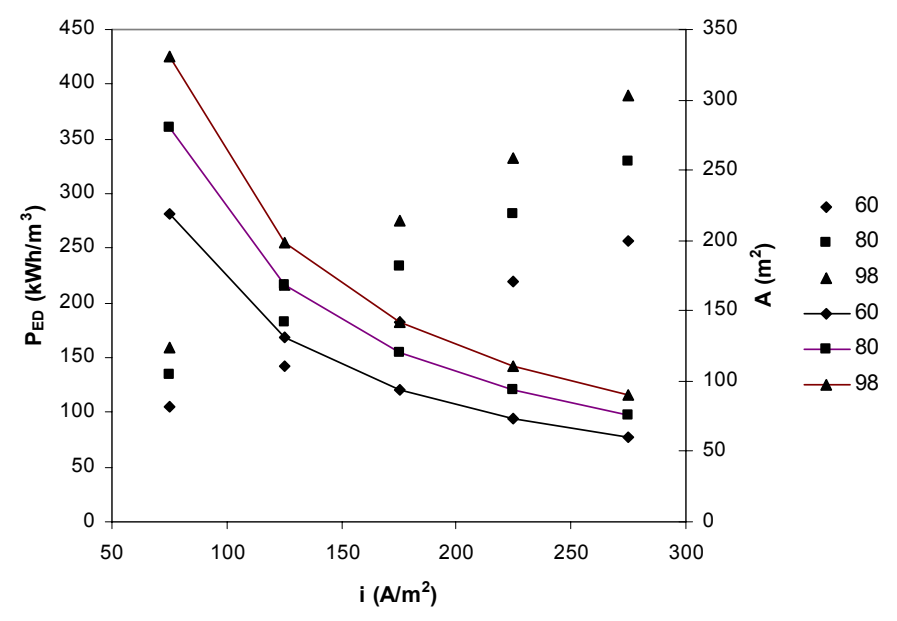

Figura 58 - Potência elétrica estimada e área de membrana (linha contínua) no processo de ED para diferentes percentuais de dessalinização.

Considerando a área de membranas um fator importante no custo total do processo, segundo a Figura 58 valores inferiores a $175 \mathrm{~A} / \mathrm{m}^{2}$ aumentariam significativamente essa fração do custo.

Os valores encontrados de consumo de energia no processo de ED são apenas ilustrativos, pois representam apenas as condições de operação estudadas. Valores significativamente inferiores ao encontrado foram reportados por Turek (2002), para processos de dessalinização de água do mar utilizando ED. Turek (2002) apresentou um consumo de energia estimado para uma planta industrial de cerca $0,155 \mathrm{kWh} / \mathrm{kg}$ de $\mathrm{NaCl}$ e valores de aproximadamente $0,59 \mathrm{kWh} / \mathrm{kg}$ de $\mathrm{NaCl}$ apresentados na literatura (Chen, Chen e Tan, 1995; Yamamoto et al., 2000; Tanaka, 1999 apud Turek (2002)). O valor obtido neste trabalho, como mostrado Figura 58, corresponde a aproximadamente $5 \mathrm{kWh} / \mathrm{kg}$ de $\mathrm{NaCl}$. De uma maneira geral, o processo oxidativo é afetado pela concentração de $\mathrm{NaCl}$ em cerca de $0,52 \mathrm{kWh} / \mathrm{kg}$ de $\mathrm{NaCl}$ (comparando-se os resultados de 60 e $80 \%$ de dessalinização; em que os cenários apresentam uma diferença de 10 $\left.\mathrm{kWh} / \mathrm{m}^{3}\right)$.

Para os diferentes percentuais de dessalinização estudados, 60, 80 e 98\%, os valores de potência estimada na fotodegradação são: 90,3, 80,3 e 70,6 kWh/m³ respectivamente. 
Finalmente, considerando os valores de consumo de energia de uma planta de ED real, a integração dos processos de ED e degradação oxidativa pode ser considerada factível, embora análises mais detalhadas do consumo de energia e outros fatores de custo devem ser consideradas. É válido ressaltar que a baixa concentração de sal do efluente tratado, ou seja, maior fator de dessalinização, possibilita o reuso da água em processos nos quais o efluente foi gerado e em outras aplicações. 
Capítulo 6: CONCLUSÕES 
Neste trabalho a desmineralização de um efluente fenólico por ED foi investigada com o objetivo de integrá-la ao processo de oxidação como pré-tratamento.

Um modelo fenomenológico foi proposto e uma estratégia experimental foi delineada para avaliar os fenômenos de transporte envolvidos. Para tanto, realizou-se experimentos com e sem corrente elétrica com soluções modelos contendo diferentes concentrações de $\mathrm{NaCl}$ e fenol. Este estudo possibilitou a identificação de fenômenos limitantes em relação à transferência de solutos, fenol e sal. Quanto à transferência de água, a contribuição da eletro-osmose ao fluxo mostrou-se preponderante quando comparada a da osmose. Igualmente, em relação ao sal, a transferência devido à migração apresentou-se preponderante quando comparada à da difusão. Assim, a intensidade de corrente foi considerada a variável mais importante para a transferência de sal e água no processo de ED.

Sendo o fenol um composto neutro, uma contribuição convectiva, correlacionada com o fluxo da água, mostrou-se significativa tanto quanto a difusão. Esta última apresentou-se independente à variação de concentração de sal em solução. A proporção de fenol transferido por difusão e convecção depende das condições de operação. No entanto, a contribuição convectiva mostrou-se significativa na faixa de densidade de corrente normalmente utilizada em ED.

Nas condições de operação deste estudo, ou seja, considerando os solutos e membranas utilizadas, os parâmetros característicos do modelo, que relacionam as diferentes contribuições para a transferência de massa, foram determinados. Esta determinação foi realizada pelo ajuste dos resultados experimentais pelos calculados pelo modelo. Mais adiante, a variação de concentração de sal e fenol nos compartimentos foi descrita a partir de equações de balanço de massa em função de seus valores iniciais no processo e da densidade de corrente. Estas equações dependem basicamente dos parâmetros de transporte que devem ser estimados para cada sistema de membrana a ser utilizado.

$\mathrm{O}$ desempenho do processo de $\mathrm{ED}$, que está relacionado à perda de fenol e a concentração de sal no efluente desmineralizado, pode ser estimado em função dos 
parâmetros operacionais, como: a densidade de corrente e a concentração inicial de sal na alimentação.

Visando minimizar a transferência de fenol, alguns experimentos foram realizados em uma célula de difusão que avaliou a permeabilidade ao soluto de cada membrana, MTC e MTA. Os resultados obtidos sugerem que a transferência de fenol se dá principalmente através da membrana catiônica, MTC. Portanto, sendo a perda de fenol uma limitação ao processo, a utilização de outra MTC deve ser considerada.

A partir dos parâmetros obtidos experimentalmente e equações de fluxos do solvente e solutos, um modelo matemático foi desenvolvido permitindo a avaliação do processo em diferentes configurações, incluindo o modo contínuo. O modelo foi validado pela comparação dos dados obtidos experimentalmente e por simulações de mesma configuração.

Quanto ao processo foto-Fenton observou-se que a concentração de $\mathrm{NaCl}$ não é diretamente proporcional aos distúrbios que esta causa no perfil de remoção de COT. O sistema foi avaliado a partir de diferentes respostas que descrevem o comportamento do processo para as diferentes condições de operação, como os tempos de inversão de perfil da curva, velocidade de decaimento e remoção final, o que permitiu a avaliação do processo em função das diferentes variáveis estudadas.

$\mathrm{O}$ processo fotoquímico foi modelado por redes neurais artificiais, mostrando-se uma metodologia efetiva e adequada para descrever o comportamento complexo do sistema em função das variáveis manipuladas dentro da faixa de condições experimentais adotadas. O primeiro modelo obtido permitiu simulações e validação do processo nas condições realizadas experimentalmente, em modo batelada, a partir do equacionamento do decaimento de COT em função do tempo; e mais adiante, um segundo modelo descrevendo a taxa de reação em função do COT permitiu simulações do processo em modo contínuo.

Os modelos desenvolvidos para as diferentes etapas permitiram a avaliação da integração dos processos em diferentes cenários. A partir do modelo integrado uma estimativa dos custos envolvidos com base no consumo de energia não pode ser comparada aos valores reais encontrados na literatura, uma vez que representam as 
condições de operação utilizadas, no entanto ilustraram o potencial do modelo para estudos de custo mais detalhados.

$\mathrm{O}$ interesse em desmineralizar o efluente antes do processo de oxidação deve considerar os custos adicionais devido à dessalinização, melhorias na eficiência de separação e o consumo de reagentes na etapa de oxidação.

Os modelos obtidos de ambos os processos são essenciais para projetos em escala industrial e o modelo integrado mostrou-se adequado para futuros estudos de otimização do sistema.

Sugere-se para trabalhos futuros o uso da metodologia de integração para a otimização do processo usando diferentes fatores limitantes como a qualidade do efluente tratado, o consumo de reagentes e energia e o custo; a avaliação de outros tipos de membranas no processo de eletrodiálise, uma avaliação detalhada de custo do processo integrado; e, a avaliação e adaptação do modelo para outros efluentes contendo diferentes sais e poluentes. 
Capítulo 7: REFERÊNCIAS 
Abdulah, M.; Low, G.K.-C; Matthews, W. Effects of common inorganic anions on rates of photocatalytic of organic carbon over illuminated titanium dioxide. Journal of Physics Chemistry, v.94, p.6820-6825, 1990.

Andreozzi, R.; Caprio, V.; Insola, A.; Marotta, R. Advanced oxidation processes (AOP) for water purification and recovery. Catalysis Today, n.53, p.51-59, 1999.

Astom Corporation. Apresenta características de membranas iônicas Neosepta. Disponível em: <http://www.astom-corp.jp/en/en-main2-neosepta.html>. Acesso em: 21 set. 2009.

Bailly, M.; Roux-de Balmann, H.; Aimar, P.; Lutin, F.; Cheryan, M. Production processes of fermented organic acids targeted around membrane operations: design of the concentration step by conventional electrodialysis. Journal of Membrane Science, v.191, p.129-142, 2001.

Bailly, M. Stratégie de dimensionnement de procédés de production d'acides organiques intégrant des étapes eletromembranaires. Thèse de l’Université Paul Sabatier, Toulouse, 2000.

Bauer, R.; Fallmann, H. The photo-Fenton oxidation: a cheap and efficient wastewater treatment method. Research on Chemical Intermediates, v. 23, p. 341354, 1997.

Berg, P.; Hagemeyer, G.; Gimbel, R. Removal of pesticides and other micropollutants by nanofiltration, Desalination, v.113, p.208-208, 1997. 
Binder $H$. and Zschornig $O$. The effect of metal cations on the phase behavior and hydration characteristics of phospholipid membranes. Chemical and Physical Lipids, v. 115, p. 39 - 61, 2002.

Borges, F.J.; Roux-de Balmann, H.; Guardani, R. Investigation of the mass transfer processes during the desalination of water containing phenol and sodium chloride by electrodialysis. Journal of Membrane Science, v. 325, p. 130-138, 2008.

Boussahel, R.; Bouland, S.; Moussaoui, K.M.; Montiel, A. Removal of pesticides residues in water using the nanofiltration process. Desalination, v.132, p.205-209, 2005.

Chaplin, Water Structure and Behaviour. Disponível em:

<http://www.martin.chaplin.btinternet.co.uk/index/html>, Acesso em: 2004.

Chen, X.; Chen, P.; Tan, Y. Electrodialysis for the desalination of seawater and high strenght brackish water, Desalination \& Water Reuse Quaterly. v.4, p. 16-22, 1995.

Cowan, D.A.; Brown, J.H. Effect of turbulence on limiting current in electrodialysis cells. Industrial Engineering Chemistry Research, v.51, p.1445, 1959.

David, F.; Vokhmin V.; Ionova, G. Water characteristics depend on the ionic environment. Thermodynamics and modelisation of the aquo ions. Journal of Molecular Liquids, v. 90, 1-3, p. 45, 2001.

De Aguiar, P. F.; Massart, D. L. Experimental Design. The Encyclopedia of Computational Chemistry, Chichester: John Wiley \& Sons, 1998. 
Esplugas, S.; Gimenez, J.; Contreras, S.; Pascual, E.; Rodriguez, M. Comparison of different advanced oxidation processes forphenol degradation. Water Research, v.36, p. 1034-1042, 2002.

Fallmann, H.; Bauer, R.; Waldner, G.; Hager, S.; Klare, M.; Krutzler, T.; Malato, S.; Maletzky, $\mathrm{P}$. The photo-Fenton reaction and the $\mathrm{TiO}_{2} / \mathrm{UV}$ process for waste water treatment - novel developments. Catalysis Today, v.53, p.131-144, 1999.

Göb, S; Oliveros, E.; B, S.H.; Braun, A.M.; Guardani, R.;Nascimento, C.A.O. Modeling the kinetics of a photochemical water treatment process by means of artificial neural networks. Chemical Engineering and Processing, v.38, p.373-382, 1999.

Gogate, P.R.; Pandit, A.B. A review of imperative technologies for wastewater treatment oxidation technologies at ambient conditions. Advanced in Environmental Research, v.8, 501-551, 2004.

Kedem, O.; Katchalsky, A. Thermodynamic analysis of the permeability of biological membranes to no-electrolytes. Biochimica and Biophysica Acta, v.27, 229$246,1958$.

Koprivanac, N.; Bozic, A.L.; Papic, S. Cleaner production process in the synthesi of blue anthraquinone reactive dyes. Dyes Pigment, v. 44, 33-40, 2000.

Legrini, O.; Olivero E.; Braun, A.M. Photochemical processes for water treatment. Chemical. Review, 671-698, 1993. 
Lindner, M.; Bahremann, D.W.; Hirthe, B.; Griebler, W. Solar water detoxification: Novel $\mathrm{TiO}_{2}$ powders as highly active photocatalysis. Reprinted from Solar Engineering, W. B. Stine, T. Tanaka, D.E. Claridge, eds., 1995.

Lira, D.C.B. Estudo de degradação fotoquímica para reúso de águas de processo em complexo industrial petroquímico. Dissertação de Mestrado em Engenharia Química, Escola Politécnica da Universidade de São Paulo, 2006.

Lopez-Leon, T. J.-R.; Bastos-Gonzales, A. B.; Ortega-Vinuesa, D.; ,Hofmeister, J.L. Effects in the Stability and Electrophoretic Mobility of Polystyrene Latex Particules. Journal of Physical Chemistry, v.B107, p. 5696-5708, 2003.

Machulek, A. ; Moraes, J. E. ; Vautier-Giongo, C. ; Silverio, C. A. ; Friedrich, L. C. ; Nascimento, C. A. O. ; Gonzalez, M. C. ; Quina, F. H. Abatement of the inhibitory effect of chloride anions in the photo-Fenton process. Environmental Science \& Technology, v.41, p. 8459-8463, 2007

Mattews, R.W. Photocatalytic oxidation of organic contaminants in water: an aid to environmental preservation. Pure and Applied Chemistry, v.64, 1285-1290, 1992.

Middleditch, B.S. Ecological effects of produced water form offshore oil and gas production platforms. American Petroleum Institute, API 94, 172 pp, 1984.

Moraes, J.E.F; Quina, F.H.; Nascimento, C.A.O.; Silva, D.N.; Chiavone-Filho, O. Treatment of saline wastewater contaminated with hydrocarbons by the photoFenton process. Environmental Science Technology, v.38, 3746-3751, 2004.

Mulder, M. Basic principles of membrane technology. Kluwer Academic Publishers, $2^{\mathrm{a}}$ ed., 1996. 
Nascimento, C.A.O; Oliveros, E.; Braun, A.M. Neural Network modelling for photochemical processes. Chemical Engineering Processing, v.33, 319-324, 1994.

Oliveros, E.; Legrini, O.; Hohl, M.; Müller, T.; Braun, A.M. Industrial waste water treatment: large scale development of a light-enhanced Fenton reaction. Chemical Engineering Process, v.36, 397-405, 1997.

Ollis, D. Integrating Photocatalysis and Membrane Technologies for water treatment. Annals New York Academy of Sciences, v.984, p. 65-84, 2003

Perry, R.H.; Green, D.W. Perry's Chemical Engineers Handbook. The McGraw-Hill Companies, 1999.

Pignatello, J.J. Dark and photoassisted $\mathrm{Fe}^{3+}$-catalysed degradation of chlorophenoxy herbicides by hydrogen peroxide. Environmental Science Technology, v.26, 944-951, 1992.

Pigantello, J.J.; Oliveros, E.; MacKay, A. Advanced oxidation process for organic contaminant destruction based on the Fenton reaction and related chemistry. Critical Reviews in Environmental Science and Technology, v.36, 1-84, 2006.

Roux-de Balmann, H.; Casademont, E. Électrodialyse. Techniques de l'ingénieur. J 2840, Setembro, 2006.

Rutgers A. J. and Hendrikx Y. Ionic hydration. Trans. Faraday Soc., v.58, p. 2184 $2191,1962$.

Saracco, G. Transport properties of monovalent-ion-permselective membranes. Chemical Engineering Science, v.52, p. 3019-3031, 1997. 
Singlande, E. Procédés intégrés couplant l'électrodialyse et le traitement biologique: influence de la composition ionique et application au traitement des effluents salins. Thèse de l’Université Paul Sabatier, Toulouse, 2006.

Strathmann, H. Ion-exchange membrane separation processes. Membrane Science and Technology Series, v. 9, 2004.

Tanaka, Y. Regularity in ion-exchange membranes characteristic and concentration of sea water. Journal of Membrane Science, v.163, p. 277-287, 1999.

Tanaka, S.; Saha, U.K. Effects of pH on photocatalysis of 2,4,6-trichlorophenol in aqueous $\mathrm{TiO}_{2}$ suspensions. Water Science and Technology, v.30, p.47-57, 1995.

Teixeira, A.C.S.C.; Guardani, R.; Nascimento, C.A.O. Photo-fenton remediation of wastewaters containing silicone: Experimental study and neural network modeling. Chemical Engineering \& Technology, v.27, 800-810, 2004.

Toor, A. P.; Verma, A.; Jotshi, C.K.; Bajpai, P.K.; Singh, V. Photocatalytic degradation of Direct Yellow 12 dye using UV/TiO2 in a shallow pond slurry reactor. Dyes and Pigments, v.68, p.53-60, 2006.

Turek, M. Cost effective electrodialytic seawater desalination. Desalination, v.153, p. 371-376, 2002.

U.S. Environmental Protection Agency (USEPA) Risk Assessment Guidance for Superfund: Volume III - Part A, Process for Conducting Probabilistic Risk Assessment. Office of Emergency and Remedial Response. EPA 540-R-02-002. 2001. 
Van Der Bruggen, B.; Schaep, J.; Maes, W.; Wilms, D.; Vandecasteele, C. Nanofiltration as a treatment method for the removal of pesticides from ground water. Desalination, v.117, 139-147, 1998.

Wagner, J. Membrane filtration handbook. Pratical Tips and Hints. 2.ed. Osmonics Inc., nov. 2001.

Yamamoto, M.; Hanada, F.; Funaki, S.; Takashima, K. A new electrodialyzer technique for the salt production by ion-exchange membrane. 8th World Salt Symposium, Ed., Elsevier, v.1, p. 647-652, 2000.

Zhou J., Lu X., Wang, Y.; Shi, J.. Molecular dynamics investigation on the infinite dilute diffusion coefficients of organic compounds in supercritical carbon dioxide. Fluid Phase Equilibria, v.172, 2, p. 279, 2000. 


\section{ANEXO 1}

Para os resultados apresentados na Tabela 6 da seção 4.1.3, superfícies de respostas foram delineadas por regressão linear para os fluxos de água, sal e fenol utilizando as variáveis codificadas e são apresentadas nas equações A1-1 a A1-3 $\left(\mathrm{R}^{2}=\right.$ 0,998; 0,991; 0,987; respectivamente) e Figura A1-1 a A1-3. Estas figuras apresentam também os resultados experimentais versus os resultados calculados pelo modelo, sendo as equações válidas para valores de densidade de corrente e concentração inicial de sal maiores que zero.

$$
\begin{aligned}
& j_{w} \cdot 10^{-7}=1,81+1,02 i-0,003 \Delta C_{s}^{0}-0,09 i \Delta C_{s}^{0} \\
& j_{s} \cdot 10^{-5}=10,17+5,32 i+0,24 \Delta C_{s}^{0}-0,32 i \Delta C_{s}^{0}
\end{aligned}
$$

$$
j_{p} \cdot 10^{-8}=1,47+0,46 i+0,03 \Delta C_{s}^{0}+0,04 i \Delta C_{s}^{0}
$$

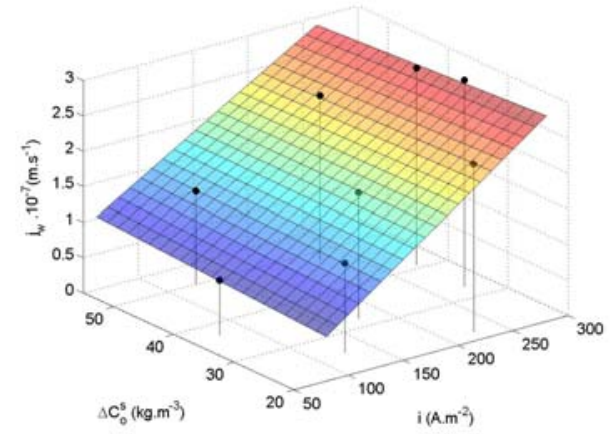

(a)

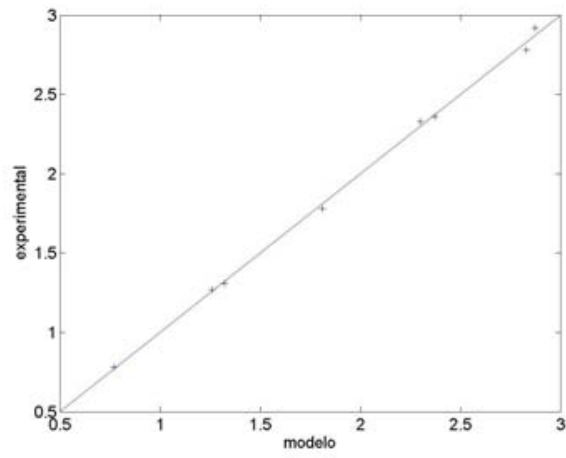

(b)

Figura A1-1. (a) superfície de resposta para o fluxo de água $\left(j_{w}\right)$; (b) resultados experimentais versus calculados para $j_{w}$. 


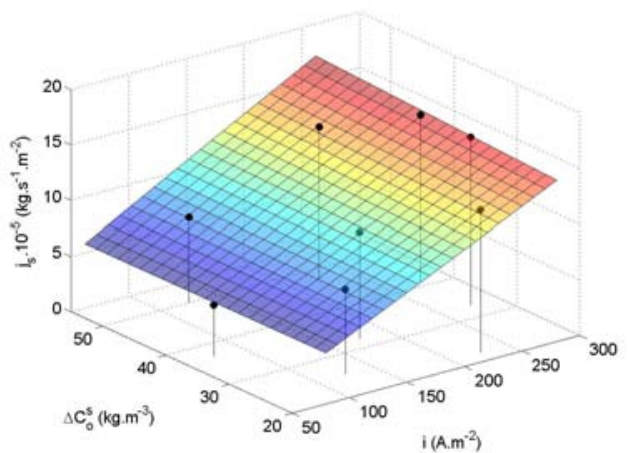

(a)

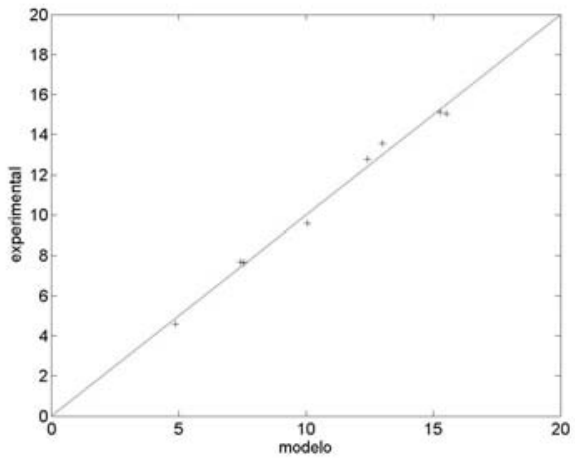

(b)

Figura A1-2. (a) superfície de resposta para o fluxo de sal $\left(j_{s}\right)$; (b) resultados experimentais versus calculados para $j_{s}$.

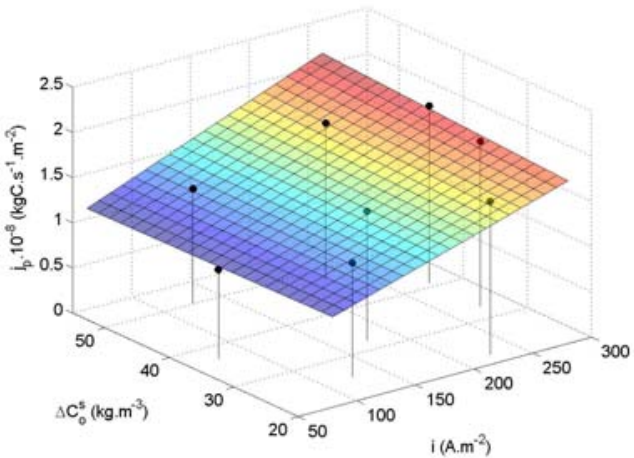

(a)

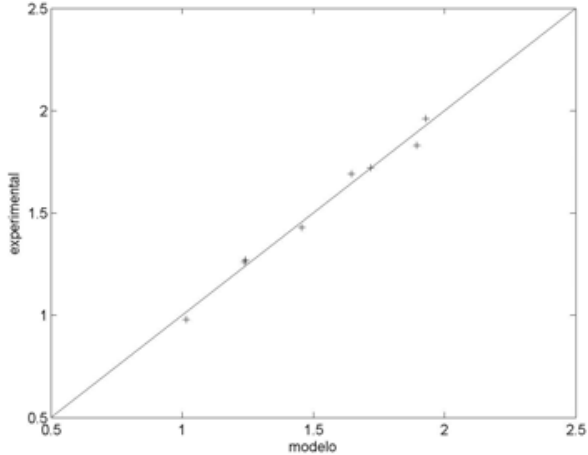

(b)

Figura A1-3. (a) superfície de resposta para o fluxo de fenol $\left(j_{p}\right)$; (b) resultados experimentais versus calculados para $j_{p}$. 


\section{ANEXO 2}

Os códigos do programas para as simulações do processo de eletrodiálise e fotoquímico são apresentados a seguir.

O código para simular o processo de eletrodiálise em modo contínuo com ou sem reciclo é composto por dois arquivos: edcontinuo e modelo:

\section{edcontinuo.m}

function $\mathrm{ydot}=\mathrm{edcontinuo}(\mathrm{t}, \mathrm{y})$

global A I

$\mathrm{QW}=1 \% \mathrm{~m} 3 / \mathrm{h}$

$\mathrm{QE}=1 \% \mathrm{~m} 3 / \mathrm{h}$

\%especificar concentrações da entrada

CAWs $=0 \% \mathrm{~kg} / \mathrm{m} 3$

$\mathrm{CAWp}=0 \% \mathrm{~kg} / \mathrm{m} 3$

CAEs $=50 \% \mathrm{~kg} / \mathrm{m} 3$

$\mathrm{CAEp}=0.1 \% \mathrm{~kg} / \mathrm{m} 3$

$\% \mathrm{~A}=$ área total para cada tipo de membrana

$\%$ fluxo fenol Jp

$\%$ fluxo água $\mathrm{Jw}$

$\%$ fluxo sal Js

$\% \mathrm{j}=$ vazão

$\% \mathrm{Jw}$ e $\mathrm{Jp}=\mathrm{j} / 2 * \mathrm{~A}$

$\% \mathrm{Js}=\mathrm{js} / \mathrm{A}$ ( o $\mathrm{NaCl}$ se divide ao passar pelas membranas, dissocia $\mathrm{Na}+\mathrm{e} \mathrm{Cl}-$ )

$\%$ Calculo Fluxos

\%calculo Js

$\mathrm{b}=1.98 \mathrm{E}-3 ; \% \mathrm{~kg} / \mathrm{h} . \mathrm{A}$ 


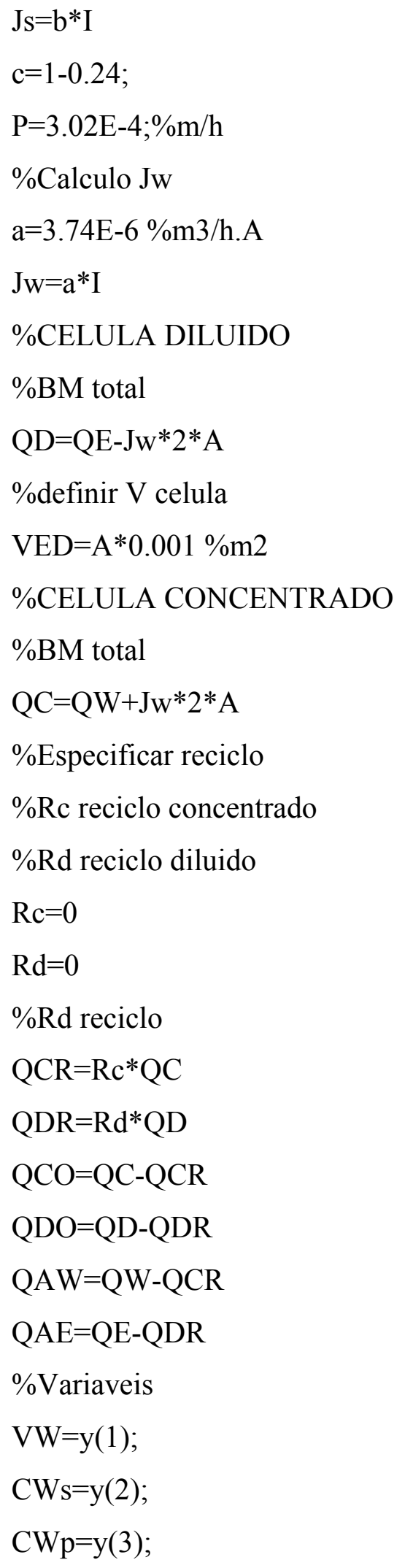




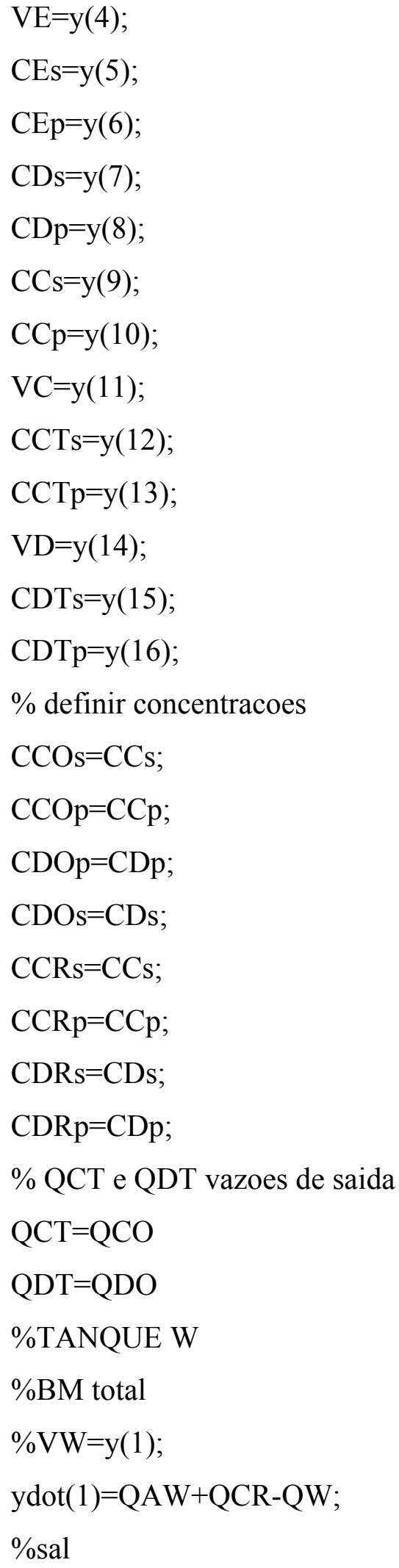


$\% \mathrm{CWs}=\mathrm{y}(2)$;

$\mathrm{ydot}(2)=(1 / \mathrm{VW}) *(\mathrm{QAW} * \mathrm{CAWs}+\mathrm{QCR} * \mathrm{CCRs}-\mathrm{QAW} * \mathrm{CWs}-\mathrm{QCR} * \mathrm{CWs})$;

$\%$ fenol

$\% \mathrm{CWp}=\mathrm{y}(3)$;

$\operatorname{ydot}(3)=(1 / \mathrm{VW}) *(\mathrm{QAW} * \mathrm{CAWp}+\mathrm{QCR} * \mathrm{CCRp}-\mathrm{QAW} * \mathrm{CWp}-\mathrm{QCR} * \mathrm{CWp})$;

$\%$ TANQUE E

$\%$ BM total

$\% \mathrm{VE}=\mathrm{y}(4)$;

$\operatorname{ydot}(4)=\mathrm{QAE}+\mathrm{QDR}-\mathrm{QE}$;

$\%$ BM sal

$\% \mathrm{CEs}=\mathrm{y}(5)$;

$\operatorname{ydot}(5)=(1 / \mathrm{VE}) *(\mathrm{QAE} * \mathrm{CAEs}+\mathrm{QDR} * \mathrm{CDRs}-\mathrm{QAE} * \mathrm{CEs}-\mathrm{QDR} * \mathrm{CEs})$;

$\%$ BM fenol

$\% \mathrm{CEp}=\mathrm{y}(6)$;

$\operatorname{ydot}(6)=(1 / \mathrm{VE}) *(\mathrm{QAE} * \mathrm{CAEp}+\mathrm{QDR} * \mathrm{CDRp}-\mathrm{QAE} * \mathrm{CEp}-\mathrm{QDR} * \mathrm{CEp})$;

$\%$ CELULA DILUIDO

$\%$ BM total

$\% \mathrm{CDs}=\mathrm{y}(7)$;

$\operatorname{ydot}(7)=(1 / \mathrm{VED}) *\left(\mathrm{QE} * \mathrm{CEs}-\mathrm{Js}_{\mathrm{s}}^{*} \mathrm{~A}-\mathrm{QD} * \mathrm{CDs}\right)$;

$\%$ BM fenol

$\%$ Calculo JP

$\mathrm{Jp}=\mathrm{P} *(\mathrm{CDp}-\mathrm{CCp})+\mathrm{c}^{*} \mathrm{Jw}^{*} \mathrm{CDp}$

$\% \mathrm{CDp}=\mathrm{y}(8)$;

$\operatorname{ydot}(8)=(1 / \mathrm{VED}) *\left(\mathrm{QE} * \mathrm{CEp}-2 * \mathrm{Jp}^{*} \mathrm{~A}-\mathrm{QD} * \mathrm{CDp}\right)$;

$\%$ CELULA CONCENTRADO

$\%$ BM sal

$\% \mathrm{CCs}=\mathrm{y}(9)$;

$\mathrm{ydot}(9)=(1 / \mathrm{VED}) *\left(\mathrm{QW} * \mathrm{CWs}+\mathrm{Js}^{*} \mathrm{~A}-\mathrm{QC} * \mathrm{CCs}\right)$;

$\% \mathrm{BM}$ fenol

$\% \mathrm{CCp}=\mathrm{y}(10)$; 


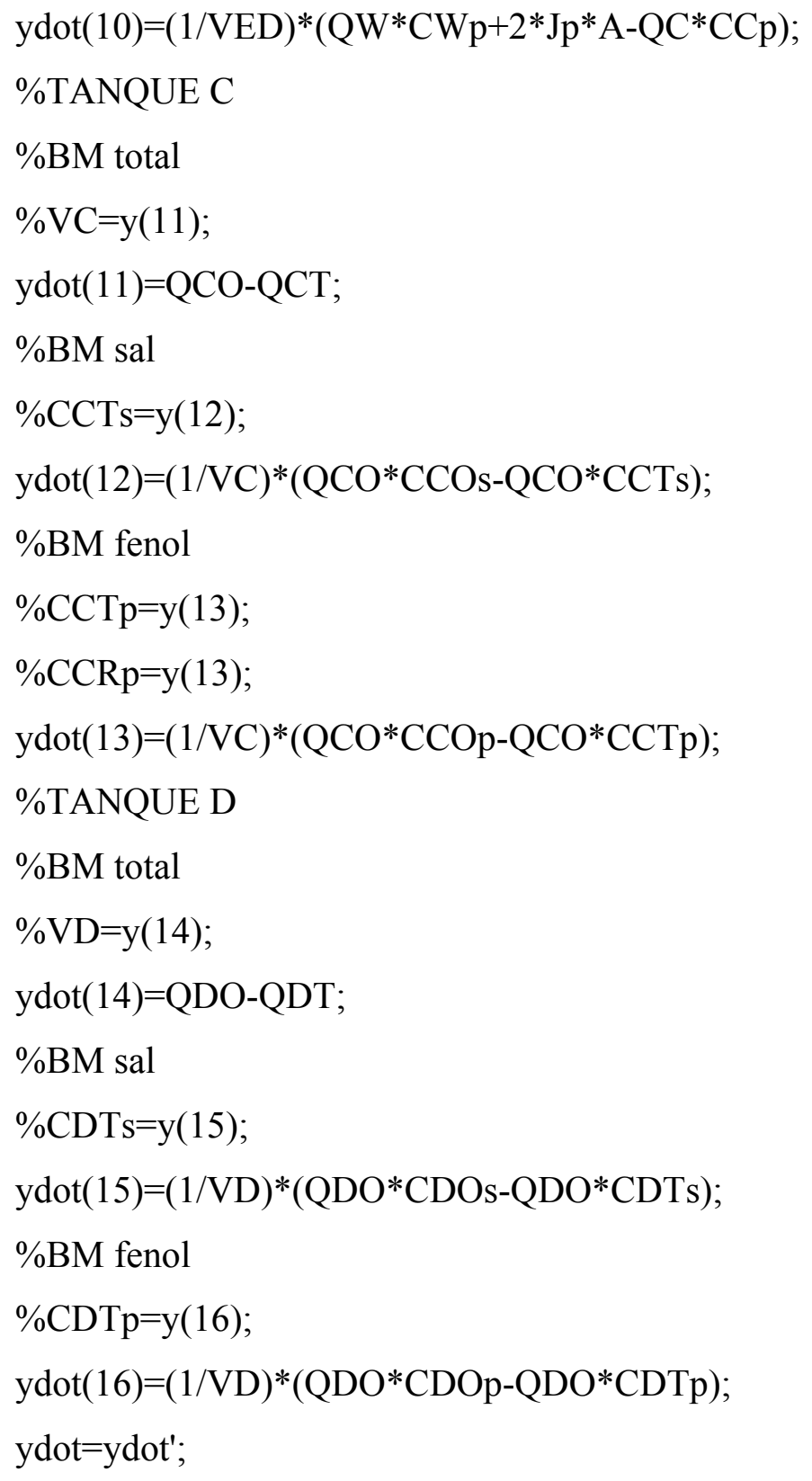

modelo.m

global A I

\%colocar valor de I

$\mathrm{I}=125 ; \% \mathrm{~A} / \mathrm{m} 3$

\%definir A 
$\mathrm{A}=198.8 ; \% \mathrm{~m} 2$

\%y0[VW CWs CWp VE CEs CEp CDs CDp CCs CCp VC CCTs CCTp VD CDTs CDTp ]

$\mathrm{y} 0=\left[\begin{array}{lllllllllllllllll}0.002 & 0 & 0 & 0.002 & 50 & 0.1 & 50 & 0.1 & 0 & 0 & 0.02 & 0 & 0 & 0.02 & 50 & 0.1\end{array}\right]$

tspan $=[0: 0.1: 2]$

$[\mathrm{t} y]=$ ode45(@edcontinuo,tspan,y0)

O código para as simulações do reator fotoquímico foi divido em quatro arquivos: events, rede, modelopf e plugflow:

\section{events.m}

function [value,isterminal,direction] $=\operatorname{events}(\mathrm{t}, \mathrm{y})$

global TOCfinal

value $=\mathrm{y}(1)-\mathrm{TOCfinal}$;

isterminal $=1$;

direction $=0$;

\section{rede.m}

function $[\mathrm{mrA}]=\operatorname{rede}(\mathrm{X})$

\%Calcula a taxa de reação partir da conc. em t e demais condições

$\mathrm{NI}=4 ; \mathrm{NO}=1 ; \mathrm{NH}=10$;

$\mathrm{MIN}=0.1 ; \mathrm{MAX}=0.9 ; \%$ intervalo de normalização

\%valores mínimos e máximos das variáveis de entrada e saída:

$$
\begin{aligned}
& \mathrm{xmin}=\left[\begin{array}{llll}
0.1 & 0.1 & 0.1 & 0.0680
\end{array}\right] ; \\
& \mathrm{xmax}=\left[\begin{array}{llll}
0.9 & 0.9 & 0.9 & 0.9809
\end{array}\right] \text {; } \\
& y \min =[1 . e-5] ; y \max =[2.824 \mathrm{E}-02] \text {; }
\end{aligned}
$$


\%pesos para a camada oculta, $\mathrm{Wij}, \mathrm{i}=1, \ldots \mathrm{n},+$ bias; $\mathrm{j}=1, \ldots \mathrm{NH}$ :

$$
\begin{aligned}
& \mathrm{WIJ}=[1.230000 \mathrm{E}+00-2.244000 \mathrm{E}-01 \quad 6.267400 \mathrm{E}+00 \quad 1.167800 \mathrm{E}+00 \\
& -8.720800 \mathrm{E}-01 \quad 2.706600 \mathrm{E}-01-2.935800 \mathrm{E}+00 \quad-6.732600 \mathrm{E}-01 \\
& 8.649200 \mathrm{E}-02-3.398400 \mathrm{E}+00 \text {; } \\
& \text { 7.561300E-01 2.091500E+00 7.646800E-01 4.257900E-01 4.292500E-01 - } \\
& \text { 4.524600E-01-1.337900E +00 6.922000E-01 1.094200E+00 7.076100E-02; } \\
& 1.364700 \mathrm{E}+00 \quad 1.759100 \mathrm{E}+00 \quad-4.096400 \mathrm{E}+00 \quad 2.841600 \mathrm{E}+00 \\
& \begin{array}{llll}
5.718300 \mathrm{E}+00 & 5.743700 \mathrm{E}+00 & 7.462200 \mathrm{E}+00 \quad-1.840500 \mathrm{E}-02
\end{array} \\
& -1.944100 \mathrm{E}+00 \quad-1.696500 \mathrm{E}+00 \\
& \begin{array}{llll}
1.553900 \mathrm{E}+00 & 8.711400 \mathrm{E}-013.986400 \mathrm{E}+00 \quad 4.462800 \mathrm{E}+00 \quad-
\end{array} \\
& \text { 4.643300E }+00 \quad 8.128100 \mathrm{E}+00 \text {; }
\end{aligned}
$$

7.339000E-01 8.987000E-01 7.585100E-01 1.192300E-01 3.791500E-01 5.748600E-02

4.138300E-01 8.546800E-01 2.106900E-01 2.279600E-01];

\%pesos para a camada de saída, $\mathrm{Wjk}, \mathrm{j}=1, \ldots \mathrm{NH},+$ bias; $\mathrm{k}=1, \ldots$ nsaídas:

$\mathrm{WJK}=[-7.13860 \mathrm{E}+00$

$-9.60340 \mathrm{E}+00$

$3.48980 \mathrm{E}+00$

$4.61100 \mathrm{E}+00$

$6.01390 \mathrm{E}+00$

$-8.32960 \mathrm{E}+00$

$-3.34230 \mathrm{E}+00$

$1.95800 \mathrm{E}+01$

$-1.31420 \mathrm{E}+01$

$-1.48550 \mathrm{E}+00$

1.67720E-01];

\%Etapa 1: normalização das variáveis de entrada:

for $\mathrm{i}=1: \mathrm{NI}$

$\mathrm{XN}(\mathrm{i})=(\mathrm{X}(\mathrm{i})-\mathrm{xmin}(\mathrm{i})) /(\mathrm{xmax}(\mathrm{i})-\mathrm{xmin}(\mathrm{i})) *(\mathrm{MAX}-\mathrm{MIN})+\mathrm{MIN}$;

end 
\%Etapa 2: calc. soma ponderada para camada oculta:

$\mathrm{XN}(\mathrm{NI}+1)=1$;

SOMA1=XN*WIJ; \%soma para cada um dos NH neurônios da camada oculta

\%Etapa 3: cal. das saídas (sigmoidal):

for $\mathrm{j}=1: \mathrm{NH}$

$\operatorname{SAI} 1(\mathrm{j})=1 /(1+\exp (-\operatorname{SOMA} 1(\mathrm{j})))$;

end

\%Etapa 4: calc. soma ponderada para camada saída:

$\mathrm{SAI}(\mathrm{NH}+1)=1$;

SOMA2=SAI1*WJK; \%soma para cada um dos NO neurônios de saída

\%Etapa5: calc. das saídas da rede

for $\mathrm{k}=1: \mathrm{NO}$

$\mathrm{YN}(\mathrm{k})=1 /(1+\exp (-\mathrm{SOMA} 2(\mathrm{k}))) ;$

end

\%Etapa 6: desnormalização da saída:

for $\mathrm{k}=1: \mathrm{NO}$

$\mathrm{y}(\mathrm{k})=(\mathrm{YN}(\mathrm{k})-\mathrm{MIN}) *(\mathrm{ymax}(\mathrm{k})-\mathrm{ymin}(\mathrm{k})) /(\mathrm{MAX}-\mathrm{MIN})+\mathrm{ymin}(\mathrm{k}) ;$

end

\%transformado para taxa em horas

$\mathrm{mrA}=\mathrm{y}(1) * 60$

\section{modelopf.m}

\%TOC/TCOo sera 1 no tempo 0 independente da conc que vem da ED\%TOC/TCOo global CDOp Cper Csal Cfer q

$\mathrm{CDOp}=0.1 ; \% \mathrm{~kg} / \mathrm{m} 3$

TOCinicial $=\mathrm{CDOp}$;

$\% \mathrm{~A}=$ área do reator e $\mathrm{L}=$ comprimento do reator

$\mathrm{V}=0.15 ; \% \mathrm{~m} 3$

Cper $=10 ; \% \mathrm{mM}$ 
Csal $=50 ; \% \mathrm{~kg} / \mathrm{m} 3$

Cfer $=0.5 ; \% \mathrm{mM}$

$\mathrm{q}=1.5 \mathrm{e}-3 * 60 ; \% \mathrm{~m} 3 / \mathrm{h}$, vazao de $1.5 \mathrm{~L} / \mathrm{min}$

$\% \mathrm{C} 0=[0.1]$

[v TOC]=ode45(@plugflow,[0:V/20:V],TOCinicial)

plot(v,TOC)

\section{plugflow.m}

function $\mathrm{dc}=\mathrm{PF}(\mathrm{z}, \mathrm{TOC})$

global CDOp Cper Csal Cfer q

$\%$ TOC é TOC/TOCo

\%TOC/TCOo sera 1 no tempo 0 independente da conc que vem da ED\%TOC/TCOo

TOCinicial=CDOp;

TOCrel=TOC/TOCinicial;

$\%$ normalizacao das variaveis para rede neural

$\%$ per $[800]$

Per $=(-((((80-$ Cper $) * 0.8) / 70)-0.9))$;

$\mathrm{Sal}=(-((((50-\mathrm{Csal}) * 0.8) / 50)-0.9))$;

$\mathrm{Fer}=(-((((0.5-\mathrm{Cfer}) * 0.8) / 0.4)-0.9))$;

$\%$ de sera em funcao da concentracao inical de fenol que vem do modelo da ED

$\mathrm{CODp}=0.1 ; \% \mathrm{~kg} / \mathrm{m} 3$

$\%$ modelo da rede estava em tocrel $/ \mathrm{min}$

$\mathrm{dc}=-2 *(\operatorname{rede}([\mathrm{Per}$ Sal Fer TOCrel $]) *$ TOCinicial $) / \mathrm{q}$;

Para o modelo integrado o arquivo edcontinuo, apresentado anteriormente e o arquivo modelo, apresentado a seguir, foram utilizados:

\section{modelo.m}


global A I QDO

global CDOp Cper Csal Cfer q

$\%$ colocar valor de I

$\mathrm{I}=275 \% \mathrm{~A} / \mathrm{m} 3$

$\%$ definir A

$\mathrm{A}=10 ; \% \mathrm{~m} 2$

\%y0[VW CWs CWp VE CEs CEp CDs CDp CCs CCp VC CCTs CCTp VD CDTs CDTp ]

$\mathrm{y} 0=\left[\begin{array}{lllllllllllllllllll}0.002 & 0 & 0 & 0.002 & 50 & 0.087 & 50 & 0.087 & 0 & 0 & 0.002 & 0 & 0 & 0.002 & 50 & 0.087\end{array}\right]$

tspan $=[0: 0.1: 1]$

[t y]=ode45(@edcontinuo,tspan,y0)

figure(1)

$\operatorname{plot}(\mathrm{t}, \mathrm{y}(:, 16))$

\%pause

$\mathrm{n}=\operatorname{length}(\mathrm{t})$;

\%TOC/TCOo sera 1 no tempo 0 independente da conc que vem da ED\%TOC/TCOo

$\mathrm{CDOp}=\mathrm{y}(\mathrm{n}, 16) ; \% \mathrm{~kg} / \mathrm{m} 3$

$\mathrm{Csal}=\mathrm{y}(\mathrm{n}, 15) \% \mathrm{~kg} / \mathrm{m} 3$

$\mathrm{y}(\mathrm{n}, 13)$

TOCinicial $=\mathrm{CDOp}$;

$\mathrm{q}=\mathrm{QDO} ; \% \mathrm{~m} 3 / \mathrm{h}$

$\% \mathrm{~A}=$ área do reator e $\mathrm{L}=$ comprimento do reator

$\mathrm{V}=0.2 ; \% \mathrm{~m} 3$

Cper $=10 ; \% \mathrm{mM}$

Cfer $=0.1 ; \% \mathrm{mM}$

$\% \mathrm{C} 0=[0.1]$

[v TOC]=ode45(@plugflow,[0:V/20:V],TOCinicial)

figure(2)

plot(v,TOC) 